2. ECN Category (mark one)

Supplemental Direct Revision Change ECN Temporary Standby Supersedure Cancel/Void
3. Originator's Name, Organization, MSIN, and Telephone No.

Mel R. Adams, Technical Basis

[] $[\mathrm{x}]$ and P]anning, R2-12, 373-6167

6. Project Title/No./Work Order No.

T.W.R.S. Process Engineering Instruction Manual

9. Document Numbers Changed by this ECN (includes sheet no. and rev.)

HNF-SD-WM-PROC-021, ReV, 1-E
Page 1 of 2 13a. Description of Change Block 10 cont inued: 643792, 643832, and 643834 .

Complete revision. ECNS:
643834.

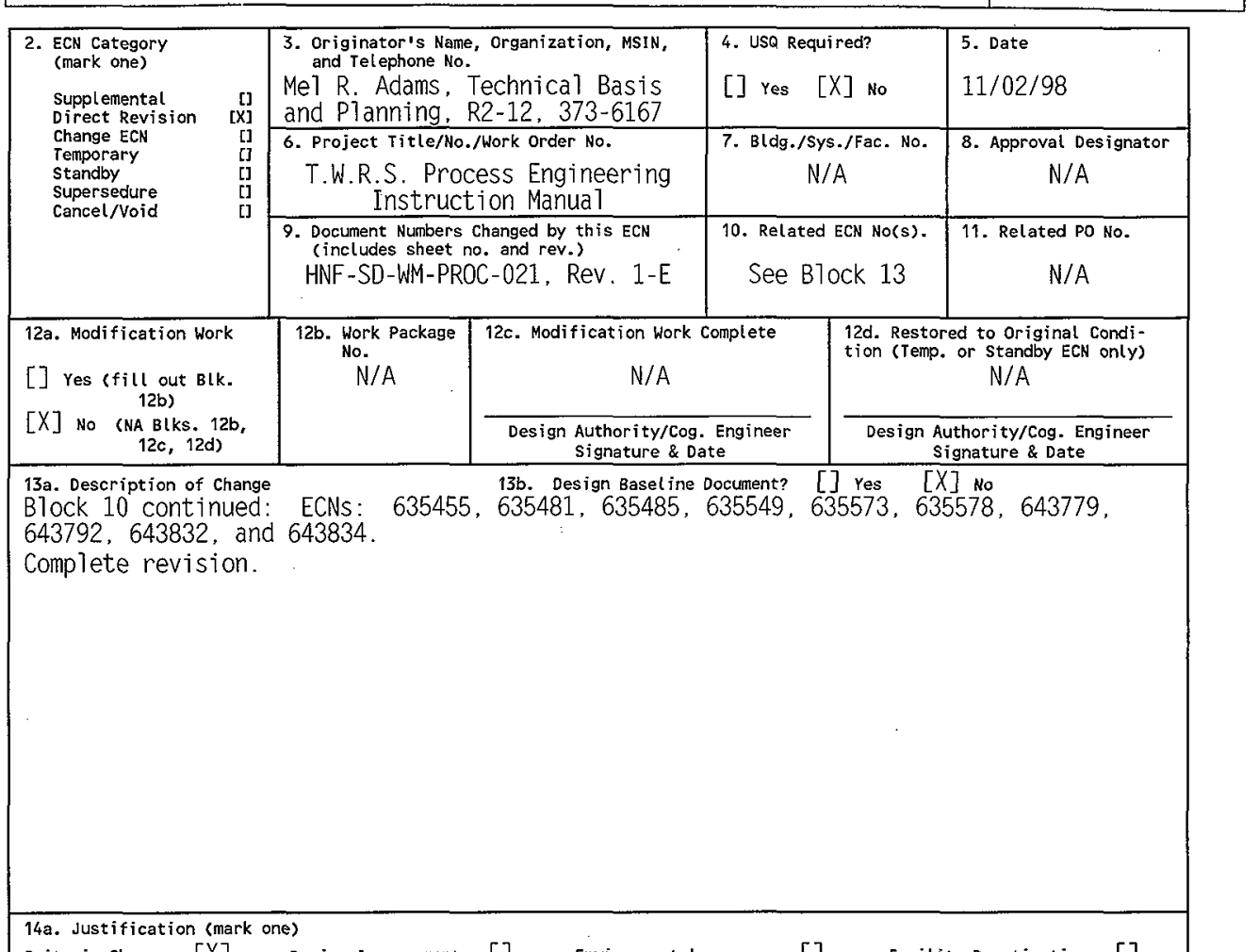

12b. Work Package 12c. Modification Work Complete No.

$\mathrm{N} / \mathrm{A}$

N/A

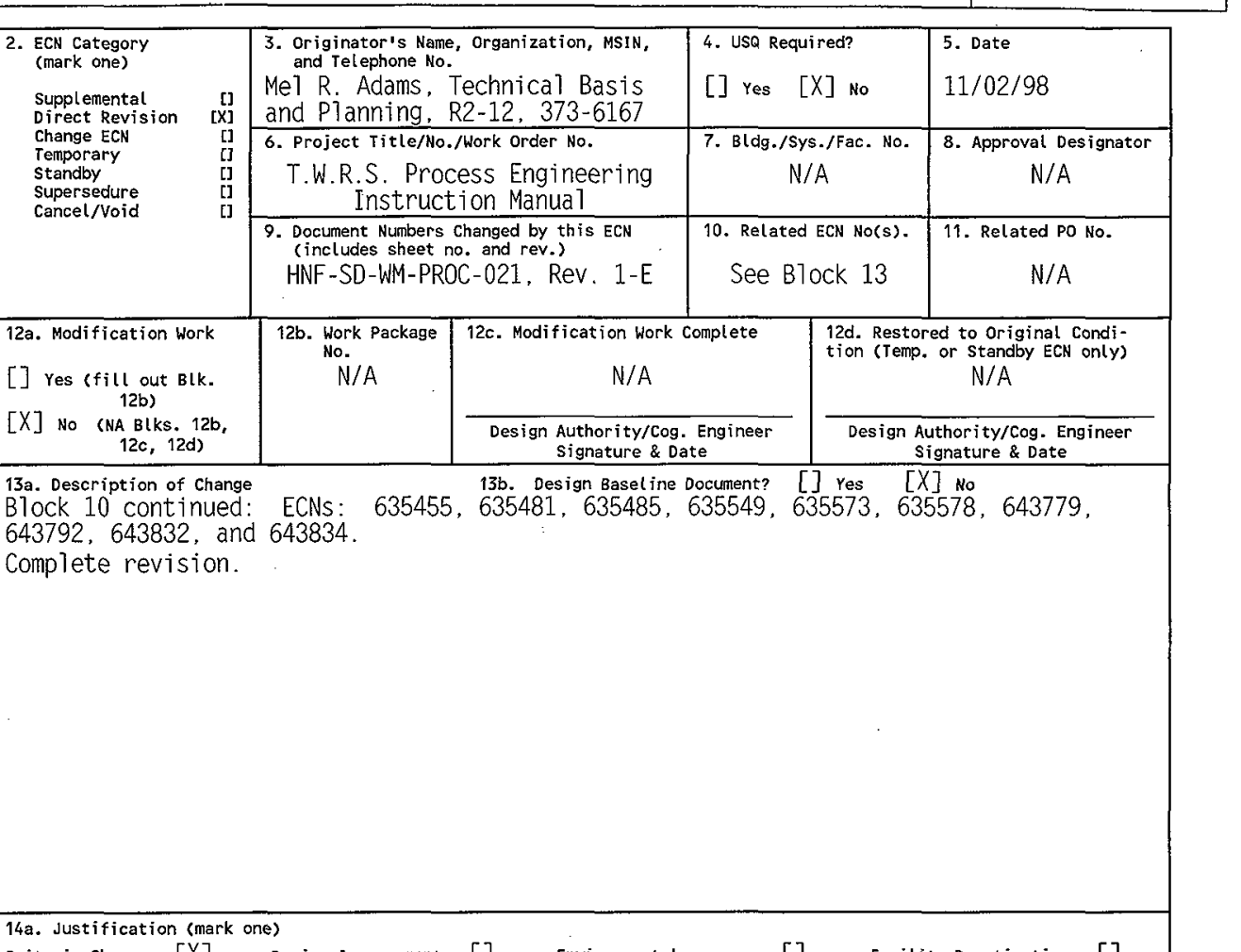

5. Date

$11 / 02 / 98$

8. Approval Designator N/A

11. Related PO No.

$N / A$

12d. Restored to Original Condition (Temp. or Standby ECN only) N/A

Design Authority/Cog. Engineer Signature \& Date 13b. Design Basel ine Document? [] Yes [X] No

ECNs: $635455,635481,635485,635549,635573,635578,643779$,

(1)

14a. Justification (mark one)

$\begin{array}{lllllllll}\text { As-Found } & {[]} & \text { Facilitate Const } & {[]} & \text { Const. Error/Omission [] } & \text { Design Error/Omission [] }\end{array}$
14b. Justification Details
This ECN was generated to reflect the new organization, corrects minor errors and
incorporates Section 25 .

15. Distribution (include name, MSIN, and no. of copies)

See attached distribution.

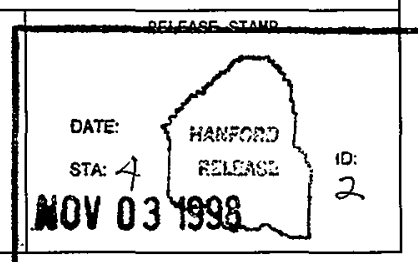




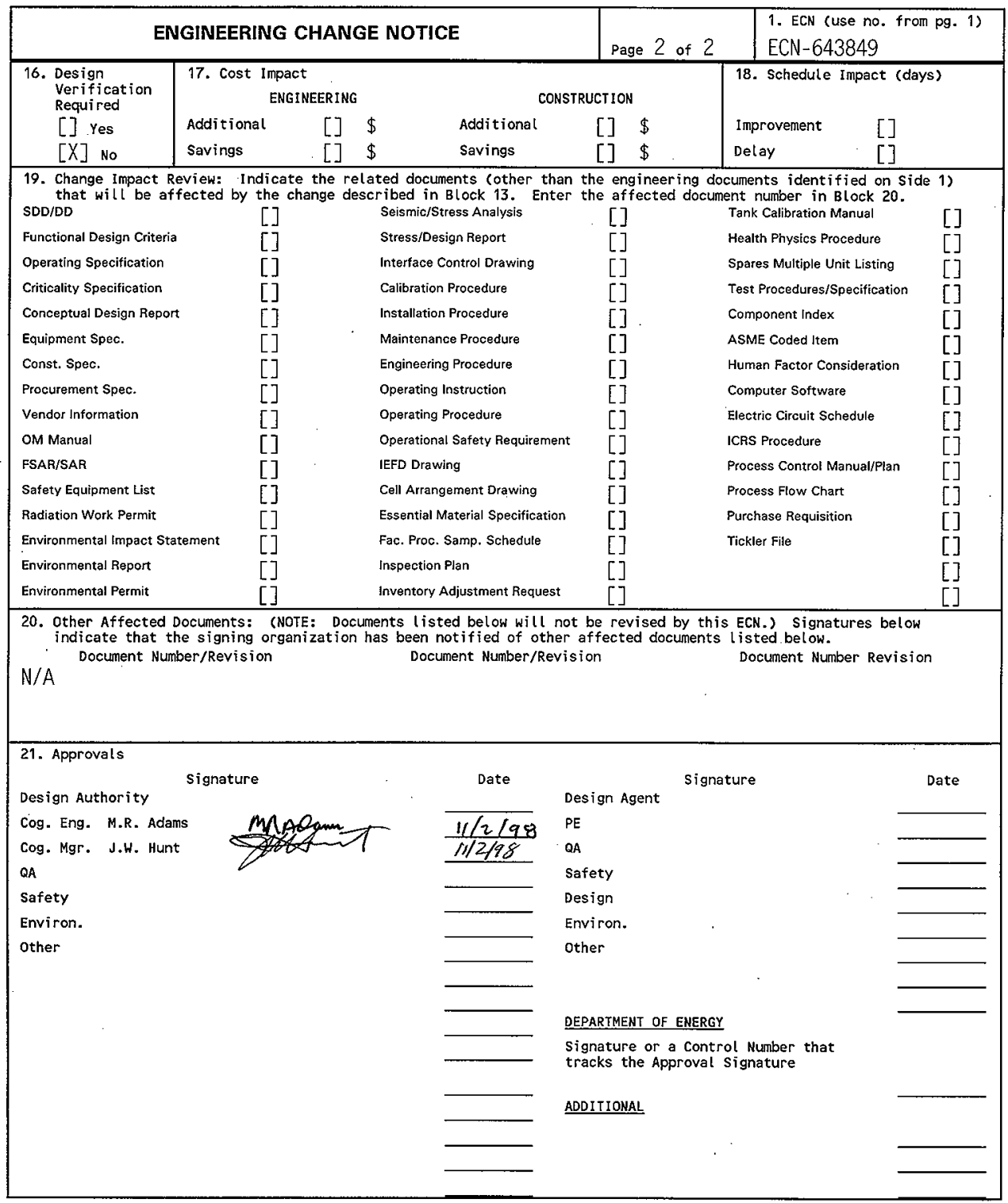




\section{Tank Waste Remediation System Process Engineering Instruction Manual}

Me] R. Adams

Lockheed Martin Hanford, Corp. , Richland, WA 99352

U.S. Department of Energy Contract DE-AC06-96RL13200

EDT/ECN: ECN-643849

UC: 2070

Org Code: $74 \mathrm{~B} 10$

B\&R Code: EW 3120074

Charge Code: CACN 102197/COA AA30

Total Pages: 168

Key Words: Tank Waste Remediation System, TWRS, Process Engineering, Instruction, Manual

Abstract: $\quad N / A$

Wordperfect is a registered trademark of Wordperfect, Corp.

TRADEMARK DISCLAIMER. Reference herein to any specific comercial product, process, or service by trade name, trademark, manufacturer, or otherwise, does not necessarily constitute or imply its endorsement, recommendation, or favoring by the United States Government or any agency thereof or its contractors or subcontractors.

Printed in the United States of America. To obtain copies of this document, contact: Document Control Services, P.0. Box 950, Mailstop H6-08, Richland WA 99352, Phone (509) 372-2420; Fax (509) 376-4989.
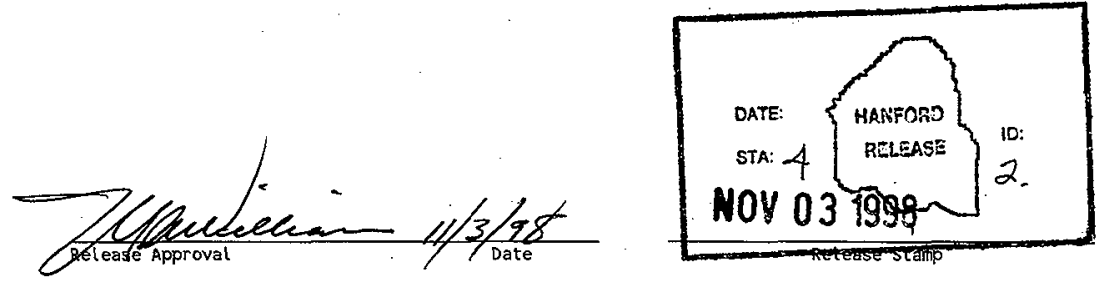

\section{Approved for Public Release}




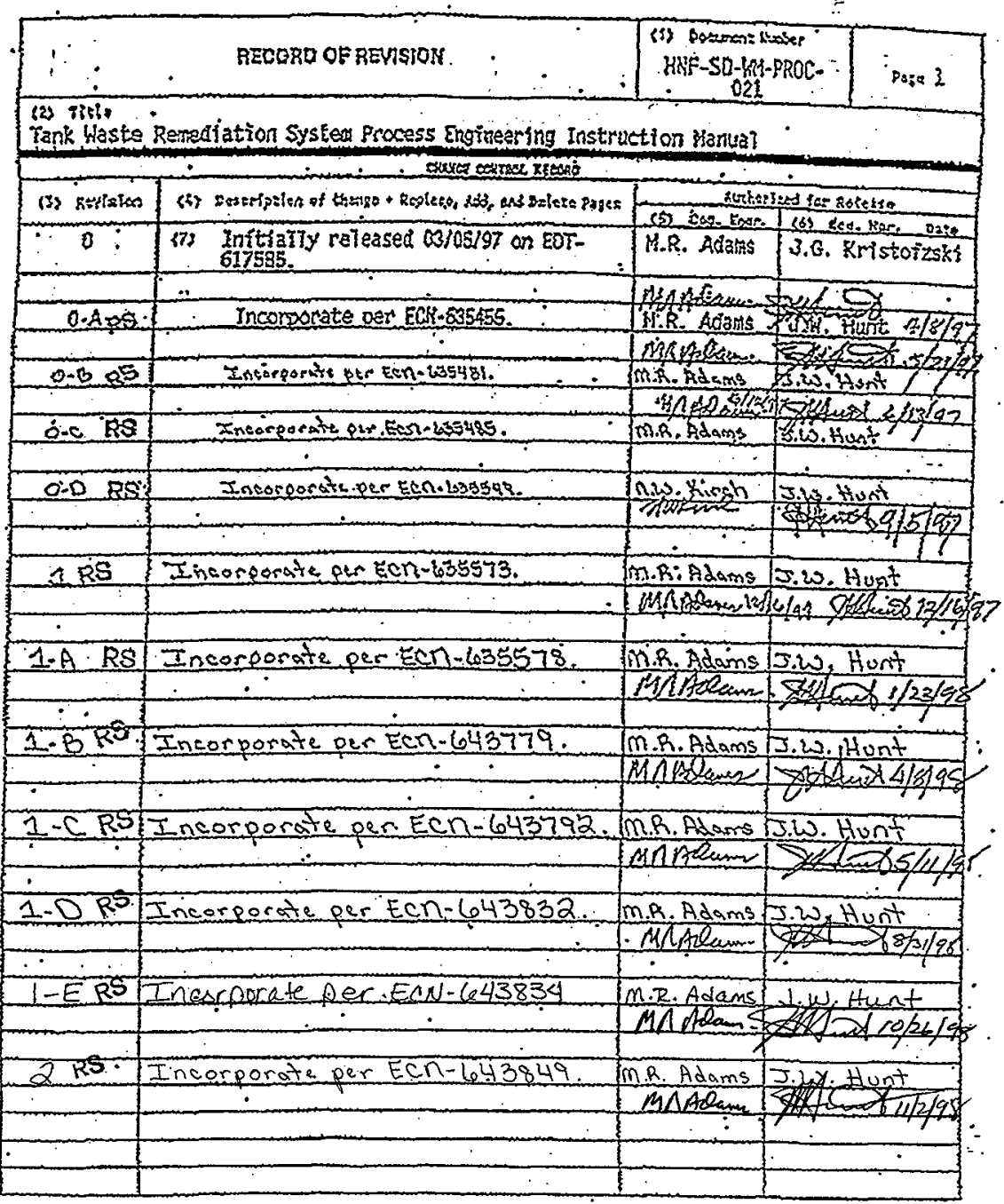

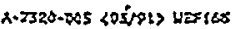


LOCKHEED MARTIN HANFORD CORPORATION

TWRS PROCESS ENGINEERING

INSTRUCTION MANUAL
Manual

HNF-SD-WM-PROC-021

Section Table of Contents, REV 2

Page

Effective Date November 15, 1998 Organization
TWRS Process

Engineering

TITLE:

TABLE OF CONTENTS

\section{Approved by}

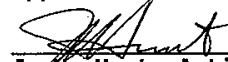

J. W. Hunt, Acting Manager

TWRS Process Engineering
Section

Number

1.0

2.0

3.0

4.0

5.0

6.0

7.0

8.0

9.0

10.0

11.0

12.0
OBJECTIVE AND PURPOSE

MANUAL CHANGE CONTROL PROCEDURE

TWRS PROCESS ENGINEERING ORGANIZATION

TWRS PROCESS ENGINEERING CHARTER

TWRS PROCESS ENGINEERING WORK PROCESS FLOWSHEET

TWRS PROCESS ENGINEERING INTERFACE CONTROL CONDUCT OF OPERATIONS APPLICABILITY CHART

LETTERS OF INSTRUCTION/STATEMENTS OF WORK MANAGEMENT DIRECTIVES

SAFETY IMPROVEMENT PLAN

GUIDELINES FOR DOCUMENT PREPARATION

11.1 INTRODUCTION

11.2 WASTE INFORMATION REQUIREMENTS DOCUMENT (WIRD)

11.3 PREPARATION OF SAMPLING AND ANALYSIS PLANS

11.4 PREPARATION OF IMMEDIATE NOTIFICATIONS

11.5 PREPARATION OF TANK CHARACTERIZATION REPORTS

11.6 PUBLICATIONS STANDARDS FOR PREPARATION OF DOCUMENTS

11.7 SUPPORTING DOCUMENT RELEASE PROCESS

11.8 TANK CHARACTERIZATION REPORT PEER AND FUNCTIONAL REVIEW
REV Org.

2 LMHC

2 LMHC

$2 \quad$ LMHC

$2 \quad$ LMHC

$2 \quad$ LMHC

$2 \quad$ LMHC

$2 \quad$ LMHC

2 LMHC

2 LMHC

2 LMHC

2 LMHC 
Section

Number

13.0

14.0

15.0

16.0

17.0

18.0

19.0

20.0

21.0

22.0

23.0

24.0

25.0

APPENDIX

A

\section{Iitle}

REV org.

SOFTWARE QUALITY ASSURANCE REQUIREMENTS

TWRS PROCESS ENGINEERING SCHEDULING AND REPORTING INCIUDING POSTINGS

REQUIRED READING

OPERATION OF TANK CHARACTERIZATION AND

SAFETY RESOURCE CENTER

PERSONNEL QUALIFICATION

ON-CALL PROCESS ENGINEER

TANK FARM DATABASE OPERATION

END-STATE ORGANIC ANALYSIS METHODOLOGY

(SINGLE-SHELL TANKS)

BEST-BASIS INVENTORY CHANGE CONTROL

BOARD - CHARTER

SAVING WORK FROM LOSS

ENGINEERING MATERIAL BALANCE FOR TANK

241-C-106 SLUICING AND RETRIEVAL

DATA MANAGEMENT REPORTING FOR TANK 241-C-106

SLUICING AND RETRIEVAL

SAMPLE ARCHIVE MANAGEMENT

2 LHMC

2. LHMC

2 LMHC

$2 \quad$ LMHC

TANK SAMPLING AND ANALYSIS PLAN TEMPLATE (RESERVED) 


\section{ACRONYMS}

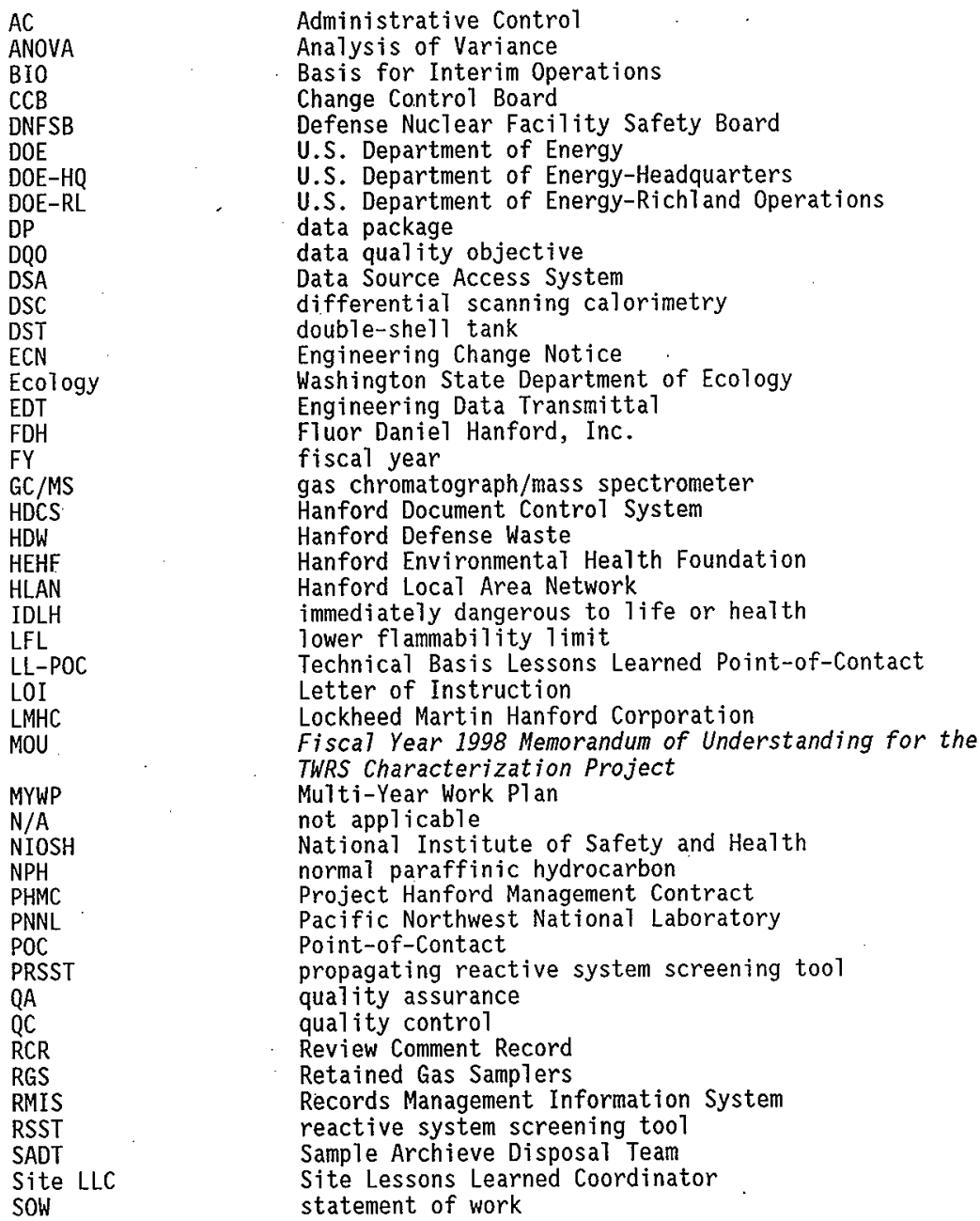




\section{ACRONYMS (Continued))}

SSS
SST
TBD
TC
TCD
TCR
TCSRC
TGA
TMXS
TOC
Tri-Party Agreement
TRU
TSAP
TSR
TVD
TWAP
TWINS
TWRS
USQ
VIDON
WIRD

secondary safety screening

single-shell tank

to be determined

Tank Coordinator

Tank Characterization Database

Tank Characterization Report

Tank Characterization and Safety Resource Center thermogravimetric analysis training matrix subsystem total organic carbon

Hanford Federal Facility Agreement and Consent Order transuranic

Tank Sampling and Analys is Plan

Technical Safety Requirements

Tank Vapor Database

Tank Waste Analys is Plan

Tank Waste Information Network System

Tank Waste Remediation System

Unreviewed Safety Question

Visual Image Digital Object Network

Waste Information Requirements Document 
LOCKHEED MARTIN HANFORD CORPORATION

TWRS PROCESS ENGINEERING

INSTRUCTION MANUAL
Manua1

Section

Page

Effective Date Organization
HNF-SD-WM-PROC-021

1.0, REV 2

1 of 2

November 15, 1998

TWRS Process

Engineering

\section{TITLE:}

OBJECTIVE AND PURPOSE

APPLICABILITY: FOR GUIDANCE

\section{Approved by}

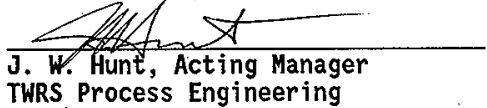

\subsection{OBJECTIVE AND PURPOSE}

The purpose of the Tank Waste Remediation System (TWRS) Process Engineering Instruction Manual is to provide guidance and direction to TWRS Process Engineering staff regarding conduct of business. The objective is to establish a disciplined and consistent approach to business such that the work processes within TWRS Process Engineering are safe, high quality, disciplined, efficient, and consistent with Lockheed Martin Hanford Corporation Policies and Procedures.

The sections within this manual are of two types: for compliance and for guidance. For compliance sections are intended to be followed per-the-letter until such time as they are formally changed per section 2.0 of this manual. For guidance sections are intended to be used by the staff for guidance in the conduct of work where technical judgment and discernment are required. The guidance sections shall also be changed per Section 2.0 of this manual.

The required header for each manual section is illustrated in Section 2.0, Manual Change Control procedure.

It is intended that this manual be used as a training and indoctrination resource for employees of the TWRS Process Engineering organization. The manual shall be required reading for a11 TWRS Process Engineering staff, matrixed, and subcontracted employees. 
LOCKHEED MARTIN HANFORD CORPORATION

TWRS PROCESS ENGINEERING

INSTRUCTION MANUAL
Manual

Section

Page

Effective Date

Organization
HNF-SD-WM-PROC-021

2.0 , REV 2

1 of 2

November 15, 1998

TWRS Process

Engineering

\section{TITLE:}

MANUAL CHANGE CONTROL PROCEDURE APPLICABILITY: FOR COMPLIANCE

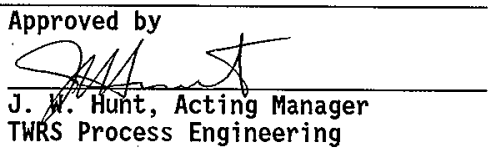

\subsection{OBJECTIVE}

The objective of this section is to provide a procedure for the controlled change of sections of this manual.

\subsection{PROCEDURAL REQUIREMENTS}

This manual shall be formally issued via the Supporting Document Release Process defined in Section 11.0 of this document.

The procedure for completing a change to this manual includes the following steps:

1. Any manual holder on the manual distribution list may initiate a change to either a for compliance or a for guidance section of this manual. The Manager of Tank Waste Remediation System (TWRS) Process Engineering, hereafter called the Manager, may also initiate changes.

2. The change initiator completes a redine markup of the proposed change and provides the proposed change to the TWRS Process Engineering Records Administrator (A. E. Young). The Records Administrator discusses the proposed change with the Manual Cognizant Engineer (M. R. Adams) and the Manager of TWRS Process Engineering. The Manager may request review of the proposed change by all or some of the manual holders. The Manager may al so request review by external parties or may discuss the change at staff meetings prior to approval. The Records Administrator shall arrange for any requested reviews. Reviewers shall respond to requests for comments within five working days. Comments may be submitted to the Manual Cognizant Engineer by electronic mail or in writing.

3. Following review, the Records Administrator will incorporate comments in consultation with the change requestor. Comments that cannot be agreed to by the change requestor shati be referred to the Manager of TWRS Process Engineering for disposition and decision.

4. Following step 3, the changed version of the section is prepared for issuance by the Records Administrator as an Engineering Change Notice (ECN) page change to HNF-SD-WM-PROC-021. Forma1 issuance of 
the ECN shall be done within three working days of approval of the change by the Manager of TWRS Process Engineering. The Manager approves the header of the section as well as the ECN form.

5. The ECN shall be distributed to all manual holders. Following issuance of the ECN, the TWRS Process Engineering Records Administrator shall notify all Process Engineering employees, matrixed, and subcontracted employees that the ECN has been issued.

\subsection{RESPONSIBILITIES}

The TWRS Process Engineering Records Administrator is responsible for preparing and processing change documentation including maintaining an up-to-date distribution 7 ist for the manual.

The Manager of TWRS Process Engineering is responsible for requesting internal/external review of proposed changes per. his/her discretion, disposing of issues between change requestors and reviewers and for approving al1 manual changes.

Manual holders and users are responsible for identifying and requesting procedure changes where necessary to assure safe and efficient work processes and operations.

\subsection{ADMINISTRATIVE REQUIREMENTS}

All sections of this manual shall have a header which contains the following items:

- TWRS PROCESS ENGINEERING INSTRUCTION MANUAL

- HNF-SD-WM-PROC-021 REV. X

- SECTION NUMBER: see table of contents

- SECTION TITLE: see tabTe of contents

- SECTION REVISION NUMBER: X

- EFFECTIVE DATE: $X X / X X / X X$

- APPLICABILITY: FOR COMPLIANCE Or FOR GUIDANCE

- APPROVAL: Manager of TWRS Process Engineering.

Each manual section shall contain (where applicable) a section objective, procedural requirements or procedural guidance, responsibilities, administrative requirements, or administrative guidance and references. 0ther content shall be included as needed to provide adequate guidance and direction. 


\begin{tabular}{llr}
\hline \hline LOCKHEED MARTIN HANFORD CORPORATION & Manua1 & HNF-SD-WM-PROC-021 \\
& Section & 3.0, REV 2 \\
TWRS PROCESS ENGINEERING & Page & 1 of 2 \\
INSTRUCTION MANUAL & Effective Date & November 15, 1998 \\
& Organization & TWRS Process \\
Engineering
\end{tabular}

TITLE:
TWRS PROCESS ENGINEERING ORGANIZATION
APPLICABILITY: FOR GUIDANCE

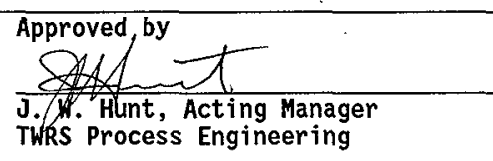

\subsection{TWRS PROCESS ENGINEERING ORGANIZATION CHART}

The following chart (Figure 1) illustrates the Tank Waste Remediation System (TWRS) Process Engineering organization. 
LOCKHEED MARTIN HANFORD CORPORATION

TWRS PROCESS ENGINEERING ORGANIZATION APPLICABILITY: FOR GUIDANCE
Manua!

Section

Page

Effective Date
HNF-SD-WM-PROC-021

3.0 , REV 2

2 of 2

15, 1998

Figure 1. TWRS Process Engineering Organization Chart.

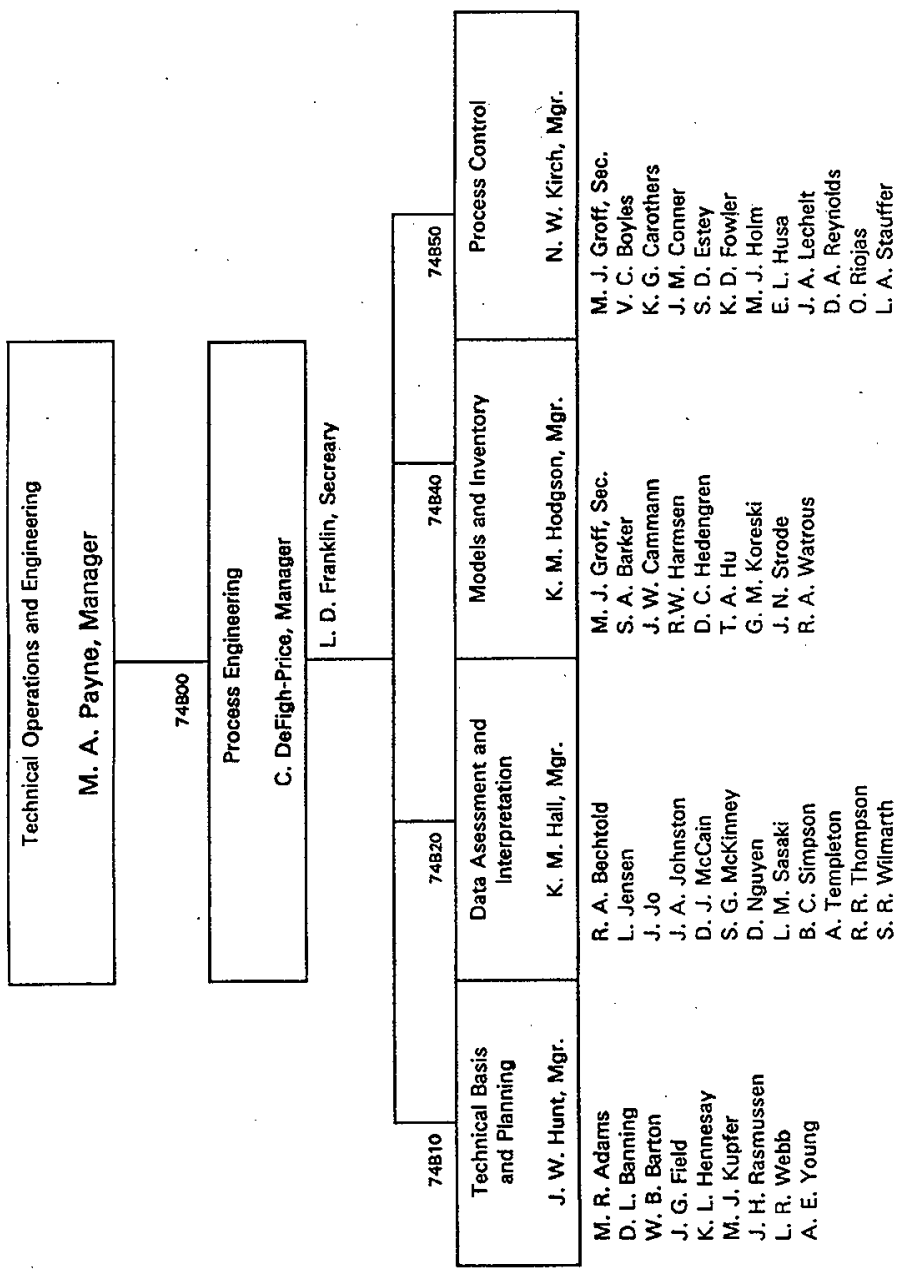


LOCKHEED MARTIN HANFORD CORPORATION

TWRS PROCESS ENGINEERING

INSTRUCTION MANUAL
Manua]

Section

Page

Effective Date

Organization
HNF-SD-WM-PROC-021

4.0, REV 2

1 of 2

November 15, 1998

TWRS Process

Engineering

\section{TITLE: \\ TWRS PROCESS ENGINEERING CHARTER APPLICABILITY: FOR GUIDANCE}

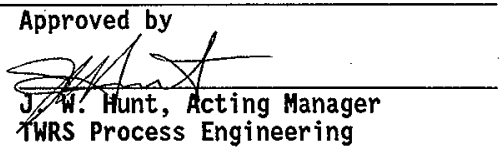

\subsection{CHARTER}

Tank Waste Remediation System (TWRS) Process Engineering is chartered to establish, implement, and maintain the technical baseline for waste behavior including parameters of interest for safe storage, retrieval, and disposal. This requires that the waste behavior characterization process be implemented including: facilitating the Data Quality objective (DQO) process, preparing best-basis inventory estimates, modeling tank contents, evaluating historical process flowsheet histories, preparing statistical analysis for tank comparison and grouping studies, managing characterization data, preparing tank sampling and analysis planning documents, and providing process engineering support and analysis including waste volume projections. The organization also is the lead for preparing tank characterization $\mathrm{planning}$ documents including the Waste Information Requirements Document (WIRD) and characterization reports such as Tank Characterization Reports (TCR) to meet Hanford Federal Facility Agreement and Consent Order (Tri-party Agreement) and Defense Nuclear Facility Safety Board (DNFSB) milestones. The organization also provides support to tank farm operations, on-call process engineer capability, and analysis and recommendations on waste compatibility and other operations problems.

\subsection{RESPONSIBILITIES}

1. Provide project management for the characterization process including development of plans, coordination of sampling and analysis, data management, data evaluation, and preparation of characterization reports.

2. Provide the technical basis for the overalt characterization effort including prioritization of tanks for sampling.

3. Support and facilitate the development and revision of DQOS and assure the DQOS are met through the coordination of historica], modeling, and analytical data.

4. Provide documented estimates of the tank waste composition for each tank, tank group or waste type based on process knowledge, sample analysis and modeling results. 


\begin{tabular}{llr}
\hline LOCKHEED MARTIN HANFORD CORPORATION & Manual & HNF-SD-WH-PROC-021 \\
& Section & 4.0, REV 2 \\
TWRS PROCESS ENGINEERING CHARTER & Page & 2 of 2 \\
APPLICABILITY: FOR GUIDANCE & Effective Date & November 15, 1998 \\
\hline
\end{tabular}

5. Provide process engineering support and analysis including waste volume projections, compatibility studies, on-call process engineering support, and associated technical support to operations.

6. Facilitate and develop statistical models, tools and methods to support the process of characterization.

7. Develop, enhance, and maintain a data management system for storing and analyzing tank and tank waste information and data including development and enhancement of electronic data management systems and electronic document templates. Maintain and enhance key process control databases.

8. Prepare documents critical to the tank characterization process including technical basis, sample analys is planning documents, tank characterization reports, data management plans, and tank inventory estimates.

\subsection{INTERFACES}

Develop and maintain effective interfaces with U.S. Department of EnergyHeadquarters (DOE-HQ), U.S. Department of Energy-Richland Operations (DOE-RL), oversight groups including DNFSB, Washington State Department of Ecology, other contractors, other TWRS organizations and programs, Pacific Northwest National Laboratory (PNNL), and private and public sector elements that effect or impose requirements on characterization of TWRS tank waste. 


\section{LOCKHEED MARTIN HANFORD CORPORATION}

TWRS PROCESS ENGINEERING

INSTRUCTION MANUAL
Manual

Section

Page

Effective Date Organization
HNF-SD-WM-PROC-021 5.0 , REV 2 1 of 2 November 15, 1998

TWRS Process Engineering

\section{TITLE:}

TWRS PROCESS ENGINEERING

WORK PROCESS FLOWSHEET

APPLICABILITY: FOR GUIDANCE

\section{Approved by}

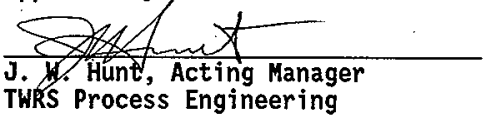

\subsection{TWRS PROCESS ENGINEERING WORK PROCESS FLOWSHEET}

The following flowsheet diagram (Figure 1) illustrates the basic characterization work flow process utilized by the Tank Waste Remediation System (TWRS) Process Engineering organization to generate, manage, evaluate, disseminate, and deploy characterization data and waste behavior expertise to solve and close waste safety and disposal problems. The sheet does not include the Process Engineering support to operations, which is described in Section 4.0 . 
LOCKHEED MARTIN HANFORD CORPORATION

TWRS PROCESS ENGINEERING

WORK PROCESS FLOWSHEET

APPLICABILITY: FOR GUIDANCE
Manual

Section

Page

Effective Date
HNF-SD-WM-PROC-021

5.0, REV 2

2 of 2

November 15,1998

Figure 1. Characterization Information Flow Diagram.

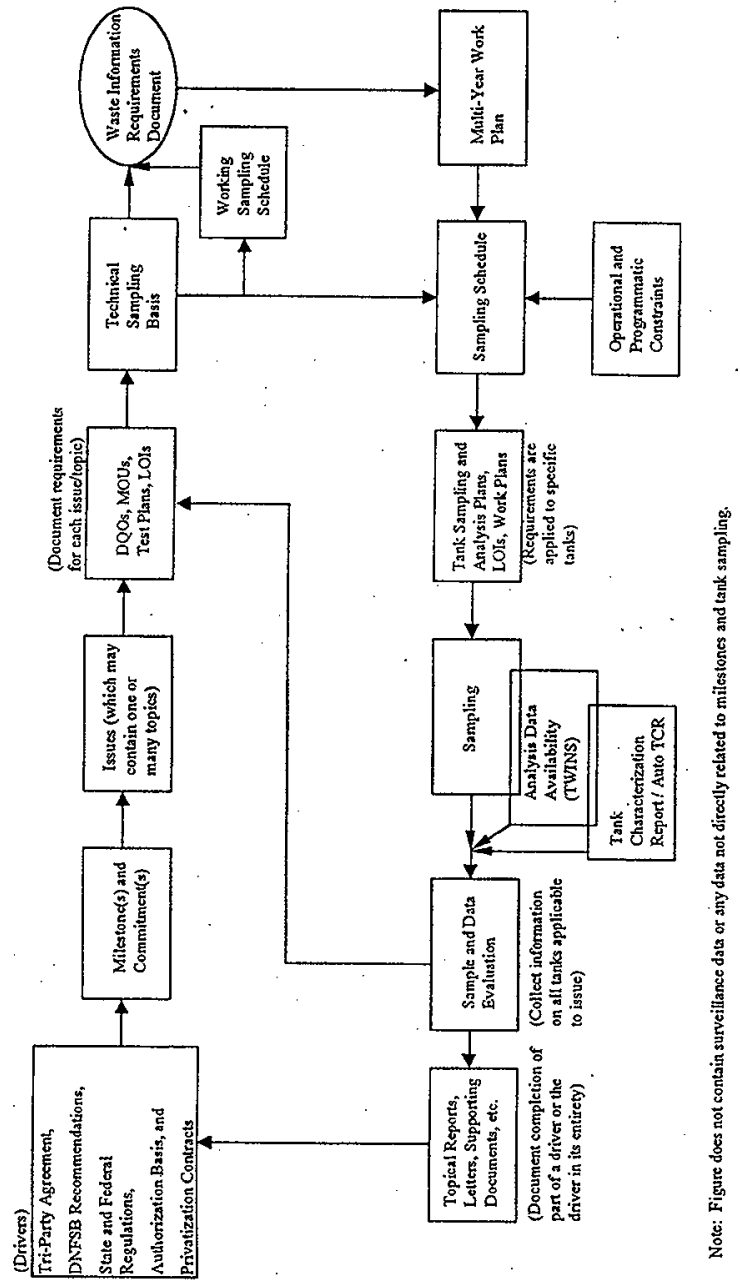




\section{LOCKHEED MARTIN HANFORD CORPORATION}

TWRS PROCESS ENGINEERING

INSTRUCTION MANUAL
Manua 1

Section

Page

Effective Date Organization
HNF-SD-WM-PROC-021

6.0, REV 2

1 of 2

November 15,1998

TWRS Process

Engineering

\section{TITLE:}

TWRS PROCESS ENGINEERING

INTERFACE CONTROL

APPLICABILITY: FOR GUIDANCE

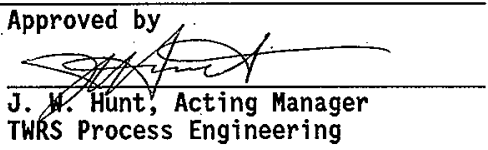

\subsection{TWRS PROCESS ENGINEERING INTERFACE CONTROL CHART}

The following Interface Control Chart diagram (Figure 1) i 1]ustrates the key interfaces utilized by the Tank Waste Remediation System (TWRS) Process Engineering organization to define and control workscope. The key interfaces are illustrated in relation to key work processes and products. 
LOCKHEED MARTIN HANFORD CORPORATION

TWRS PROCESS ENGINEERING

INTERFACE CONTROL

APPLICABILITY: FOR GUIDANCE
Manua 7

Section

Page

Effective Date November 15,1998

Figure 1. Interface Control Chart.
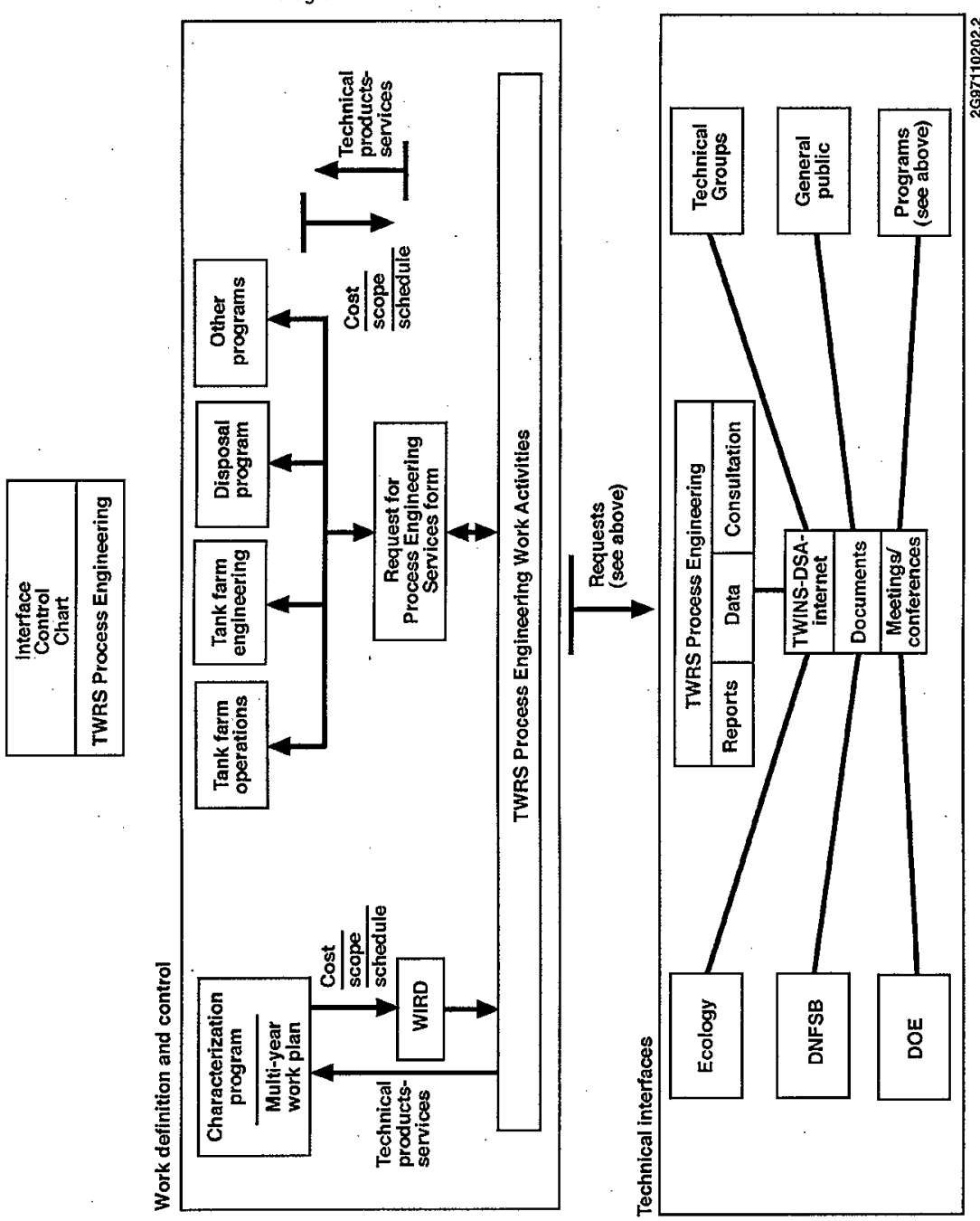


\section{LOCKHEED MARTIN HANFORD CORPORATION}

TWRS PROCESS ENGINEERING

INSTRUCTION MANUAL
Manual

Section

Page

Effective Date Organization
HNF-SD-WM-PROC-021

7.0 , REV 2

1 of 6

November 15, 1998

TWRS Process

Engineering

\section{TITLE:}

CONDUCT OF OPERATIONS

APPLICABILITY CHART

APPLICABILITY: FOR GUIDANCE

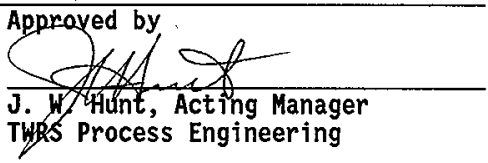

\subsection{OBJECTIVE}

The objective of this section is to provide guidance and information about the applicability of chapters of the Conduct of Operations Field Handbook to the operations and work of the Tank Waste Remediation System (TWRS) Process

Engineering organization. For chapters that are applicable, reference is made to the section of this manual that addresses the conduct of operations chapter. For chapters that are not applicable, a reason or rationale for nonapplicability is provided. The Conduct of Operations Field Handbook implements and supplements DOE Order 5480.19.

\subsection{PROCEDURAL REQUIREMENTS}

The intent is for the TWRS Process Engineering organization to maintain work processes in a sound manner consistent with the principles of conduct of operations. By following the guidance and direction provided in this manual, good conduct of operations is assured as outlined in the attached matrix (Table 1). 


\begin{tabular}{llr}
\hline LOCKHEED MARTIN HANFORD CORPORATION & Manual & HNF-SD-WN-PROC-021 \\
& Section & 7.0, REV 2 \\
CONDUCT OF OPERATIONS & Page & 2 of 6 \\
APPLICABILITY CHART & Effective Date & November 15, 1998 \\
APPLICABILITY: FOR GUIDANCE & & \\
\hline
\end{tabular}

Table 1. Applicability Matrix Chart. (4 sheets)

\begin{tabular}{|c|c|c|}
\hline 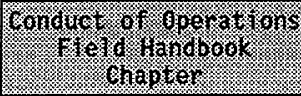 & (195. & 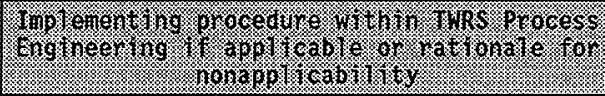 \\
\hline $\begin{array}{l}\text { 1. Operations } \\
\text { organization and } \\
\text { administration }\end{array}$ & Yes & 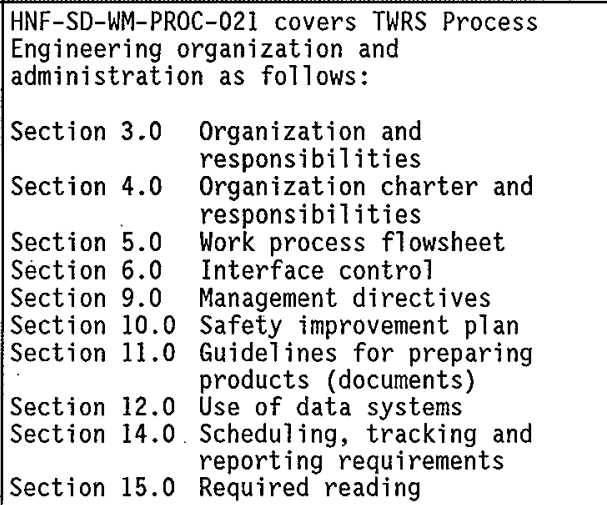 \\
\hline $\begin{array}{l}\text { 2. Shift routines } \\
\text { and operating } \\
\text { practices }\end{array}$ & No & $\begin{array}{l}\text { Except for housekeeping which is covered } \\
\text { in Section } 10.0 \text { of HNF-SD-WM-PROC-021, } \\
\text { this chapter of the Conduct of Operations } \\
\text { Field Handbook does not generally apply to } \\
\text { TWRS Process Engineering. This chapter } \\
\text { deals with operating facilities with } \\
\text { control areas and operators working } \\
\text { shifts. TWRS Process Engineering does not } \\
\text { have responsibility for such a facility. }\end{array}$ \\
\hline $\begin{array}{l}\text { 3. Control area } \\
\text { activities }\end{array}$ & No & Same rationale as above. \\
\hline 4. Communication & Yes & $\begin{array}{l}\text { TWRS Process Engineering does not directly } \\
\text { manage a facility, but Section } 10.0 \text { of } \\
\text { HNF-SD-WM-PROC-021 requires safety } \\
\text { inspections of the } 2750 E \text { facility } \\
\text { including making sure employees are aware } \\
\text { of emergency response signals for the } \\
\text { facility. The building manager does } \\
\text { conduct regular emergency drills. For } \\
\text { visits to other facilities such as } 1 \text { abs, } \\
\text { TWRS Process Engineering personnel will } \\
\text { follow the procedures for entry and } \\
\text { training required by those facilities } \\
\text { including knowing and following emergency } \\
\text { signals and communications. }\end{array}$ \\
\hline
\end{tabular}




\begin{tabular}{llr}
\hline LOCKHEED MARTIN HANFORD CORPORATION & Manual & HNF-SD-WM-PROC-021 \\
& Section & 7.0, REV 2 \\
CONDUCT OF OPERATIONS & Page & 3 of 6 \\
APPLICABILITY CHART & Effective Date & November 15, 1998 \\
APPLICABILITY: FOR GUIDANCE & & \\
\hline
\end{tabular}

Table 1. Applicability Matrix Chart. (4 sheets)

\begin{tabular}{|c|c|c|}
\hline 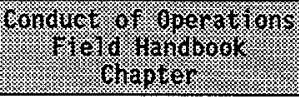 & 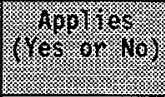 & 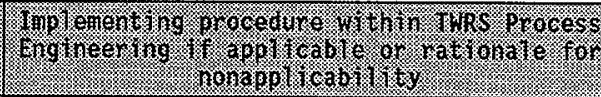 \\
\hline $\begin{array}{l}\text { 5. Control of } \\
\text { on-shift } \\
\text { training }\end{array}$ & No & $\begin{array}{l}\text { TWRS Process Engineering does not operate } \\
\text { a facility and does not require on-shift } \\
\text { (on-the-job) training for employees. } \\
\text { However, the HNF-SD-WM-PROC-02l } \\
\text { Instruction Manual is required reading for } \\
\text { all matrixed, subcontracted, and regular } \\
\text { employees in TWRS Process Engineering. } \\
\text { Training requirements are also established } \\
\text { and tracked for all employees. (See } \\
\text { Section } 17.0 \text { of this manual.) New } \\
\text { employees are also provided with informal } \\
\text { mentoring and orjentation as needed. }\end{array}$ \\
\hline $\begin{array}{l}\text { 6. Investigation of } \\
\text { abnormal events }\end{array}$ & No & $\begin{array}{l}\text { TWRS Process Engineering is not } \\
\text { responsible for an operating facility. } \\
\text { However, lessons learned from abnormal } \\
\text { events at Hanford and other DOE sites are } \\
\text { communicated in a formal manner to TWRS } \\
\text { Process Engineering employees for } \\
\text { consideration and inclusion as warranted } \\
\text { into sampling and analysis planning } \\
\text { documents. }\end{array}$ \\
\hline 7. Notifications & Yes & $\begin{array}{l}\text { TWRS Process Engineering employees are } \\
\text { required to immediately notify their } \\
\text { management if they are involved in an } \\
\text { accident or observe an unsafe condition or } \\
\text { act. Employees are also required to } \\
\text { notify managers if laboratory results } \\
\text { (analytical) indicate extreme or unsafe } \\
\text { conditions within tanks. (See } \\
\text { Section } 11.4 \text { of this manual.) }\end{array}$ \\
\hline $\begin{array}{l}\text { 8. Controt of } \\
\text { equipment and } \\
\text { system status }\end{array}$ & Yes & $\begin{array}{l}\text { TWRS Process Engineering is responsible } \\
\text { for data management systems including } \\
\text { hardware and software. (See Sections } 12.0 \\
\text { and } 13.0 \text { of this manual.) Assessments of } \\
\text { these systems are done per } \\
\text { HNF-SD-WM-TRD-005, Rev. 1., Self- } \\
\text { Assessment Standards Checklist for Data } \\
\text { Systems. }\end{array}$ \\
\hline
\end{tabular}


LOCKHEED MARTIN HANFORD CORPORATION

CONDUCT OF OPERATIONS

APPLICABILITY CHART

APPLICABILITY: FOR GUIDANCE
Hanual

Section

Page

Effective Date
HNF-SD-WM-PROC-021

7.0, REV 2

4 of 6

November 15, 1998

Table 1. Applicability Matrix Chart. (4 sheets)

\begin{tabular}{|c|c|c|}
\hline 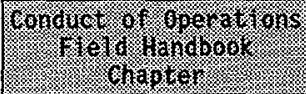 & 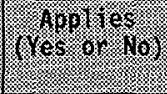 & 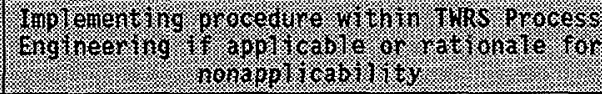 \\
\hline $\begin{array}{l}\text { 9. Lockouts and } \\
\text { tagouts }\end{array}$ & No & $\begin{array}{l}\text { TWRS Process Engineering is not } \\
\text { responsible for an operating facility. } \\
\text { However, all employees obtain basic } \\
\text { training regarding lockout and tagouts as } \\
\text { part of the Hanford General Education } \\
\text { Training. }\end{array}$ \\
\hline $\begin{array}{l}\text { 10. } \begin{array}{l}\text { Independent } \\
\text { verification }\end{array} \\
\text { verion }\end{array}$ & Yes & $\begin{array}{l}\text { This chapter is applicable to TWRS Process } \\
\text { Engineering only for the data management } \\
\text { systems under the direct control and } \\
\text { responsibility of TWRS Process } \\
\text { Engineering. Independent verification is } \\
\text { done per HNF-SD-WM-TRD-005, Rev. 1, } \\
\text { assessments. The assessment team includes } \\
\text { an independent member from the Quality } \\
\text { Assurance organization. }\end{array}$ \\
\hline 11. Logkeeping & No & Applicable only to operating facilities. \\
\hline $\begin{array}{l}\text { 12. Operations } \\
\text { turnover }\end{array}$ & No & $\begin{array}{l}\text { Applicable only to shift turnover at } \\
\text { operating facilities. }\end{array}$ \\
\hline $\begin{array}{l}\text { 13. Operations } \\
\text { aspects of } \\
\text { facility } \\
\text { chemistry and } \\
\text { unique processes }\end{array}$ & Yes & $\begin{array}{l}\text { TWRS Process Engineering analyzes data } \\
\text { from tank farms relative to process } \\
\text { history, tank chemistry, process } \\
\text { flowsheets, unique tank characteristics } \\
\text { and content, etc. Guidelines for drafting } \\
\text { Tank Characterization Report documents and } \\
\text { requirements for immediate notification of } \\
\text { tank content safety issues are described } \\
\text { in Section } 11.4 \text { of this manual. } \\
\text { Requirements for Engineering Material } \\
\text { Balance Analysis for tank C-106 are given } \\
\text { in Section } 23.0 \text { and Data Management Report } \\
\text { requirements for tank C-106 are given in } \\
\text { Section } 24.0\end{array}$ \\
\hline 14. Required reading & Yes & $\begin{array}{l}\text { Procedures for TWRS Process Engineering } \\
\text { required reading execution and } \\
\text { documentation are found in Section } 15.0 \text { of } \\
\text { this manual. }\end{array}$ \\
\hline $\begin{array}{l}\text { 15. Timely orders to } \\
\text { operate }\end{array}$ & Yes & $\begin{array}{l}\text { Dissemination of timely information and } \\
\text { instructions to personnel is handled by } \\
\text { management directives as outlined in } \\
\text { Section } 9.0 \text { of this manual. }\end{array}$ \\
\hline
\end{tabular}


Table 1. Applicability Matrix Chart. (4 sheets)

\begin{tabular}{|c|c|c|c|}
\hline & 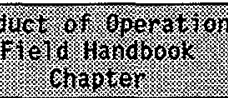 & (lies & 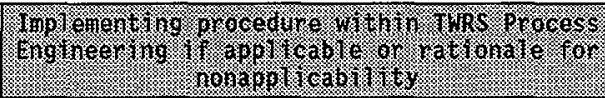 \\
\hline & $\begin{array}{l}\text { Operations } \\
\text { procedures }\end{array}$ & Yes & $\begin{array}{l}\text { Procedures and guidance for conducting } \\
\text { work within TWRS Process Engineering are } \\
\text { provided in this manual. The procedure } \\
\text { for making changes in this manual is } \\
\text { contained in Section } 2.0 \text {. }\end{array}$ \\
\hline & $\begin{array}{l}\text { Operator aid } \\
\text { postings }\end{array}$ & Yes & $\begin{array}{l}\text { Postings to assist employees with tracking } \\
\text { and performing their work including safety } \\
\text { postings are used within TWRS Process } \\
\text { Engineering and are described in } \\
\text { Section } 14.0 \text { of this manual. }\end{array}$ \\
\hline 18. & $\begin{array}{l}\text { Equipment and } \\
\text { piping labeling }\end{array}$ & No & $\begin{array}{l}\text { Applicable only to operating facilities. } \\
\text { TWRS Process Engineering is not } \\
\text { responsible for an operating facility. }\end{array}$ \\
\hline
\end{tabular}


Effective Date November 15, 1998

This page intentionally left blank. 
LOCKHEED MARTIN HANFORD CORPORATION

TWRS PROCESS ENGINEERING

INSTRUCTION MANUAL
Manua 1

Section

Page

Effective Date Organization
HNF-SD-WM-PROC-021

8.0, REV 2

1 of 4

November 15, 1998

TWRS Process

Engineering

\section{TITLE: \\ LETTERS OF INSTRUCTION/STATEMENTS OF WORK APPLICABILITY: FOR COMPLIANCE}

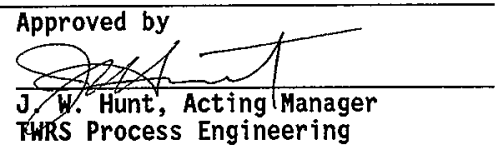

\subsection{OBJECTIVE}

The objective of this section is to provide direction to employees charged with preparing and managing work orders and Letters of Instruction (LOI) or Statements of Work (SOW) to Pacific Northwest National Laboratory (PNNL), enterprise companies, subcontractors, or supporting internal organizations. Work orders shall always be accompanied by an LOI or SOW in order to properly define and control the work.

\subsection{PROCEDURAL REQUIREMENTS}

The following items shall be addressed in an LOI/SOW in the order given. If the item is not applicable to the work at hand, place N/A (not applicable) behind the item title.

1. Subject:

The subject listed shail correspond to the subject listed on the work order form.

2. References:

List selected references, relevant plans or documents, and/or relevant standards or specifications.

3. Task Objective:

Describe the overall goal and objective of the task. What is the successfut end point of the effort?

4. Introduction and Overal1 Scope:

Describe the scope of the required services.

5. Functional Requirements:

List and describe the functionality required in the deliverables. What requirements shall the deliverabies be able to satisfy? 


\begin{tabular}{llr}
\hline LOCKHEED MARTIN HANFORD CORPORATION & Manual & HNF-SD-WM-PROC-021 \\
& $\begin{array}{l}\text { Section } \\
\text { LETTERS OF INSTRUCTION/STATEMENT OF WORK }\end{array}$ & $\begin{array}{l}\text { Page } \\
\text { REV } 2 \\
\text { APPLICABILITY: FOR COMPLIANCE }\end{array}$ \\
\hline
\end{tabular}

6. Schedule:

Provide scheduled completion dates and milestones including interim milestones if any.

7. Cost:

Indicate cost ceilings that the task shall not exceed. Costs should be based on formal estimates and established rates and shall include a) 1 overheads, adders, and taxes.

8. Procurement:

Describe materials or subcontracted services-the vendor is to supply including dates of delivery if not covered in item 6 above. Also describe and list items to be provided by you the customer.

9. Permits:

List any special permits, approvals, or work plans required.

10. Specific Services and Special Instructions:

Describe in detail the tasks to be accomplished including the methods to be used as necessary.

11. Deliverables:

State the products or services to be delivered including due dates if not covered in item 6 above. If the deliverables are documents, include editorial standards for the documents, acceptable formats, and electronic deliverable requirements. State the number of copies of the documents to be delivered and review required prior to delivery. (See Section 11.0, Part 6.0 for publication standards for documents.)

12. Meetings, Reports, and Activities:

Establish required standing meeting times, places, and agendas.

Establish the format and content of required routine reports

including financial reports. Describe approval process for making changes to the LOI/SOW.

13. Quality Assurance (QA) Requirements:

List QA requirements or standards that are to be applied to the work including national or international codes, standards, or conventions. 


\begin{tabular}{llr}
\hline LOCKHEED MARTIN HANFORD CORPORATION & Manual & HNF-SD-WM-PROC-021 \\
LETTERS OF INSTRUCTION/STATEMENT OF WORK & Section & Page \\
APPLICABILITY: FOR COMPLIANCE & Effective Date & November 15, 1998 \\
\hline
\end{tabular}

14. Safety Requirements:

List special safety requirements to be adhered to including safety training required.

15. Task Management:

Name customer and supplier points-of-contact including responsible task or project managers and budget analyst.

16. Other:

As needed.

\subsection{ADNINISTRATIVE REQUIREMENTS}

The LOI/SOW shall be approved and dated by the customer (requestor) and his/her manager. The cost account manager and/or technical lead shall also approve tasks within the scope of their responsibility. The cost account manager shall verify with the budget analyst that funds are available. The LOI/SOW shall be accompanied by an approved work order form of the same title. Copjes of the LOI/SOW shall be kept in the requestors project file with copies distributed to those approving the LOI/SOW. Copies shall also be provided to the parties listed in Section 15 of the LOI/SOW.

\subsection{RESPONSIBILITIES}

The customer (requestor) of services is responsible for preparing and securing approvals of the LOI/SOW in accordance with this procedure. 
This page intentionally left blank. 
LOCKHEED MARTIN HANFORD CORPORATION

TWRS PROCESS ENGINEERING

INSTRUCTION MANUAL
Manual

Section

Page

Effective Date

Organization
HNF-SD-WH-PROC-021

9.0 , REV 2

1 of 6

November 15, 1998

TWRS Process

Engineering

TITLE:

Approved by

MANAGENENT DIRECTIVES

APPLICABILITY: FOR COMPLIANCE

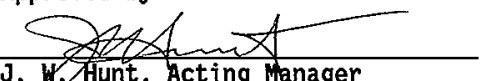

J. W. Hunt, Acting Hanager

TWRS Process Engineering

\subsection{OBJECTIVE}

This procedure describes requirements for preparing, using, distributing, and controlling management directives.

\subsection{SCOPE}

This procedure applies to all employees of the Tank Waste Remediation System (TWRS). Process Engineering organization of Lockheed Martin Hanford Corporation (LMHC). It is intended that this procedure be consistent with LMHC's contractual agreements to Fluor Daniel Hanford, Inc. (FDH) under the Project Hanford Management Contract (PHMC). In the event of conflicting direction, the LMHC contract with FDH shall prevai?.

\subsection{DEFINITIONS}

The management directive system is a mechanism for controlling and numbering documents used to convey to employees direction, guidance, clarification, or emphasis on matters related to the operations of the TWRS Process Engineering organization. The management directive system provides a concise and consistent method for formally documenting management direction, indexing the information, and filing for easy retrieval.

The management directive system may be used by TWRS Process Engineering management to supplement formal policies and procedures prescribed by the U.S. Department of Energy-Richland Operations Office (DOE-RL), FDH, or LMHC and provide immediate direction to TWRS Process Engineering employees in the event of contractual, programmatic, or customer-directed changes. Management directives may be issued to provide directions or instructions related to operational protocols, policies, procedures, or other related activities important to the operations of the TWRS Process Engineering organization. 


\subsection{REQUTREMENTS}

\subsection{Preparation/Approval Authority}

The following individuals are authorized to prepare management directives and can be delegated approval authority by the Manager of the TWRS Process

Engineering organization:

- Manager, Models and Inventory

- Manager, Technical Basis and Planning

- Manager, Data Assessment and Interpretation

- Manager, Process Control.

Final approval authority of management directives for compliance resides with the Manager of the Process Engineering organization. A centralized approval authority is established to ensure consistency of management directive preparation and application across the TWRS Process Engineering organization.

\subsection{Administration of the Management Directive System}

1. The management directive system sha11 be administered by the Secretary of the TWRS Process Engineering organization. Subordinate secretarial staff can be used at the discretion of the Secretary of the TWRS Process Engineering organization to process and release management directives. The Secretary of the TWRS Process Engineering organization is responsible for coordinating and integrating the following actions/activities:

a. Working with the Manager of the TWRS Process Engineering organization and subordinate management staff to establish standards for the management directives.

b. Working with subordinate secretarial staff to establish a system for assigning and tracking management directive control numbers.

c. Working with TWRS Process Engineering management and staff to coordinate review and approval of management directives, as necessary.

d. Processing approved management directives for reproduction, distribution, and archiving for easy retrieval.

e. Maintaining a subject index and a current version of each management directive in both electronic and hard copy format. 
f. Maintaining the current status of management directives including the status of management reviews, waiver requests, and the overall applicability.

g. Ensuring that management directives are posted on Hanford Local Area Network (HLAN) and that the network address is provided to Process Engineering employees.

2. Management directives may supersede, amend, or modify existing policies, requirements, or procedures in the TWRS Process

Engineering Instruction Manual. Management directives may also be used to provide interpretations of other controlled manual requirements. Management directives shall only be used where special circumstances require rapid communication of policy or procedure changes that must be implemented immediately. The existing TWRS Process Engineering Instruction Manual shall be updated periodically or amended to incorporate management directives, as appropriate. Initiation of required updates and amendments to the TWRS Process Engineering Instruction Manual shal1 be done per Section 2.0 of this manual.

3. Management directives are not intended as permanent substitutes for policies and procedures contained in the TWRS Process Engineering Instruction Manual or other controlled manuals. Management directives that are used to modify existing TWRS Process Engineering Instruction Manual requirements shall be reviewed by management every 3 to 6 months to determine their applicability and continued need. If a review determines that a particular management directive is no longer needed or has been incorporated through updates or amendments to the TWRS Process Engineering Instruction Manual, then the Manager of the TWRS Process Engineering organization shall take immediate action to rescind the management directive.

4. Management directives impacting the TWRS Process Engineering Instruction Manual shall clearly reference the affected section and paragraph. Copies of approved management directives must be printed on colored paper and be sent to al1 manual holders with instructions for insertion into the appropriate area of the affected policy or procedure. Management directives shall also be posted on HLAN and the address provided to Process Engineering employees. The management directives shall be effective as of the date they are approved. 
LOCKHEED MARTIN HANFORD CORPORATION

MANAGEMENT DIRECTIVES

APPLICABILITY: FOR COMPLIANCE
Manua T

Section

Page

Effective Date
HNF-SD-WM-PROC-021

9.0 , REV 2

4 of 6

November 15, 1998

\subsection{Requesting Waivers from Management Directives}

1. Any employee of the TWRS Process Engineering organization can request a waiver from a management directive if obtaining a waiver is cost effective, good business practice, or compliance cannot be achieved in a timely manner. To request a waiver from a management directive, perform the following steps:

a. Identify the management directive number, title, and date.

b. List the specific paragraph(s) for which a waiver is being requested.

c. Indicate whether the waiver is permanent or temporary. (Temporary waivers are typically for less than one year until compliance can be achieved and may not be renewed more than once.)

d. Estimate potential cost savings associated with approving the waiver.

e. Assess the impact of the waiver including a summary of applicable risks, corrective actions planned or taken, and a schedule for completion.

f. Describe the waiver circumstances including specifications, drawings, engineering orders, or sketches that might be available.

g. Explain why compliance with the management directive cannot or should not be achieved.

h. Show any violations or conflicts between the management directive and other directives, standards, codes, 1 aws, policies, or procedures.

i. Describe the steps that will be taken to ensure quality, safety, health, and environmental protection. Include necessary practices, means, methods, operations, and processes that must be adopted and used to provide required coverage.

j. Analyze the worst-case scenario and compare the benefits of the waiver versus the negative impacts to the program. This analysis should include any likely program or departmental impacts if the waiver is not approved.

2. Use the information provided to prepare a formal waiver request letter written to the Manager of the TWRS Process Engineering organization.

3. Route the letter for sign off by your immediate manager. 
LOCKHEED MARTIN HANFORD CORPORATION

MANAGEMENT DIRECTIVES

APPLICABILITY: FOR COMPLIANCE
Manual

Section

Page

Effective Date
HNF-SD-WM-PROC-021
9.0, REV 2
5 of 6

November 15,1998

4. Submit the waiver request to the Manager of the TWRS Process Engineering organization following review and approval by the immediate manager.

5. Update the management directive status documentation required under Section 9.4.2.1.f.

5.0 REFERENCES

The following documents were used as references in preparing this management directive procedure to ensure compatibility and consistency with overall LMHC policies and procedures regarding management directives:

1. LMHC, 1997, "Managing DOE Directives," HNF-PR0-116, Rev. 0, (supersedes WHC-CM-1-3, Section 1.1, "Managing DOE Directives"), Lockheed Martin Hanford, Corp. for Fluor Daniel Hanford, Inc., Richland, Washington. 
LOCKHEED MARTIN HANFORD CORPORATION

MANAGEMENT DIRECTIVES

APPLICABILITY: FOR COMPLIANCE
Manual

Section

Page

Effective Date
HNF-SD-WM-PROC-021

9.0, REV 2

6 of 6

November 15,1998

This page intentionally left blank. 
LOCKHEED MARTIN HANFORD CORPORATION

TWRS PROCESS ENGINEERING

INSTRUCTION MANUAL
Manual

Section

Page

Effective Date

Organization
HNF-SD-WM-PROC-021

10.0, REV 2

1 of 4

November 15, 1998

TWRS Process

Engineering

\section{TITLE:}

SAFETY IMPROVEMENT PLAN

\section{APPLICABILITY: FOR COMPLIANCE}

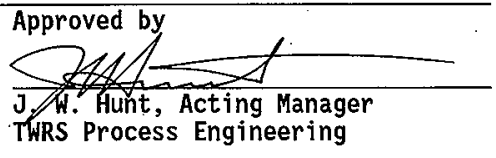

\subsection{OBJECTIVE}

The following safety improvement plan provides the goals and initiatives that a11 Process Engineering staff sha11 support for the continued safe performance of Tank Waste Remediation System (TWRS) Process Engineering work activities.

Working safely is the highest priority for all work conducted at Hanford. Safety shall be maintained as a key value in TWRS Process Engineering. Work activities shall be performed in such a way as to ensure personal safety, co-worker safety, and the safety of the environment.

\subsection{GOALS AND INITIATIVES}

The safety goal of TWRS Process Engineering is to strive for 0 Lost/Restricted Workday Cases during Fiscal Year (FY) 1998.

- This shall be achieved by maintaining safety as a value, improving housekeeping, expanding individual safety knowledge, willingly correcting unsafe behaviors, and complimenting safe behaviors.

The following initiatives are the baseline for TWRS Process Engineering's strategy for safety improvement.

- MANAgEMENT COMMITMENT

- Increase Management Field Time: TWRS Process Engineering managers are committed to increasing their awareness of employee working conditions, work practices, and equipment conditions by visiting employees at their stations of employment.

GOAL: $\quad 50 \%$ field time (20 hours per week) for first-leve1 managers and $20 \%$ ( 8 hours per week) for the Process Engineering manager. 
- Safety Issues: The management of TWRS Process Engineering shall support the employee goal of remediation of safety issues.

GOAL: $\quad 100 \%$ resolution of issues identified during FY 1998 for which TWRS Process Engineering has the responsibility and authority to resolve.

- Training: TWRS Process Engineering management shall review and update required training needs for the employees as related to the individual workscope.

GOAL: Complete and up-to-date on an ongoing basis.

- Safety shall be included as the first agenda item of each staff meeting.

- EMPLOYEE INVOLVEMENT

- Safety Meetings: Each TWRS Process Engineering employee sha11 participate in the planning and conducting of monthiy safety meetings.

GOAL: $\quad 100 \%$ involvement in planning and conducting one safety meeting during FY 1998. $100 \%$ attendance for monthly safety meetings.

- TWRS Engineering Safety Committee: TWRS Process Engineering personnel sha17 be represented at aT1 TWRS Engineering Safety Committee meetings. This representative will serve as a liaison/facilitator between TWRS Process Engineering and TWRS Engineering.

GOAL: Attendance at $100 \%$ of the Safety Committee meetings.

- WORK SITE ANALYSIS

- Housekeeping Inspection: TWRS Process Engineering shall conduct monthly housekeeping inspections.

GOAL: $\quad$ Continued improvement towards maintaining a clean safe work area. Compliance with $95 \%$ of the items on the Office Safety Checklist(s) as inspected each month. Resolution of a11 noncompliant items before the next inspection.

- Job Hazard Review: TWRS Process Engineering personne] shall conduct a Job Hazard Review when appropriate to increase employee awareness of job safety hazards. 
- HAZARD PREVENTION and CONTROL

GOAL: $\quad$ Conduct periodic ergonomic review of group work practices with $100 \%$ of a 11 work stations assessed for ergonomics.

- SAFETY AND HEALTH TRAINING

- Job-Specific Hazard Training: TWRS Process Engineering recognizes education as a primary factor in working safely. Employees will receive all required training necessary to perform any activity associated with their particular workscope.

G0AL: Existing Employees - 100\% completion of required training prior to expiration of any given required class. New Employees - $100 \%$ completion of required training within 6 months of reporting to work.

TWRS Process Engineering recognizes working safely is a personal responsibility. The safe work habits of each individual can be improved through awareness of unsafe conditions and practices. The initiatives outlined above will promote safety awareness and lead to successfully attaining the TWRS Process Engineering safety goals. 
LOCKHEED MARTIN HANFORD CORPORATION

SAFETY IMPROVEMENT PLAN

APPLICABILITY: FOR COMPLIANCE
Manual

Section

Page

Effective Date
HNF-SD-WH-PROC-021

10.0, REV 2

4 of 4

November 15, 1998

This page intentionally left blank. 
LOCKHEED MARTIN HANFORD CORPORATION

TWRS PROCESS ENGINEERINGEffective Date INSTRUCTION MANUAL
Manua 1

Section

Page

Organization
HNF-SD-HH-PROC-021

11.0 , REV 2

1 of 18

November 15, 1998

TWRS Process

Engineering

TITLE:

Approved by

GUIDELINES FOR DOCUMENT PREPARATION

APPLICABILITY: FOR GUIDANCE

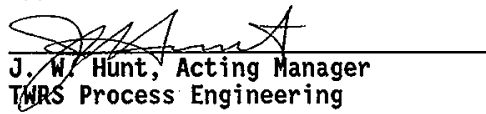

\subsection{INTRODUCTION}

The following sections provide guidance for preparing documents that are produced by Tank Waste Remediation System (TWRS) Process Engineering.

\subsection{WASTE INFORMATION REQUIREMENTS DOCUMENT (WIRD)}

The Waste Information Requirements Document (WIRD) is an annual document which describes the activities of the TWRS Characterization Project that provide information on Hanford Site waste tanks. The WIRD, which is prepared by Process Engineering, replaced the annual Tank Waste Analys is Plan (TWAP) and Tank Characterization Plans.

The WIRD has two annual Hanford Federal Facility Agreement and Consent Order (Tri-party Agreement) milestones associated with it. The WIRD is prepared annually in draft form (milestone 1) and final form (milestone 2). It addresses activities identified through fiscal year (FY) 2002 for which the Characterization Project is responsible for supplying sample material, analyses, and/or other forms of tank waste information such as reports and studies. Although WIRD due dates are generally in May (draft) and August (final), authors must consult the annual Characterization Project Multi-Year Work Plan (MYWP) milestone description sheets for specific WIRD delivery dates to U.S. Department of Energy-Richland Operations (DOE-RL) and the Washington State Department of Ecology (Ecology).

The WIRD is based on the best information available at the time it is issued. other supporting documents and activities such as the Tank Characterization Technical Sampling Basis (Brown et al. [current revision]) or its revisions, data quality objective revisions, issue closures, discussions with the Ecology, and management decisions may cause subsequent updates to the WIRD during the year. Information contained in the WIRD is derived from various sources and includes Tri-party Agreement milestones, Defense Nuclear Facility Safety Board (DNFSB) recommendations, DOE-RL directions, regulatory drivers, the Authorization Basis, data quality objectives, program logic, topical reports, test plans, etc. From these sources, each TWRS engineering, operating, safety, retrieval, and disposal program has the responsibility to identify their information needs for safely operating and monitoring facilities that store, receive, retrieve, treat, or dispose of waste materials. In coordination with the programs, Process Engineering collects the information on perceived needs, evaluates the validity of these needs, and documents the agreed needs in the WIRD. 
LOCKHEED MARTIN HANFORD CORPORATION

GUIDELINES FOR DOCUMENT PREPARATION APPLICABILITY: FOR GUIDANCE
Manual

Section

Page

Effective Date
HNF-SD-WM-PROC-021

11.0 , REV 2

2 of 18

November 15, 1998

As the WIRD is prepared, the Tank Characterization Sampling Priority Basis (Brown et al. [current revision]) and the characterization field sampling schedule is being developed. These documents must be coordinated and integrated into the WIRD for activities involving sampling and analysis.

For guidance purposes, Figure 1 shows the Contents pages of the current WIRD.

\subsection{PREPARATION OF SAMPLING AND ANALYSIS PLANS}

The Tank Sampling and Analysis Plan (TSAP) provides direction to sampling and laboratory organizations for obtaining data required by organizations such as Safety and Retrieval. Because the TSAP is one document used to initiate tankintrusive field work and analytical services, the preparation of this document should be completed in as timely a manner as possible. Each tank coordinator is responsible for reviewing the latest sampling schedule and ensuring the TSAP is completed in sufficient time that the sampling event is not delayed.

The tank coordinator needs to be aware of all possible interested parties regarding sampling activities. Because multiple organizations frequently are interested in obtaining data from the same tank, the tank coordinator must incorporate all these needs into an easily understood set of requirements for the sampling and laboratory organizations. The primary source documentation needed to write a TSAP is the data quaTity objective (DQO), although other work-authorizing documents such as Letters of Instruction (LOI), Memoranda of Understanding (MOU), or test plans may be used where a DQO is not available. Requests for data, which are not formally communicated to the Process Engineering organization in a referenced manner, should not be included in the TSAP.

Because the TSAP has approval designator "Q," it must be signed by the tank coordinator, the responsible manager (Technical Basis and Planning), and a representative from TWRS Quality Assurance. In addition, responsible individuals for each applicable DQO and service organization (e.g., 222-S Laboratory, Characterization Project Operations) may need to sign the TSAP. Final TSAP approval authority rests with the Technical Basis and PTanning manager. ATl TSAPs and engineering change notices (ECNS) to TSAPS shall be released by the Process Engineering organization through the Document Control System. 
Figure 1. WIRD Table of Contents. (4 sheets)

\section{CONTENTS}

1.0 PURPOSE AND BACKGROUND ......................... . . . . . . .

1.1 PURPOSE ......................... . . . . . . . . . . .

1.2 BACKGROUND . . . . . . . . . . . . . . . . . . . . 1-1

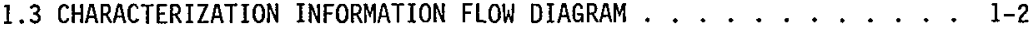

2.0 TWRS CHARACTERIZATION INFORMATION DRIVERS AND SUPPORTING DOCUMENTS . $2-1$ 2.1 CHARACTERIZATION INFORMATION DRIVER SOURCES .......... 2-2

2.1.1 Tri-Party Agreement Milestone . . . . . . . . . . . 2-2

2.1.1.1 Tri-Party Agreement Major Milestone M-40-00,

"Mitigate/Resolve Tank Safety Issues for High

Priority Watch List Tanks" . . . . . . . . . 2-2

2.1.1.2 Tri-Party Agreement Major Milestone M-41-00, "Complete Single-Shell Tank Interim Stabilization" . 2-2

2.1.1.3 Tri-Party Agreement Major Milestone M-43-00, "Complete Tank Farm Upgrades" . . . . . . . . . 2-2

2.1.1.4 Tri-Party Agreement Major Milestone M-44-00

2.1:1.5 Tri-Party Agreement Major Milestone M-45-00, "Complete Closure of A17 Single-She7l Tanks".... . 2-3

2.1.1.6 Tri-Party Agreement Major Milestone M-50-00, "Complete Pretreatment Processing of Hanford Tank Waste" .................. 2-3

2.1.1.7 Tri-Party Agreement Major Milestone M-51-00, "Complete Vitrification of Hanford High Leve]

Tank Waste". ................ 2-3

2.1.1.8 Tri-Party Agreement Milestone M-60-00, "Submit

Conceptual Design and Initiate Definitive Design of LLW Vitrification Facility" . . . . . . . . . . 2-4

2.1.1.9 Tri-Party Agreement Major Milestone M-61-00, "Complete Pretreatment and Immobilization of Hanford Low-Activity Waste (LAW)" .......... . 2-4

2.1.1.10 Tri-Party Agreement Major Milestone M-90-00, "Complete Acquisition of New Facilities, Modification of Existing Facilities, and/or Modification of Planned Facilities as Necessary for Storage of Hanford Site IHLW and ILAW, and Disposal of ILAW" . . . . . . . . 2-4

2.1.2 DNFSB Recommendation 93-5 Implementation Plan . . . . . . 2-4

2,1.2.1 Safe Storage of Tank Wastes and Safe Operation

of Tank Farm .................... 2-5

2.1.2.2 Disposal Program Data Requirements . . . . . . 2-5

2.1.2.3 Technical Basis for Characterization ..... . 2-5

2.1.3 Regulatory Drivers to Characterization . . . . . . . . 2-5

2.1.4 Authorization Basis............. . . 2-6 
Figure 1. WIRD Table of Contents. (4 sheets)

\section{CONTENTS (Continued)}

2.1.5 Privatization Contract and Supporting TWRS Retrieval and Disposal Mission Readiness-to-Proceed Memorandum . . 2-7

2.2 SUPPORTING DOCUMENTS ............... 2-8

2.2.1 Waste Characterization Program Multi-Year Work Plan . . . 2-9

2.2.2 TWRS Topical Reports ............ 2-9

2.2.3 Tank Characterization Technical Sampling Basis . . . . 2-9

2.2.4 Data Quality Objectives.............. 2-9

2.3 MILESTONES AND ISSUES TABLES .....................

3.0 ISSUES AND REQUIREMENTS ADDRESSED BY CHARACTERIZATION

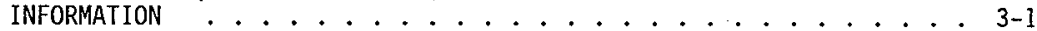

3.1 SAFETY ISSUE RESOLUTION ....................

3.1 .1 Flammable Gas . . . . . . . . . . . . 3-2

3.1 .2 Sluicing of Tank 241-C-106 ............. 3-3

3.2 OPERATIONS AND MAINTENANCE .................... 3-3

3.2.1 Waste Transfers and Compatibility ........... 3-3

3.2.1.1 Saltwel1 Pumping (Interim Stabilization) ..... 3-4

3.2.1.2 Waste Transfers to Support Evaporator Operations . 3-4

3.2.2 Evaporator Operations .............. 3-4

3.2 .3 Caustic Mitigation .................. 3-5

3.2 .4 Process Sampling ................ . . 3-6

3.3 DISPOSAL .................... . . . . . . . .

3.3.1 Waste Feed Del ivery (Phase I) $\ldots 3-6$

3.3.2 Privatization Phase I -DOE Management of Private Contract . 3-7

3.3.3 Privatization Phase I - Direct Samples to

Private Contractor ............. 3-8

3.3.4 Retrieval and Immobilization (Phase II) . . . . . 3-8

3.3.5 Single-She11 Tank Waste Retrieval and Tank Closure:

Hanford Tank . . . . . . . . . . . . 3-9

3.4 CHARACTERIZATION FOR HISTORICAL DATA EVALUATION ...... . . 3-11

3.5 REGULATORY REQUIREMENTS .........................

3.5.1 Air Emissions . . . . . . . . . . . . . . . . . . . 3-11

3.5 .2 Dangerous Waste . . . . . . . . . . 3-12

3.5 .3 Wastewater . . . . . . . . . . . . . . 3-12

3.6 DATA SYSTEMS MANAGEMENT . . . . . . . . . . . . . $3-12$

3.7 INACTIVE MISCELLANEOUS UNDERGROUND STORAGE TANKS (IMUST) $\ldots 3-13$

3.8 CHARACTERIZATION PROGRESS: ISSUES WITH CLOSURE PENDING . . . . 3-13

3.8.1 Organic Fuels (Complexants) . . . . . . . . . . 3-13

3.8 .2 Safety Screening ............... . . . . . . . . .

3.8 .3 Organic Solvents ................... . . . . . . . . . .

3.8 .4 Vapor Space Phenomenology ............ 3-14 


\begin{tabular}{llr}
\hline LOCKHEED MARTIN HANFORD CORPORATION & Manual & HNF-SD-WM-PROC-021 \\
& Section & 11.0, REV 2 \\
GUIDELINES FOR DOCUMENT PREPARATION & Page & 5 of 18 \\
APPLICABILITY: FOR GUIDANCE & Effective Date & November 15, 1998
\end{tabular}

Figure 1. WIRD Table of Contents. (4 sheets)

CONTENTS (Continued)

\subsection{TECHNICAL SAMPLING BASIS FOR CHARACTERIZATION - DEVELOPMENT OF SAMPLING PRIORITIES AND SCHEDULES . . ............ . . $4-1$ \\ 4.1 DEVELOPMENT OF SAMPLING PRIORITY NUMBERS $\ldots . . . . . .4$. \\ 4.1.1 Sampling Basis Priority Numbers . . . . . . . . . . . . 4-1 \\ 4.1.2 Operations Priority Numbers . . . . . . . . . . . 4-2 \\ 4.2 MEANING OF SAMPLING PRIORITY NUMBERS ........... 4-2 \\ 4.3 DESCRIPTION OF THE SAMPLING PRIORITY TABLE ........ . . . $4-3$ \\ 4.4 USE OF PRIORITY TABLES IN CHARACTERIZATION SCHEDULING}

5.0 REPORTING AND MEASURING CHARACTERIZATION PROGRESS . . . . . . 5-1

6.0 DESCRIPTION OF DELIVERABLES AND ACCEPTANCE CRITERIA . . . . . . 6-1

6.1 CHARACTERIZATION PROJECT SAMPLING ACTIVITIES ........ . $6-1$

6.1 .1 Core Sampiing ................ 6-1

6.1 .2 Grab Sampling ................. 6-1

6.1 .3 Auger Sampling ................ . 6-1

6.1 .4 Vapor Sampling ................ . . 6-2

6.2 TANK CHARACTERIZATION REPORTS ........... 6-2

6.3 ACCEPTANCE CRITERIA FOR ECOLOGY DELIVERABLES . . . . . . . 6-2

6.3.1 Waste Information Requirements Document . . . . . . . . 6-2

6.3.2 Quarterly Reports ................. 6-3

6.3 .3 Characterization Deliverabies Report ...... 6-3

7.0 REFERENCES ........................... . . . . .

\section{APPENDIXES}

APPENDIX A: MILESTONE.LIST: TRI-PARTY AGREEMENT AND DNFSB

MILESTONES ............................. 
Figure 1. WIRD Table of Contents. (4 sheets)

\section{LIST OF FIGURES}

1-1 Characterization Information Flow Diagram . . . . . . . . . . 1-3

\section{LIST OF TABLES}

2-1 Tri-Party Agreement Milestones and Issues . . . . . . . . . 2-10

2-2 Non-Tri-Party Agreement Milestones and Issues . . . . . . . . . 2-14

2-3 Active TWRS Characterization Program Data Quality Objectives and Other Comparable Requirements Documents . . . . . . . . 2-16

5-1a Summary of Sampling/Reporting by Issue . . . . . . . . . . . . 5-2

5-1b Total Sampling/Reporting (minimum) . . . . . . . . . . . . 5-3

5-2 Tank List with Associated Sampling Priority Values . . . . . . . . 5-4 
The structure and formatting of a TSAP will generally follow the description provided below.

\subsection{SAMPLING AND ANALYSIS OBJECTIVES}

This section identifies the tank to be sampled and analyzed and states the applicable DQOs, test plans, or work-authorizing documentation used to generate the TSAP. The list of applicable issues for each tank is in the Tank Characterization Technical Sampling Basis (Brown et al. [current revision 1). If an issue identified in Brown et a1. is not being incorporated into the TSAP, a short sentence explaining the omission needs to be included. For example, vapor screening issues are outside the scope of a core sampling event TSAP; therefore, a sentence stating such should be included in the paragraph.

\subsection{SAMPLING EVENT REQUIREMENTS}

This section begins with a paragraph describing the tank contents (i.e., total waste volume, height of the waste as measured from either the centerline or baseline of the tank, and a breakdown of volume by matrix or waste type [s]udge, saltcake, or drainable liquid]). Volume information should be obtained from the monthly waste tank summary report unless more current or correct information exists. The waste height should be calculated by the tank coordinator. If the tank is on a Watch List, it should be identified. This section also includes a reference to Appendix A of the TSAP which provides the physical profile prediction of the tank. Physical profile predictions are prepared for the tank coordinator on request.

The second paragraph identifies the need to measure the tank headspace for flammable gases before sampling occurs. This is a standard paragraph and should not be changed unless a global TSAP change is warranted.

The third paragraph identifies the type of sampling to be performed (push mode core, rotary mode core, auger, or grab) and the risers to be sampled. The number of segments expected are stated, based on the height of the waste volume calculated in the first paragraph and the physical profile predictions provided in Appendix A of the TSAR. The selection of risers depends on the ability of the sampling organization to use the riser and the need for a spatial distribution between cores removed from the tank. The tank coordinator should refer to Waste Tank Risers Available for Sampling (Lipnicki 1997) and work with a Characterization Project Operations work package planner to agree on the riser selection. Once the riser selection is determined, work package numbers will be assigned. This information is included in this section of the TSAP.

If the tank is to be sampled with retained gas samplers in addition to or in place of universal samplers, or if other special sampling is necessary, this section must contain sufficient instructions to perform 
the work or to provide information about where instructions may be found. This section also must address the use of field blanks or lithium bromide solution. Special conditions, field testing, or time constraints should be outlined and justified, as appropriate. Specific needs for information on the chain-of-custody form for the samples should be described.

\subsection{LABORATORY ANALYSIS REQUIREMENTS}

This section discusses the laboratory analysis scheme. For retained gas samples, a test plan will be written by Pacific Northwest National Laboratory and should be referenced. For other samples, this section cites the routine extrusion procedure, the need for video tape and photographic records, the handling of drainable liquids, guidance about segmentation, and sample archive needs. For core or auger sampling TSAPs, this section also cites the Safety and Analysis Report for Packaging (Clements 1996) and specifies the time limit for storage of the transportation casks before venting is necessary.

The "Chemical, Radiological, and Physical Analytical Requirements" tables are an important part of the TSAP. These tables identify the analyses to be performed on solid and liquid samples. The analyses are separated into primary, secondary and sometimes tertiary analyses. The following information is required for each analysis:

- The program requesting the analysis

- The method and analysis name and the procedure number

- The type of subsegment to be analyzed, e.g., half-segment, composite, drainable liquid

- The type of preparation necessary, if any

- The quality control required including duplicate analyses, spikes, calibration blanks, and standards

- The result units, expected range for the analyte, and notification limits that may pertain to the analysis

- The format of reporting required.

Unless more recent analytical data are available, the expected ranges for each analyte may be found in the best-basis inventory for the tank.

If retained gas samples are to be taken, the TSAP needs to specify the analyses to be performed and the assocjated quality control requirements. 


\subsection{QUALITY ASSURANCE AND QUALITY CONTROL}

This section contains the required references for the plans that guide and govern the custodial responsibilities and analytical services performing the listed work. Citations are made to the approved procedures for transport and reception of the sample casks. This section also includes a table showing precision and accuracy requirements for the solid and 1 iquid analyses. These requirements include relative percent difference criteria, spike and standard recoveries, and blank result criteria. Each analyte in the "Chemical, Radiological, and Physical Analytical Requirements" tables should be included in this table.

\subsection{EXCEPTIONS, CLARIFICATIONS, AND ASSUMPTIONS}

The TSAP writer has an opportunity to include modifications and exceptions to the DQOS applied to the tank in Section 5.I (Exceptions to DQO Requirements). This section describes and justifies all modifications and exceptions to the DQOs applied to the tank.

Section 5.2 (Clarifications and Assumptions) is typically reserved for expanding on the details established for the analyses.

\subsection{ORGANIZATION}

A table is the normal format for this section. It is a quick reference to the points-of-contact for the performing organizations. At a minimum, it contains the names, organizations, and telephone numbers of the tank coordinator, the performing laboratories, and Tank Farms operations (i.e., the point-of contact for violations of a notification limit).

\subsection{DELIVERABLES}

A prescribed format exists for each type of report. Each report format is explained in Fisca 7 Year 1997 Memorandum of Understanding for the TWRS Characterization Project (Schreiber. [current revision]). This section of the TSAP provides a brief description of each report format and requires that the data be placed in the Tank Characterization Database using the standard electronic format referenced in the memorandum of understanding.

\subsection{CHANGE CONTROL}

The wording of this section assigns the tank coordinator the responsibility of exercising technical judgment in modifying the described work. It places on the tank coordinator the responsibility for justifying that modifications are technically sound and well documented. It establishes the level of documentation required when changes to the described work in the TSAP are made. 


\begin{tabular}{llr}
\hline LOCKHEED MARTIN HANFORD CORPORATION & Manual & HNF-SD-WM-PROC-021 \\
& Section & 11.0, REV 2 \\
GUIDELINES FOR DOCUNENT PREPARATION & Page & 10 of 18 \\
APPLICABILITY: FOR GUIDANCE & Effective Date & November 15, 1998 \\
\hline
\end{tabular}

\subsection{REFERENCES}

A11 cited material, correspondence, memoranda, and documents should be listed. in the recommended format and style.

\section{I1.4 PREPARATION OF IMMEDIATE NOTIFICATIONS}

Upon receipt of an immediate notification from the laboratory, the tank coordinator will consult the on-call engineer. A written memorandum will be supplied (via cc:mail) to Process Engineering Management and the affected DQO owner discussing the history of the tank and the significance of the data. This notification shall trigger a presentation to the Data Review Committee.

\subsection{PREPARATION OF TANK CHARACTERIZATION REPORTS}

The Tank Characterization Report (TCR) is a publicly released document that addresses pertinent characterization information about a waste tank. It is available to all end users and stakeholders. The document is built through an jterative process; available historical records are augmented by results of current activities (e.g., sampling and analyses since 1989) and earlier verified data. The document al so includes the best-basis inventory. The TCR identifies the most current revision of each $D Q 0$ that is used to gather information. When new sampling and/or inventory information becomes available, a TCR will be revised on an established schedule.

The required format of a TCR is documented in a standard electronic temp 1 ate available via the Data Source Access utility at http://pctwins.pnl.gov/ tcr.nsf. Analytical data tables in the TCR are generated as standard reports from the Tank Characterization Database. Best-basis numbers are to be used for inventory estimates.

\subsection{PUBLICATIONS STANDARDS FOR PREPARATION OF DOCUMENTS}

The following information and instructions are based on the suggested Statement of Work for Resource Documentation Supplied by Subcontractor. It includes modifications that pertain to Tank Characterization Reports.

Scope, Work Tasks, Descriptions and Requirements:

1. Supplier shall provide a hard copy and an electronic copy of documentation. Supplier shall use. a 3.5-in. double-sided high density diskette and shall provide a list of contents. 
2. Documentation text shall be provided in WordPerfect $5.1,6.0$, or 6.1 for WordPerfect documents, or Microsoft Word 97 for Microsoft Word documents. Graphics shall be provided in software that is compatible with WordPerfect 6.1 or Microsoft Word 97.

3. Document numbers will be supplied by the author.

Documents shall be formatted as follows:

1. Font shall be 12 pt. CG Times for WordPerfect documents or 12 pt Times Roman for Microsoft Word documents.

2. Font size shall not be less than 12 pt in text, tables, and graphics. If necessary, tables shall be placed horizontally on the page to fit. If a table will not fit on a horizontal page, the font size of the title shall be $12 \mathrm{pt}$, the remaining table contents shall be $10 \mathrm{pt}$.

3. Margins

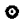

a. Top: 0.5 in. from page top to header (centered document and revision numbers on each page) and $0.5 \mathrm{in}$. between header and text.

b. Bottom: 0.5 in. from bottom of text to footer (centered page number) and $0.5 \mathrm{in}$. marg in from footer to page bottom.

c. Sides: 1 in.

4. Table of Contents

a. Shall be electronically generated.

b. Shall include all section titles through the third order, figures, and tables. Appendix and attachment titles only shall appear after section titles and before figures and tables. Within the Table of Contents, the individual appendices will be titled as follows:

A TITLE OF APPENDIX

B TITLE OF APPENDIX

c. Shall be numbered $i$, ij, etc.

5. A List of Terms including acronyms (ALARA) and measurements ( $\mathrm{KL}$ ) shall follow the Table of Contents.

6. Appendices

a. Shall not have separate tables of contents or lists of figures, tables, or terms. 
b. Sections shall be numbered as follows: Al.0, Al.1, Al.1.1 etc.

7. Documentation Headings

a. Headings through the third level shall have decimal numbers $(1.0,1.1,1.1 .1)$

b. First order headings (section titles as 1.0 ) shall be centered and in bold caps.

c. Second order headings (1.1) shall be left justified and in bold caps.

d. Third order headings (1.1.1) shall be left justified and in bold with initial caps.

e: Fourth order headings shall be left justified and in bold with initial caps followed by a period.

f. Two spaces shall be inserted between level heading numbers and the text that follows.

8. Measurements shall be written in international system units.

Measurements should be abbreviated in the text and spelled out in the List of Terms. If desired, US measurements can follow international system units in parentheses.

9. Superscripts and subscripts shall be used when appropriate, e.g., for footnoting or in chemical names: $\left(\mathrm{H}_{2} \mathrm{O}\right.$ or $\left.{ }^{241} \mathrm{Am}\right)$.

10. Figures and drawings shall have numbers and tities that appear above the figure or drawing. Figures shall be referenced in the text (see Figure 1) and be $p$ laced as close to the first reference as is possible. Figures shall fit within allowable margins or on $11 \times 17$ in. pages.

Figures and drawings shall be compatible with WordPerfect $5.1,6.0$, 6.1 for WordPerfect documents, or Microsoft Word 97 for Microsoft Word documents. Figures that cannot be made compatible with WordPerfect or Microsoft Word 97 must be as electronically generated and printed on a laser jet printer. Photographs sha 11 be submitted as half-tones.

11. Tables shall meet the following requirements:

a. Shal1 be done in WordPerfect $5.1,6.0,6.1$, or Microsoft Word 97 . 
b. Shall have a number and a title which are included in the top cell that has no visible top or side lines. If the title is footnoted, the footnote number shall follow the title, e.g., Title ${ }^{1}$. If the table has more than one page, the number of pages shall be noted after the title, e.g., Title. (2 sheets)

c. Column title rows should be bottom justified and shaded. Column titles should be initial capitalized except for words such as "a," and "and."

d. Shall be formatted using indents (not spaces).

e. Shall be referenced in text (see Table 1) and be placed as close to that reference as possible.

f. Footnotes

1) Shall be included at the bottom of the table in a cell that has no visible bottom or side Tines.

2) The first line of the cell shall be blank and the second line shall say Note: or Notes:. Footnotes shall begin on the third line. An exception is as follows: if leaving the first line of the cell blank results in bumping the footnote cell to the next page, the blank 1 ine will be deleted if, by so doing, the cell will fit the current page.

3) Footnotes shall be indented.

4) Where there is more than one footnote, and a footnote is more than a single line, double-space between footnotes. An exception is as follows: if double-spacing footnotes will bump the footnote cell to the next page, delete double-spacing if, by so doing, the cell will fit the current page.

5) Footnotes shall be in 10 pt type.

g. References within footnotes should be text-type references, e.g., Babad (1994). Do not follow reference with a period. A full reference should appear in the reference section.

h. Tables of two or more pages shall have the table titie and header row(s) marked as header rows.

\section{Equations}

a. A11 equations shall be input using the WordPerfect equation editor or Microsoft Equation 3.0. 
LOCKHEED MARTIN HANFORD CORPORATION

GUIDELINES FOR DOCUMENT PREPARATION APPLICABILITY: FOR GUIDANCE
Manua]

Section

Page

Effective Date
HNF-SD-WM-PROC-021

11.0 , REV 2

14 of 18

b. Equations shal1 be in $12 \mathrm{pt}$ or $10 \mathrm{pt}$ type depending on size of the equation. Use discretion and consistency. Equations should not be italicized.

13. References shall include the following in consecutive order and separated by comas: (indent) (shift tab), last name and initials of primary author, initials and last names of other authors in alphabetical order, year of publication, title of document, document number, document revision, publisher, city, and state. Within text a reference is cited (author last name followed by the year of publication) or (author last name et al. followed by the year of publication).

14. Acronyms and Abbreviations

Acronyms are used when the name or term is used repeatedly throughout the document; they are not used when the term is used a limited number of times. Each acronym is spelled out when first used, e.g., transuranics (TRU); thereafter TRU. Acronyms shall appear in a List of Terms after the Table of Contents and before the first section.

Abbreviations shall appear in the List of Terms.

15. A trademarked name shall be marked as follows. The first time a trademarked name appears, it shall be followed by a footnote that includes the product name, owner, city, and state when appropriate, e.g., "WordPerfect is a trademark of the WordPerfect Corporation within the United States," or "SUMMA is a trademark of Molectrics, Inc., Cleveland, Ohio." Footnotes shall be in $10 \mathrm{pt}$ type. Thereafter, a trademarked name should be followed by ${ }^{\mathrm{TM}}$ or ${ }^{\circledR}$ as appropriate.

16. Pagination

a. Short documents, i.e., fewer than 25 pages, can be numbered as 1,2 , and 3 , etc.

b. Longer documents, i.e., more than 25 pages, or documents with sections shall be numbered 1-1, 1-2, 2-1, and 2-2, etc.

c. Documents with sections shall have all sections beginning on odd numbered pages. Therefore, if a section ends on an odd numbered page, it shall be followed by a blank page.

d. Documents longer than 25 pages shall be printed back-to-back. 
17. Referencing a Database

The correct reference format for a database is given in this example:

LMHC, 1998, Best-Basis Inventory for Tank 241-XX-YYY, Tank Characterization Database, Month, Day, Year, internet at http://twins.pn1 . gov:8001/TCD/main. htm1.

\subsection{SUPPORTING DOCUMENT RELEASE PROCESS}

1. Obtain a supporting document number. It is the tank coordinator's or other author's responsibility to obtain a number for the supporting document. This is done by calling Station 4 (Document Control Services - North) in 2750-E/Rm D-173 on 373-2995 or 373-5877. For data packages, the supporting document number is provided by personnel on 373-2272.

The Document Control clerk will ask for a document title, author's name, what program document is supporting, and what type of document it is (ie., report, plan). When the clerk has this information a supporting document number will be assigned.

2. The tank coordinator or author will contact the TWRS Process Engineering Document Control Administrator when a document is close to completion. The administrator will prepare aIl release documentation paperwork required. It is as follows:

a. Engineering Data Transmittal (EDT) - This is for the first time a document is being released (Rev. 0). It is the author's responsibility to identify the signatures required on the EDT.

b. Engineering Change Notice (ECN) - This is for a document that has been previously released and is now being revised. It is the project coordinator's responsibility to identify the signatures necessary on the ECN.

c. Supporting Document Coversheet - Required for all revisions.

d. Record of Revision - Required only if the document is being revised. Contains the history of the document including initial publication (Rev. 0) and changes.

e. A distribution sheet is needed for a 71 documents. If the distribution is too large to be shown on the EDT, a separate distribution sheet must be provided. The TWRS Process Engineering Production Lead (R. R. Thompson) shall be included on all distribution sheets for Process Engineering generated documents. 


\begin{tabular}{llr}
\hline LOCKHEED MARTIN HANFORD CORPORATION & Manual & HNF-SD-WM-PROC-021 \\
& Section & 11.0, REV 2 \\
GUIDELINES FOR DOCUMENT PREPARATION & Page & 16 of 18 \\
APPLICABILITY: FOR GUIDANCE & Effective Date & November 15, 1998 \\
\hline
\end{tabular}

f. For Impact Leve] "N/A" (e.g., TCRs), the only required signatures are those of the author and respective manager.

g. For Impact Level " $Q$," the only required signatures are those of the project coordinator, the respective manager, and Quality Assurance (QA).

h. It is the author's responsibility to identify the impact level of the document and the signatories on the EDT or ECN.

3. After the supporting document paperwork has been generated, the paperwork is given to the author. It is the author's responsibitity to process the document for approval.

4. When the document has been approved by all the signatories, the author will give the document to TWRS Process Engineering Document Control Administrator who will take it through the release process. Alternatively, the author may do this him/herself.

5. Al1 documents must go through Document Clearance.

6. After Document Clearance has signed the Supporting Document Coversheet, the document is taken to Station 4/Document Control Services - North.

7. When the document has been stamped "Hanford Release," the TWRS Process Engineering Document Control Administrator or the author must obtain a copy of the entire document and al7 supporting document paperwork (EDT or ECN, SD Coversheet, Record of Revision, and Distribution sheet) with release stamps on it. This is to ensure the author has a copy. which can be used for duplication purposes to meet document milestone delivery dates:

a. If the document is a TSAP, the author must obtain a copy of the entire document and its paperwork.

b. If the document is a ER or a DP, the author must obtain a copy of the supporting document paperwork (EDT or ECN, Supporting Document Coversheet, Record of Revision and Distribution Sheet) with the release stamps on it.

\subsection{TANK CHARACTERIZATION REPORT PEER AND FUNCTIONAL REVIEW}

"TCR review" refers to a review of the report by a qualified individual other than the person(s) who authored the report. It is the responsibility of the reviewer to review the report for the following items:

- Basic assumptions

- Calculations

- Drawings

- Consistency 


\begin{tabular}{llr}
\hline LOCKHEED MARTIN HANFORD CORPORATION & Manual & HNF-SD-WM-PROC-021 \\
GUIDELINES FOR DOCUMENT PREPARATION & Section & 11.0, REV 2 \\
PagPLICABILITY: FOR GUIDANCE & Effective Date & November 15,1998 \\
\hline
\end{tabular}

- Accuracy

- Technical soundness.

After a TCR has been drafted, it is given to at least two peer reviewers. Peer reviewers may be from the authoring organization and may include author's manager as long as the manager did not make significant contributions to the report. The document should be reviewed for the items listed above, and the comments should be provided to the TCR author(s) for comment resolution.

After the peer review has been completed and comments are incorporated, the TCR is given to the functional reviewers. The individuals performing the functional review shall be qualified in the subjects being reviewed. The reviewers should be from other organizations, projects, programs, or companies. The document should be reviewed for the items 1 isted above, and comments should be provided to the TCR authors for comment resolution.

Checklist reviews are conducted as follows:

- Technical checklist: Conducted concurrent with peer or functional review.

- Editor checklist: Conducted on final draft before being sent to DOE for review. 


\begin{tabular}{llr} 
LOCKHEED MARTIN HANFORD CORPORATION & Manual & HNF-SD-WM-PROC-021 \\
& Section & 11.0, REV 2 \\
GUIDELINES FOR DOCUMENT PREPARATION & Page & 18 of 18 \\
APPLICABILITY: FOR GUIDANCE & Effective Date & November 15, 1998 \\
\hline
\end{tabular}

This page intentionally left blank. 
LOCKHEED MARTIN HANFORD CORPORATION

TWRS PROCESS ENGINEERING

INSTRUCTION MANUAL
Manual

Section

Page

Effective Date

Organization
HNF-SD-WH-PROC-021

12.0 , REV 2

1 of 4

November 15,1998

TWRS Process

Engineering

TITLE:

DATA SYSTEMS RESOURCES

APPLICABILITY: FOR CONPLIANCE

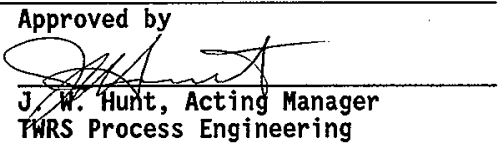

Existing data resources to be used by characterization project employees are listed in Table 1. The table provides notes on the type of data or information available in each source, the custodian, and notes about the status and appropriate use of the database or data source. Similar information is also available in the Yellow. Pages on the Hanford Home Page (Characterization Project Author's Page).

The official source for tank content data is the Tank Waste Information Network System (TWINS) which is available on the Internet at http://twins.pn1.gov:8001/TCD/main.html. The home page contains a complete users guide for TWINS. The TWINS can be queried by tank number, chemical constituent, chemical group, and date. It contains post-1989 analytical data, historical analytical data, physical properties data, best-basis inventory data, tank vapor data, and data from a number of sources. (Best-basis inventory data are official inventory numbers and shall be used in a11 TWRS technical documents and communications.) Tank levels, temperature profiles, and tank vapor data can be obtained from the same query field. The data can be viewed and printed with or without Quality Control (QC) data.

Another resource is the Tank Characterization and Safety Resource Center (TCSRC) located in building 2750 , East Area. The center contains a major collection of hard copy documents and photos, historic and current, regarding tanks and tank wastes. A major listing of avajlable documents related to tanks and tank waste is also maintained in the center. Additional information about TCSRC is available through the Characterization Project Author's Page.

An electronic template is also available and shall be used by authors in preparing Tank Characterization Reports (TCRs) in standard format. The template is available via the Data Source Access (DSA) feature at http://pctwins.pnl.gov/tcr.nsf/. The DSA also provides access to Visual Image Digital Object Network (VIDON), Records Management Information System (RMIS), and numerous other information and data sources relevant to the Process Engineering workscope and TCR production. The DSA contains powerful tankspecific and keyword search capabilities and an extensive users guide. Tank characterization Report drafts and final electronic TCR reports shall also be posted to CHARDOCS at the IIAPO12\CHARDOCS share area.

To assure that desktop computing capabilities for the TWRS Process Engineering organization are in line with need, a Process Engineering Computing Needs Assessment and Work Station Profile has been prepared and shall be updated semi-annually by the TWRS Characterization Data Administrator. 
LOCKHEED MARTIN HANFORD CORPORATION

DATA SYSTEMS RESOURCES

APPLICABILITY: FOR COMPLIANCE
Manual

Section

Page

Table 1. Existing Characterization Data Resources. (3 sheets)

\begin{tabular}{|c|c|c|c|c|}
\hline short & F) & (3) & U. & 1 the \\
\hline CASS & $\begin{array}{l}\text { Computer Automated } \\
\text { Survei11 ance System }\end{array}$ & 2,5 & Barnes, David & $\begin{array}{l}\text { Data } \\
\text { Acquisition } \\
\text { System }\end{array}$ \\
\hline CST & $\begin{array}{l}\text { Characterization } \\
\text { Status Table }\end{array}$ & & McCain, Dennis & $\begin{array}{l}\text { Status } \\
\text { Sheet }\end{array}$ \\
\hline DACS & $\begin{array}{l}\text { Tank 101-SY Data } \\
\text { Acquisition and } \\
\text { Control System }\end{array}$ & $2,5,6$ & Gauck, Gregory & $\begin{array}{l}\text { Data } \\
\text { Acquisition } \\
\text { and Control }\end{array}$ \\
\hline DQOs & $\begin{array}{l}\text { Data Quality } \\
\text { Objectives }\end{array}$ & 3 & Banning, Dave & Document \\
\hline $\begin{array}{l}\text { EXTRUSION } \\
\text { VIDEOS }\end{array}$ & $\begin{array}{l}\text { Tank Core Extrusion } \\
\text { Video Tapes }\end{array}$ & & Benally, Attlee & $\begin{array}{l}\text { Video } \\
\text { Library }\end{array}$ \\
\hline GCS & $\begin{array}{l}\text { Gas } \\
\text { Characterization } \\
\text { System }\end{array}$ & 2,5 & Bauer, Roger & $\begin{array}{l}\text { Data } \\
\text { Acquisition } \\
\text { System }\end{array}$ \\
\hline $\begin{array}{l}\text { GEN TRAN } \\
D \text { SHT }\end{array}$ & $\begin{array}{l}\text { General Transfer } \\
\text { Data Sheet }\end{array}$ & & Koreski, Jerry & $\begin{array}{l}\text { Data } \\
\text { Acquisition } \\
\text { System }\end{array}$ \\
\hline GMS-2 & $\begin{array}{l}\text { Gas Monitoring } \\
\text { System } 2\end{array}$ & 2,5 & Bauer, Roger & $\begin{array}{l}\text { Data } \\
\text { Acquisition } \\
\text { System }\end{array}$ \\
\hline HDAT & $\begin{array}{l}\text { Hand-held Data } \\
\text { Acquisition System }\end{array}$ & 4,5 & Starghi11, Charles & $\begin{array}{l}\text { Data } \\
\text { Acquisition } \\
\text { System }\end{array}$ \\
\hline HDWM & $\begin{array}{l}\text { Hanford Defined } \\
\text { Waste Model }\end{array}$ & & Agnew, Steve & $\begin{array}{l}\text { Predictive } \\
\text { Model }\end{array}$ \\
\hline HEIS & $\begin{array}{l}\text { Hanford } \\
\text { Environmental } \\
\text { Information System }\end{array}$ & 1,5 & Schwab, Mike & Database \\
\hline HTCE & $\begin{array}{l}\text { Historjc Tank } \\
\text { Contents Estimate }\end{array}$ & & Cammann, Jerry & $\begin{array}{l}\text { Inventory } \\
\text { Estimates }\end{array}$ \\
\hline IDB & Integrated Database & & Cooney, Mike & Database \\
\hline $\begin{array}{l}\text { LABCORE/ } \\
\text { LIMS } \\
\end{array}$ & $\begin{array}{l}\text { Labcore/Laboratory } \\
\text { Information } \\
\text { Management System }\end{array}$ & 2,5 & Kerns, Robert & Database \\
\hline $\begin{array}{l}\text { PHOTO/VIDEO } \\
\text { SURV }\end{array}$ & $\begin{array}{l}\text { Tank Farm } \\
\text { Surveillance Video } \\
\text { and Photo Library }\end{array}$ & & Hisaw, Roger & $\begin{array}{l}\text { Video/Photo } \\
\text { Library }\end{array}$ \\
\hline PU INVENTORY & Plutonium Inventory & 5,6 & Stauffer, Leslie & $\begin{array}{l}\text { Inventory } \\
\text { Estimates }\end{array}$ \\
\hline
\end{tabular}


LOCKHEED MARTIN HANFORD CORPORATION

DATA SYSTEMS RESOURCES

APPLICABILITY: FOR COMPLIANCE
Manua 1

Section

Page

Effective Date
HNF-SD-HM-PROC-021

12.0 , REV 2

3 of 4

Table 1. Existing Characterization Data Resources. (3 sheets)

\begin{tabular}{|c|c|c|c|c|}
\hline (110) & 筑簿 & 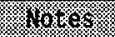 & (5) & Xe \\
\hline RGS & $\begin{array}{l}\text { Retained Gas } \\
\text { Sampler }\end{array}$ & & Knight, Craig & $\begin{array}{l}\text { Equipment } \\
\text { Data } \\
\text { Acquisition }\end{array}$ \\
\hline SACS & $\begin{array}{l}\text { Surveillance } \\
\text { Analysis Computer } \\
\text { System }\end{array}$ & $1,2,5$ & Barnes, David & Database \\
\hline SHMS & $\begin{array}{l}\text { Standard Hydrogen } \\
\text { Monitoring System }\end{array}$ & 2,5 & Bauer, Roger & $\begin{array}{l}\text { Data } \\
\text { Acquisition } \\
\text { System }\end{array}$ \\
\hline SMMS & $\begin{array}{l}\text { Surface Moisture } \\
\text { Monitoring System }\end{array}$ & & $\begin{array}{l}\text { Vargo, George } \\
\text { Stockes, Troy }\end{array}$ & $\begin{array}{l}\text { Data } \\
\text { Acquisition } \\
\text { System }\end{array}$ \\
\hline TCD & $\begin{array}{l}\text { Tank } \\
\text { Characterization } \\
\text { Database }\end{array}$ & $\begin{array}{l}1,2 \\
5,6\end{array}$ & Adams, Mel & Database \\
\hline TCRs & $\begin{array}{l}\text { Tank } \\
\text { Characterization } \\
\text { Reports }\end{array}$ & 3 & Ha]1, Kathleen & Documents \\
\hline TCSRC & $\begin{array}{l}\text { Tank } \\
\text { Characterization } \\
\text { and Safety Resource } \\
\text { Center }\end{array}$ & & Young, Ann & $\begin{array}{l}\text { Document } \\
\text { Resource } \\
\text { Center }\end{array}$ \\
\hline TFDB & Tank Farm Database & 5,6 & Koreski, Jerry & Database \\
\hline TMACS & $\begin{array}{l}\text { Tank Monitoring and } \\
\text { Control System }\end{array}$ & 2,5 & Barnes, David & $\begin{array}{l}\text { Data } \\
\text { Acquisition } \\
\text { and Control }\end{array}$ \\
\hline TRAC & $\begin{array}{l}\text { Track Radioactive } \\
\text { Components }\end{array}$ & 5 & Simpson, Brett & $\begin{array}{l}\text { Predictive } \\
\text { Model }\end{array}$ \\
\hline TWINS2 & $\begin{array}{l}\text { Tank Waste } \\
\text { Information Network } \\
\text { System }\end{array}$ & $2,5,6$ & Bobrowski, Steve & $\begin{array}{l}\text { Database } \\
\text { Access }\end{array}$ \\
\hline TVD & Tank Vapor Database & $1,2,6$ & Simonen, Christine & Database \\
\hline VFI & $\begin{array}{l}\text { Void Fraction } \\
\text { Instrument }\end{array}$ & 5 & Bauer, Roger & Instruments \\
\hline VIDON & $\begin{array}{l}\text { Visual Image } \\
\text { Digital Object } \\
\text { Network }\end{array}$ & & Schalla, Elaine & $\begin{array}{l}\text { Image } \\
\text { Library } \\
\text { including } \\
\text { Digital } \\
\end{array}$ \\
\hline WHC-EP-0182 & $\begin{array}{l}\text { Waste Tank Summary } \\
\text { for Month Ending }\end{array}$ & & Hanlon, Betty & Document \\
\hline
\end{tabular}


Table 1. Existing Characterization Data Resources. (3 sheets)

\begin{tabular}{|l|l|l|l|l|}
\hline WIDS & $\begin{array}{l}\text { Waste Information } \\
\text { Database System }\end{array}$ & 2,5 & Schwab, Mike & Database \\
\hline WSTRS/LANL & $\begin{array}{l}\text { Waste Status and } \\
\text { Transaction Summary }\end{array}$ & & Agnew, Steve & Database \\
\hline WVPS & $\begin{array}{l}\text { Waste Volume } \\
\text { Projection System }\end{array}$ & 6 & Strode, James & $\begin{array}{l}\text { Algorithm/ } \\
\text { Database }\end{array}$ \\
\hline
\end{tabular}

Notes:

LANL $=$ Los Alamos National Laboratory

$1=$ Tri-Party Agreement related database

$2=$ Hanford architecture key system

3 = Key document type: Tri-Party Agreement

4 = Inactive

$5 \quad=$ Registered in Hanford Information System Inventory

$6=$ Certified Year 2000 compliant 
LOCKHEED MARTIN HANFORD CORPORATION

TWRS PROCESS ENGINEERING INSTRUCTION MANUAL
Manual

Section

Page

Effective Date Organization
HNF-SD-WM-PROC-021

13.0, REV 2

1 of 2

November 15, 1998

TWRS Process

Engineering
TITLE:

SOFTWARE QUALITY ASSURANCE REQUIREMENTS APPLICABILITY: FOR COMPLIANCE
Approved by

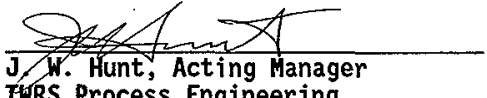

THRS Process Engineering

Quality requirements have been established for organizations that procure, develop, use, or maintain computer software. These requirements are clarified in Hanford procedures which are listed in a table in HNF-SD-WM-TRD-005, Rev. 1, Self-Assessment Standards Checklist for Data Systems. In addition, an industry standard for testing computer programs and associated computer systems is found in ASME NQA-1, Supplement 115-2, Supplementary Requirements for Computer Program Testing.

A checklist has been developed and approved for self-assessment of hardware, software and data administration of data systems (HNF-SD-WM-TRD-005, Rev. 1). This checklist. is used to conduct annual self-assessments of key data systems such as the Tank Characterization Database. It is used also to identify and assure compliance with appropriate quality requirements for data systems.

In addition, the Tank Waste Information Network System (TWINS) has been placed under configuration change control. All proposed changes to data fields, views, standard reports, data tables, and other TWINS output must be documented in a change request obtainable from the lead for Data Management. The change shall be approved by the manager, Data Assessment and Integretation. 
LOCKHEED MARTIN HANFORD CORPORATION

SOFTWARE QUALITY ASSURANCE REQUIRENENTS

APPLICABILITY: FOR COMPLIANCE
Manual

Section

Page

Effective Date
HNF-SD-WM-PROC-021

13.0, REV 2

2 of 2

November 15,1998

This page intentionally left blank. 
LOCKHEED MARTIN HANFORD CORPORATION

TWRS PROCESS ENGINEERING

INSTRUCTION MANUAL
Manual

Section

Page

Effective Date

Organization
HNF-SD-WM-PROC-021

14.0 , REV 2

1 of 4

November 15,1998

TWRS Process

Engineering

\section{TITLE:}

TWRS PROCESS ENGINEERING PERFORMANCE

SCHEDULING AND REPORTING

INCLUDING POSTINGS

APPLICABILITY: FOR GUIDANCE

\section{Approved by}

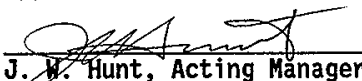

TWRS Process Engineering

\subsection{PURPOSE}

The Tank Waste Remediation System (TWRS) Process Engineering Performance Scheduling and Reporting activity purpose is to provide tracking tools, appropriate schedules, budget and resource analyses, and performance indicators and reports necessary to manage the work and resources assigned to the Process Engineering organization.

\subsection{ASSIGNHENT}

Leadership for TWRS Process Engineering Performance Scheduling and Reporting is assigned to the TWRS Process Engineering Performance Lead ( $R$. R. Thompson). The Performance Lead sha 11 be informed and participate in matters relevant to the purpose above.

\subsection{TRACKING TOOLS}

The following tracking tools are maintained by the Process Engineering Performance Lead to enable successful management of Process Engineering work assignments and resources:

- Task package and work order list

- Assignment notebook

- Milestone and deliverable graphic charts

- Forecasts of resource assignments and assessment of actuals.

\subsection{SCHEDULES}

Schedules are maintained by Program Control to track schedules against baseline plans and budgets. Detailed work schedules are maintained by managers and task leaders to track the details of work in progress. The Process Engineering Performance Lead maintains schedules to assure timely completion and reporting of milestones and deliverables accomplished by the 
LOCKHEED MARTIN HANFORD CORPORATION

TWRS PROCESS ENGINEERING PERFORMANCE

SCHEDULING AND REPORTING

INCLUDING POSTINGS

APPLICABILITY: FOR GUIDANCE
Manual

Section

Page

Effective Date
HNF-SD-WM-PROC-021

14.0, REV 2

2 of 4

November 15,1998

group and the work of other organizations contributing to assigned milestones and deliverables. Among the schedules which may be required to accomplish this purpose are the following:

- Tank Characterization Report schedule

- Specific Detailed Schedules as required by managers or process engineering leads.

\subsection{BUDGET AND RESOURCE ANALYSIS}

Process Engineering managers and leads are required to report status and variance to Program Control periodically. Additional analysis of work accomplished, schedule status, and remaining work are the key to accurate evaluation of current status and forecast of future expenditure and requirements. Records maintained and analyses made by the Process Engineering Performance Lead will be enhanced by the following standing assignments:

- Forecast monthly work by employee by task based on input from managers and project leads.

- Assess actual work performed by monthly analysis of work hours charged.

\subsection{PERFORMANCE INDICATORS AND REPORTS}

Data and records maintained by Performance Lead will be the source of information used to produce the following performance indicators:

- Fiscal Year Tank Characterization Reports (bar and line Graphs)

- TWRS Process Engineering Actual and Budget Hours - (pie chart)

- Tank Characterization Report Bar Charts (to Program Control monthly)

- TCR Progress (Exce ${ }^{1}$ chart of steps to complete)

- Process Engineering Milestone Commitments (box chart)

- Tank Summary Spreadsheet

- Forms for Request for Process Engineering services or other form as may be required. 
LOCKHEED MARTIN HANFORD CORPORATION

TWRS PROCESS ENGINEERING PERFORMANCE

SCHEDULING AND REPORTING

INCLUDING POSTINGS

APPLICABILITY: FOR GUIDANCE
Manual

Section

Page

Effective Date
HNF-SD-WM-PROC-021

14.0 , REV 2

3 of 4

November 15, 1998

\subsection{PERFORMANCE INPUT}

Periodic status input will be provided by Process Engineering personnel as required for periodic update and development of performance reports, schedules, and forecasts.

\subsection{POSTINGS}

Process Engineering bulletin boards are maintained in building 2750E/A wing (second floor) and include but are not necessarily limited to:

- Safety bulletin boards

- Lockheed corporate identity, news, and mission materials

- Performance indicators and reports

- Tracking materials

- Schedules

- Budget and resource reports

- Other postings and reports.

\subsection{TANK CHARACTERIZATION REPORT TASK DEFINITIONS}

The Tank Characterization Report (TCR) preparation process includes a significant number of activities and dependencies that are to occur in the development of a Tank Characterization Report. Schedules that reflect these activities are prepared and updated on a weekly basis. These schedules are used to monitor performance in meeting commitments to deliver a completed TCR. To assist in understanding the various activities identified in the schedule, the following dictionary of definitions is provided.

- Receipt of Sample at Laboratory

- The date the "last" sample is received at the laboratory. This activity starts the clock for activities which follow.

- Laboratory Analysis/Final Report

- Completion of this activity is marked by issue of a waste management data package reporting the analysis of samples and results obtained in accordance with the requirements of the Tank Sampling and Analys is Plan (TSAP). This activity is timed from the day the "last" sample is received at the laboratory.

- Data from Labcore to Tank Characterization Database (TCD)

- The Final Laboratory Report is transmitted from the 222-S "Labcore" system to the TCD. 
LOCKHEED MARTIN HANFORD CORPORATION

TWRS PROCESS ENGINEERING PERFORMANCE

SCHEDULING AND REPORTING

INCLUDING POSTINGS

APPLICABILITY: FOR GUIDANCE
Manual

Section

Page

Effective Date November 15,1998

- Historical Data and Graphics

- The Historical Tank Information and Tank Sampling Overview as well as a tank configuration graphic are prepared for direct incorporation into the draft of the TCR.

- Statistical Data

- The data are analyzed statistically to determine the confidence levels of the data evaluated and calculate means and other measures of values analyzed.

- Draft TCR

- The historical, analytical, inventory, and statistical information are combined into a report on the tank characterization. Summaries, description of current sampling event, and extrusion results can be written early.

- Peer and Functional Review

- Peers of the author and those persons whose functions include generation or inventory of the tank perform reviews of the TCRs.

- Technicar Editing

- Tables and text are molded into a standard format with language consistent with Site standards. (See Section 11.6 of this document).

- Technical Checklist

- Key calculations, logical consistency, and response to applicable DQOs are checked.

- Edit Checklist

- Final technical editing is checked to verify that requested changes are included.

- RL Review

- U.S. Department of Energy, Richiand Office, reviews draft TCR before release.

- Issue TCR

- Obtain the required approval signatures, document release, immediate copy printing, and issue the TCR. 
LOCKHEED MARTIN HANFORD CORPORATION

TWRS PROCESS ENGINEERING

INSTRUCTION MANUAL
Manual

Section

Page

Effective Date

Organization
HNF-SD-WM-PROC-021

$15.0, \operatorname{REV} 2$

1 of 4

November 15, 1998

TWRS Process

Engineering

\section{TITLE: $\quad$ Approved by \\ REQUIRED READING \\ APPLICABILITY: FOR COMPLIANCE Hunt, Acting Manager \\ TWeS Process Engineering}

\subsection{OBJECTIVE}

The objective of this section is to provide direction for managing required reading for Tank Waste Remediation System (TWRS) Process Engineering employees to assure that required reading is identified, tracked, completed, and documented.

\subsection{PROCEDURAL REQUIREMENTS}

1. The responsible manager shall semi-annualiy (January and June) establish and/or review required reading for each employee.

For new employees, the reading requirements shall be established at entry to the organization.

2. Required reading shall be documented on the attached form. The reader shall initial the form upon completion of reading for each assigned document.

The initial signifies that the reading was done and understood. If the material was not understood, the employee shall question the manager until the material is understood.

\subsection{ADMINISTRATIVE REQUIREMENTS}

1. Required reading shall be documented on the required reading form which is maintained in the Tank Characterization and Safety Resource Center (TCSRC) located in $2750 \mathrm{E} /$ Room $\mathrm{C}-116$. 
LOCKHEED MARTIN HANFORD CORPORATION

REQUIRED READING

APPLICABILITY: FOR COMPLIANCE
Manual

Section

Page

Effective Date
HNF-SD-WM-PROC-021

15.0, REV 2

2 of 4

November 15, 1998

\subsection{RESPONSIBILITIES}

Managers are responsible for establishing required reading in consultation with the employee as necessary. Managers are also responsible for employee completion of all required reading. Employees are responsible for reading, understanding, and certifying required reading. Required reading signoff and certification forms are maintained in the Tank Characterization and Safety Resource Center (TCSRC). The Records Administrator in TCSRC shal1 send a11 Process Engineering managers a monthly notice of required reading delinquencies. 
LOCKHEED MARTIN HANFORD CORPORATION

REQUIRED READING.

APPLICABILITY: FOR COMPLIANCE
Manual

Section

Page

Effective Date November 15, 1998

TWRS PROCESS ENGINEERING

REQUIRED READING FORM

Emp loyee

Manager

Date Reviewed

NOTE: Forms kept on file in

Tank Characterization and

Safety Resource Center

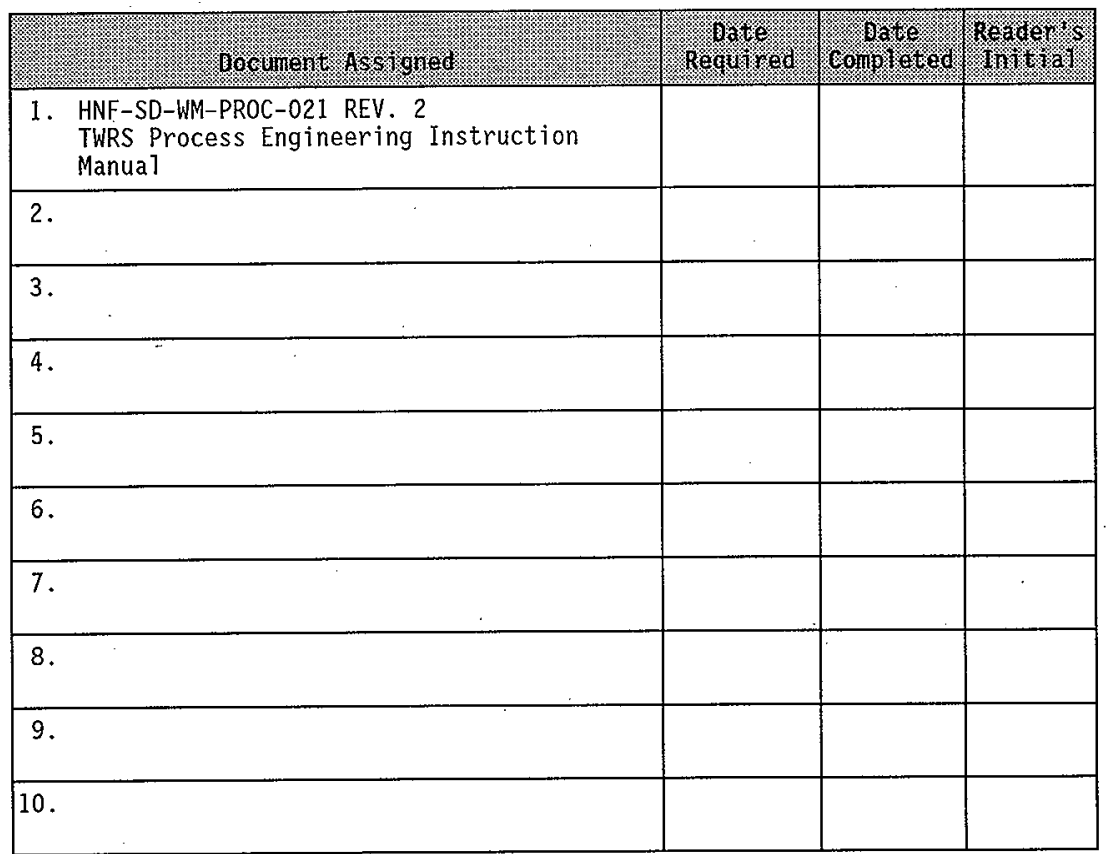

Note:

${ }^{1}$ Empioyee initials means that the reading was completed and understood by the employee. If the material was not understood, the employee is required to ask manager questions regarding material until it is understood. 
This page intentionally left blank. 
LOCKHEED MARTIN HANFORD CORPORATION

TWRS PROCESS ENGINEERING INSTRUCTION MANUAL.
Manua1

Section

Page

Effective Date Organization
HNF-SD-WM-PROC-021

16.0, REV 2

1 of 4

November I5, 1998

TWRS Process

Engineering
TITLE:

OPERATION OF TANK CHARACTERIZATION

AND SAFETY RESOURCE CENTER

APPLICABILITY: FOR COMPLIANCE
Approved by

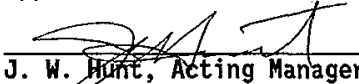

TWRS Process Engineering

\subsection{SCOPE AND PURPOSE}

The scope of this section includes the Tank Characterization and Safety Resource Center (TCSRC). The purpose is to identify the functions of TCSRC, specify general procedures for operation of the TCSRC, and identify responsible individuals for operation of the TCSRC.

\subsection{FUNCTIONS OF THE TCSRC}

The functions of the TCSRC include:

1. Provide storage, control and access to documents, letters, reports, photos, files and other information concerning tanks, tank waste and tank safety. Many of the documents are one-of-a-kind with historic value.

2. Provide control of and access to one "gold copy" (quality control [QC] record copy) location and five "si]ver copy" locations of Authorization Basis documents.

3. Provide courtesy copy access to released characterization documents such as Tank Characterization Reports (TCR).

4. Provide control of and access to historic tank photo files and tank interior photo mosaics.

5. Provide document location technical assistance using electronic inventories and access to the Records Management Information System (RMIS) and the Hanford Document Control System (HDCS).

6. Provide technical assistance in document release procedures. 
LOCKHEED MARTIN HANFORD CORPORATION

OPERATION OF TANK CHARACTERIZATION

AND SAFETY RESOURCE CENTER

APPLICABILITY: FOR CONPLIANCE
Manua1

Section

Page

Effective Date
HNF-SD-WM-PROC-021

16.0, REV 2

2 of 4

November 15,1998

\subsection{GENERAL PROCEDURES FOR TCSRC OPERATION}

\subsection{Historic (One-of-a-Kind) Documents And Photos}

Historic documents shall be filed by tank number or by topical area and maintained in locked files under the supervision of the TCSRC Records Specialist (A. E. Young). These documents shall be scanned into RMIS as soon as practical. They also shall be listed in the TCSRC electronic inventory. These documents may be copied or. used in the TCSRC, but the originals shall not be checked-out or leave the TCSRC except under the direct supervision of the TCSRC Records Specialist.

\subsection{Oversize Photo Mosaics}

Oversize photo mosaics shall be filed by tank number and stored in special cabinets in the TCSRC. The photo mosaics may be checked-out according to the procedures in Section 3.5 of this procedure.

\subsection{Characterization Document Courtesy Files}

Files of released documents including TCRs, tank sampling and analysis pians (TSAPS), laboratory data package summaries and selected tank characterization technical documents shall be maintained by tank number in files in the TCSRC. Courtesy copies of TCRs may be checked-out, used in TCSRC, or provided for free.

\subsection{Gold Copies of Tank Safety Documents}

Gold copies (QC record copies) of Authorization. Basis documents shall be maintained in locked lateral files, listed in the electronic inventory, and used in TCSRC only under the direct supervision of the Records Specialist. Gold copy files shall consist of:

1. The original document

2. Subsequent page changes (Engineering Change Notices) filed separate7y

3. The original document with page changes incorporated (the gold copy).

Document 3 shall be used to make "silver" copies or working copies of the gold copy. Silver copies shall be made under the direct supervision and control of the records specialist. 
LOCKHEED MARTIN HANFORD CORPORATION

OPERATION OF TANK CHARACTERIZATION

AND SAFETY RESOURCE CENTER

APPLICABILITY: FOR COMPLIANCE
Manual

Section

Page

Effective Date
HNF-SD-WM-PROC-021

16.0, REV 2

3 of 4

November 15, 1998

\subsection{TCSRC Document Checkout}

For documents that can be checked out, a checkout sheet shall be maintained in TCSRC indicating document title and number, revision number and date, name of person checking out document and checkout date. This information shal1 also be maintained on the TCSRC electronic checkout database. Normally, documents are checked out for one month. If not returned by the due date, the TCSRC Records Specialist shall notify the customer by voice or electronic means to renew the checkout or to recover the document. Management assistance may be requested by the Records Specialist to enable document recovery from persons that abuse checkout privileges.

\subsection{Document Release Services}

Document release services shall be provided by the TCSRC Records Specialist in accordance with HNF-SD-WM-PROC-021, Section 11.0, part 7.0, Supporting Document Release Process, and in accordance with HNF-PRO-604, Hanford Document Numbering System.

\subsection{TCSRC Electronic Inventory}

An electronic inventory of TCSRC documents shall be maintained on Microsoft ${ }^{1}$ Exce $1^{2}$ spreadsheets ( 736 kbyte). Every attempt sha11 be made to reconcile the TCSRC electronic inventory with RMIS and HDCS listings including scanning of TCSRC documents into RMIS/HDCS as required.

Only the Records Specialist and others designated by the lead for data management shall have write access to the TCSRC electronic inventory by password. Others may have read only access on an as-needed basis.

\subsection{LOCATION OF TCSRC}

The TCSRC and the Records Specialist is located in $2750 \mathrm{E} / \mathrm{Room} \mathrm{C}-116$. Access to the room shall be controlled by the records specialist (or delegate) and the building administrator.

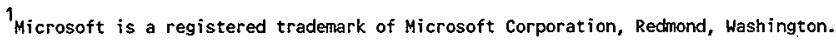

${ }^{2}$ Excel is a trademark of Microsoft Corporation, Inc.., Rednond, Washington.
} 


\subsection{RESPONSIBILITIES}

The overall responsibility for supervising the TCSRC resides with the TWRS Lead for Data Management, M. R. Adams. Operation of the TCSRC resides with the Records Specialist (A. E. Young). The Building Administrator is Ray Meredith. 
LOCKHEED MARTIN HANFORD CORPORATION

TWRS PROCESS ENGINEERING INSTRUCTION MANUAL
Manual

Section

Page

Effective Date Organization
HNF-SD-WM-PROC-021

17.0, REV 2

1 of 2

November 15, 1998

TWRS Process

Engineering

\section{TITLE:}

PERSONNEL QUALIFICATION

APPLICABILITY: FOR COMPLIANCE

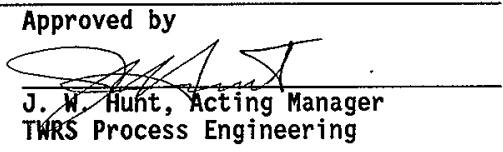

\subsection{SCOPE AND PURPOSE}

The scope of this section is to identify training requirements for Tank Waste Remediation System (TWRS) Process Engineering personnel. Compliance with this procedure enables TWRS Process Engineering personnel to sign as "cognizant engineer" on the following document types: tank characterization reports; characterization planning documents such as the Waste Information Requirements Document, Tank Characterization Sampling Basis, and sampling and analysis plans; immediate notifications; data management plans, best-basis inventory documents; data quality objectives; topical and technical reports related to tank characterization; and TWRS process engineering instructions and other document types assigned by Process Engineering managers.

\subsection{PROCEDURAL REQUIREMENTS}

\subsection{Training Records and Requirements}

The Process Engineering staff has been given signature authority as "cognizant engineer" to release and approve Process Engineering documents (see above). Their demonstrated experience and knowledge is documented through two Process Engineering qualification cards (Process Control Engineer and Characterization Process Engineer). The training required for Process Control Engineer and Characterization Process Engineer is identified in Table 1 along with the training required for all Process Training personnel. Some Process Engineering staff require additional training if they function as on-call engineers or tank coordinators. The additional training required by these individuals is identified in Table 1 .

Training records shall be maintained by the TWRS Process Engineering Training Coordinator using the Training Matrix Subsystem (TMXS). It is the responsibility of individual staff members to schedule and attend required training before the expiration date of such training or retraining. The individual staff member shall report to the Training Coordinator ( $L$. $R$. Webb) the course number, data, and date. the course was completed immediately upon completion of the course. The Training Coordinator shall provide management with monthly training calendars and notices of impending expiration for staff dissemination. 
LOCKHEED MARTIN HANFORD CORPORATION

PERSONNEL QUALIFICATION

APPLICABILITY: FOR COMPLIANCE
Manua 1

Section

Page

Effective Date
HNF-SD-WM-PROC-021

17.0 , REV 2

2 of 2

Table 1. TWRS Process Engineering Personnel Training Requirements.

\begin{tabular}{|c|c|c|c|}
\hline (6.10) & 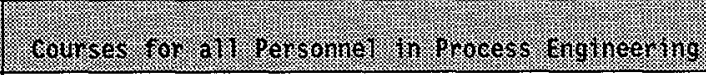 & (1) & 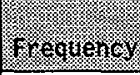 \\
\hline $\begin{array}{l}000001 \\
350930 / \\
350931\end{array}$ & $\begin{array}{l}\text { Hanford General Employee Training HGET } \\
\text { TWRS BIO Training }\end{array}$ & $\begin{array}{l}4 \\
2\end{array}$ & $\begin{array}{l}\text { yearly } \\
\text { once only }\end{array}$ \\
\hline $03 \mathrm{E} 060$ & $\begin{array}{l}\text { Building Emergency Plan (for those who reside in } \\
2750-E \text { ) }\end{array}$ & .5 & yearly \\
\hline \multicolumn{4}{|c|}{ 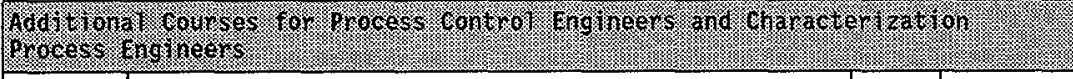 } \\
\hline 350935 & USQ Training & 8 & once on ly \\
\hline $\begin{array}{l}351910 \\
001000\end{array}$ & $\begin{array}{l}\text { Approval Designator Training } \\
\text { Conduct of Operations - Intro }\end{array}$ & $\begin{array}{l}4 \\
4\end{array}$ & $\begin{array}{l}\text { once only } \\
\text { once only }\end{array}$ \\
\hline $\begin{array}{l}350710 \\
350761 \\
\end{array}$ & $\begin{array}{l}\text { Tank Farm Facility Orientation } \\
\text { Tank Farm Facility Reorientation HGET }\end{array}$ & $\begin{array}{l}4 \\
1 / 2 \\
\end{array}$ & $\begin{array}{l}\text { once only } \\
\text { yearly }\end{array}$ \\
\hline 350255 & Qual ification Card (Process Control Engineer) & & once only \\
\hline 350250 & $\begin{array}{l}\text { Qual ification Card (Characterization Process } \\
\text { Engineer) }\end{array}$ & & once only \\
\hline \multicolumn{4}{|c|}{ 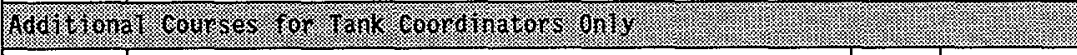 } \\
\hline 020001 & Radiation Worker Training II - Initial & 20 & \\
\hline 020003 & Radiation Worker Training II - Retrain & 8 & 24 months \\
\hline \multicolumn{4}{|c|}{ 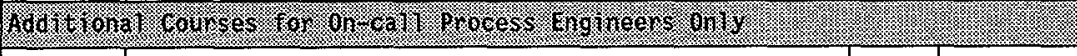 } \\
\hline 020012 & $\begin{array}{l}\text { Criticality Safety Training for Managers and } \\
\text { Engineers - Initial } \\
\text { Criticality Safety Retraining }\end{array}$ & 8 & 24 months \\
\hline
\end{tabular}

Note:

Process engineering managers also need the training courses for the categories of personnel they manage (for example, process control engineer) unless personnel are matrixed to another manager. 
LOCKHEED MARTIN HANFORD CORPORATION

TWRS PROCESS ENGINEERING INSTRUCTION MANUAL
Manual

Section

Page

Effective Date

Organization
HNF-SD-WM-PROC-021

18.0 , REV 2

1 of 6

November 15, 1998

TWRS Process

Engineering
TITLE:

ON-CALL PROCESS ENGINEER

APPLICABILITY: FOR COMPLIANCE
Approved by

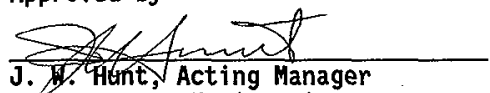

\subsection{SCOPE AND PURPOSE}

The scope of this section includes the assignment, responsibilities and duties of on-cal1 process engineers within the TWRS Process Engineering organization. The purpose is to provide specific procedures relating to the assignment and fulfillment of duties of on-call process engineers.

\subsection{REFERENCED DOCUMENTS}

1. OSD-T-151-00007, Operating Specifications for the 241-AN, AP, AW, AZ and SY Tank Farms.

2. OSD-T-151-00013, Operating Specifications for the Single Shell Tanks.

3. OSD-T-15I-00017, Operating Specifications for Aging Waste Operations in 241-AY and 241-AZ.

4. OSD-T-15l-00030, Watch List Tanks.

5. HNF-IP-0842, Volume II 5.10, Response to Anomalous Sample Results.

\subsection{ASSIGNMENT OF ON-CALL PROCESS ENGINEERS}

On-call process engineers and their on-call schedule shall be assigned by the Manager of Process Control (Nick Kirch). The manager shall establish an on-call sign-up sheet, communicate with on-call engineers to verify dates established for on-cail duty, assure that on-call engineers have received training on this procedure, verify that on-call engineers have read and understood this procedure. The manager shall formally delegate managerial duties and notify on-call engineers of such delegation when not available to perform those managerial duties. 0n-call duty shall normally be of one (1) week duration. If an on-calt engineer prior to or during duty hours cannot perform the duty because of illness or emergency, the on-cali engineer shall notify the Manager of Process Control or designated delegate as soon as possible. 


\subsection{GENERAL FUNCTION OF THE ON-CALL PROCESS ENGINEER}

The on-call process engineer provides a gateway into the Process Engineering organization for urgent issues that arise. Therefore, the on-call process engineer should have a general knowledge of the type of work being performed throughout the organization.

The on-call process engineer has the authority to contact anyone in Process Engineering for assistance in responding to urgent issues.

The on-call process engineer shail:

- Support TWRS plant shift operations

- Assist responsible shift managers in responding to out-of-limit data from both monitoring equipment and analysis of samples.

- Support TWRS management with expertise within the Process

Engineering scope of work.

\subsection{SPECIFIC DUTIES OF THE ON-CALL PROCESS ENGINEER}

The specific duties of the on-call process engineer are:

- Take possession of pager (85-9654) and the on-ca77 process engineer logbook during the period of duty and keep them in possession during the duty tour.

- Log all notifications of out-of-limit conditions in the logbook using guidance in Conduct of Operations, Chapter 11, "Logkeeping."

- Review notification information against criteria identified in the appropriate OSD Tisted in Section 2.0 of this procedure. If the data indicate the tank may exceed Watch List criteria, recommend to shift manager that Watch List controls be implemented pending further evaluation of the data. (This guidance is provided to shift operations via a standing order.) Document this recommendation in the logbook with time, date, initials and name of person spoken to. Follow-up by notifying the Manager of Process Control or designated delegate as soon as possible.

- If additional technical support is required, contact the Manager of Process Control or designated delegate as soon as posșible.

- If uncertainty exists as to whether the data indicate an exceeded limit, treat the data as exceeding the limit and seek assistance from Process Engineering management.

- Notify appropriate tank coordinator of any notifications on the tank coordinators respective tank. 
LOCKHEED MARTIN HANFORD CORPORATION

ON-CALL PROCESS ENGINEER

APPLICABILITY: FOR COMPLIANCE
Manual

Section

Page

Effective Date November 15,1998

\subsection{ANALYTICAL PARAMETERS TO BE MONITORED FOR OUT-OF-LIMIT CONDITION}

The following analytical parameters are monitored for potential out-of-limit conditions. The Tank Sampling Analysis and Plans (TSAPs) shall call out the following notification limits. Laboratory shift operations shall notify the on-calt process engineer if analyses fall outside of the notification limits.

Tank Composition $\mathrm{COH}^{-}, \mathrm{pH}, \mathrm{NO}_{3}^{-}, \mathrm{NO}_{2-}^{-}$

Variable

$\left[\mathrm{OH}^{-}\right]$

$\mathrm{pH}$
Notification Limit

$\leq 0.01 \mathrm{M}$

$\leq 0.01 \underline{\mathrm{M}}$

$<12$

Criticality

Variable

Notification Limit

Maximum plutonium $(P u)$ density

after in tank concentration

Heat Generation Rate

Variable

Maximum concentration

cesium-137 (Cs-137)

Maximum concentration

strontium-90. ( $\mathrm{Sr}-90)$
$1 \mathrm{~g} / \mathrm{L}(41 \mu \mathrm{Ci} / \mathrm{g})$ in solids

Notification Limit

$5.74 \times 10^{5} \mu \mathrm{Ci} / \mathrm{L}$ for $241-\mathrm{AN}, \mathrm{AP}$, and AW.

$4.10 \times 10^{5} \mu \mathrm{Ci} / \mathrm{L}$ for $241-S Y$.

$3.28 \times 10^{5} \mu \mathrm{Ci} / \mathrm{L}$ for SSTs.

$4.04 \times 10^{5} \mu \mathrm{Ci} / \mathrm{L}$ for $241-\mathrm{AN}, \mathrm{AP}$, and AW.

$2.88 \times 10^{5} \mu \mathrm{Ci} / \mathrm{L}$ for $241-\mathrm{SY}$.

$2.30 \times 10^{5} \mu \mathrm{Ci} / \mathrm{L}$ for SSTS.

Total Fuel Concentration (for example, energetics)

Variable

Maximum total fuel

concentration (energetics)
Notification Limit

480 joules $/ g$

Organic Salts (for example, total organic carbon [TOC])

Variable

TOC (drywt\%)
Notification Limit

$\leq 4.5$

where - TOC (drywt\%) is the percent weight of the TOC in hypothetically dried waste.

Organic Solvents (for example, detectable separate organic phase)

Variable

Organic material
Notification Limit

No separable phase 
Compounds with Toxicological Properties (for example, n-butanol, ammonia, nitric oxide, nitrogen dioxide)

Variable

Compounds with toxicological properties

\section{Notification Limit}

Level designated by the National Institute of Safety and Health (NIOSH) as immediately dangerous to life or health (IDLH)

Below is a list of the most common vapors that are most likely to be present in the Tank Farms. The complete list is not limited to those below:

$\begin{array}{lr}\text { Vapor } & \frac{\text { IDLH }}{1,400} \\ \text { n-butanol } & 300 \\ \text { ammonia } & 100 \\ \text { nitric oxide } & 20 \\ \text { nitrogen dioxide } & \end{array}$

Flammable Gases and Vapors

Variable

Flammable gas concentrations

Notification Limit $>25 \%$ of the lower flammability limit $(\mathrm{LFL})$

The following limits identify conditions that are beyond anticipated conditions in tanks and require management attention. If the following limits are exceeded, notify Process Engineering management immediately:

- Total alpha greater than $41 \mu \mathrm{Ci} / \mathrm{g}$ or plutonium greater than $1 \mathrm{~g} / \mathrm{L}$

- Differential scanning calorimetry energetics greater than $1,200 \mathrm{~J} / \mathrm{g}$

- Total organic carbon greater than $4.5 \mathrm{wt} \%(45,000 \mu \mathrm{g} / \mathrm{g})$

- Ammonia greater than $1,000 \mathrm{ppm}$

- Any other toxic vapor limit immediately dangerous to life or health

- Flammable gases greater than $50 \%$ of the LFL

- Hydrogen greater than $1 \%(10,000 \mathrm{ppm})$. 


\subsection{LOGKEEPING REQUIREMENTS}

The on-call process engineering logbook sha11 be maintained according to the following requirements:

- Make a7l entries in black ink

- Indicate all date/time entries in 24-hour clock

- Include all the name of person who called (or person contacted)

- Make certain all entries contain relevant information

- Make certain a11 entries contain notes of guidance or recommendations provided where applicable

- Draw a single line through a11 errors and initial and date

- Draw an ink line through all logbook lines that are not used

- Sign or initial all entries. 
LOCKHEED MARTIN HANFORD CORPORATION

TWRS PROCESS ENGINEERING

INSTRUCTION MANUAL.
Manual

Section

Page

Effective Date

Organization
HNF-SD-WM-PROC-021

19.0, REV 2

1 of 2

November 15, 1998

TWRS Process

Engineering

\section{TITLE: \\ TANK FARM DATABASE (TFDB) OPERATION APPLICABILITY: FOR COMPLIANCE}

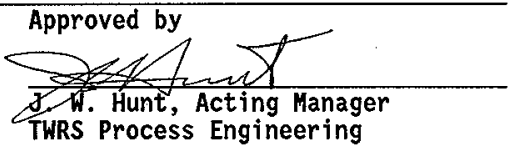

\subsection{SCOPE AND PURPOSE}

The Tank Farm Database (TFDB) is used to collect and report data about waste transfers, additions, evaporator runs, and so forth, for double-shell tanks. Tank farm waste volumes are tracked based upon input from Daily Round Sheets, Transfer Data Sheets, Raw Water Data Sheets, and Process Memos (from steam cleaner truck usage). A number of spreadsheets and graphics are updated every month.

\subsection{PROCEDURE}

The following procedures shall be followed as minimum requirements for maintaining the TFDB.

\subsection{Data Collection}

The system custodian is responsible for collecting data from the following sources as input for the TFDB:

- Daily Round Sheets (daily liquid levels)

- Transfer Data Sheets (intertank transfers)

- Raw Water Data Sheets (liquid used to flush lines after transfer)

- Process Memos (used to log liquid generated when flushing equipment).

\subsection{Data Entry/Update}

The system custodian shall update the workbook, spreadsheet, graphics, and database hierarchy monthiy. Entry and update tasks will be performed according to Doub7e-She77 Tank Waste Inventory Guidebook (HNF-SD-WM-SWD-038).

\subsection{DOCUMENTATION}

The TFDB system documentation shall be maintained according to all known policies and procedures governing the waste volume projection process, quality 
LOCKHEED MARTIN HANFORD CORPORATION

TANK FARM DATABASE (TFDB) OPERATION APPLICABILITY: FOR COMPLIANCE
Manual

Section

Page

Effective Date
HNF-SD-WM-PROC-021

19.0 , REV 2

2 of 2

assurance, data management, and software practices. System documentation is contained in HNF-SD-WM-SWD-038. This document will be revised by Engineering Change Notice (ECN) as necessary to accommodate system changes.

\subsection{SECURITY}

Al] hard copy and electronic systems associated with the TFDB shall be supervised during normal working hours, and protected in a locked office during off-hours. Original or hard copy files, which are one-of-a-kind, shall be stored in locked cabinets. Electronic systems shall be password protected and secured in a locked office when unattended.

\subsection{BACKUPS}

System backups shall be made of electronic files which are not stored on network devices. The backups shall be performed weekly. System backups shall be stored in a fireproof cabinet in the Tank Characterization and Safety Resource Center (TCSRC).

\subsection{CONTINGENCY PLANNING}

A contingency plan shall be maintajned, which provides direction in the event of system failure or a disaster. The contingency plan shall include concise discussion of tasks, which would be performed in the event of a hard-drive failure, network faiture, personnel turnover, or disaster such as a fire or other unusual event. This plan shall be updated annually and attached to HNF-SD-WM-SWD-038 as an appendix.

\subsection{RESPONSIBILITIES}

The TFDB shall have a primary and secondary custodian responsible for system compliance with this procedure. The primary system custodian is Jerry Koreski. The secondary system custodian is Jim Strode.

\subsection{REFERENCE}

1. Koreski, G. M., 1997, Double-Shell Tank Waste Inventory Guidebook, HNF-SD-WM-SWD-038, Rev. 0, Lockheed Martin Hanford Company, Richland, Washington. 
LOCKHEED MARTIN HANFORD CORPORATION

TWRS PROCESS ENGINEERING INSTRUCTION MANUAL
Nanual

Section

Page

Effective Date

Organization
HNF-SD-WM-PROC-021

20.0 , REV 2

1 of 10

November 15, 1998

TWRS Process

Engineering

TITLE:

END-STATE ORGANIC ANALYSIS

METHODOLOGY (SINGLE-SHELL TANKS)

APPLICABILITY: FOR CONPLIANCE

\section{Approved by}

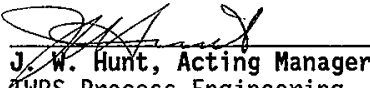

TWRS Process Engineering

\subsection{PURPOSE}

This document defines, presents the methodology and criteria, and describes how to document the results of an organic end-state analysis.

\subsection{SCOPE}

This document applies to the organic end-state analys is of single-shell tanks (SSTs). This analys is is required as a compensatory action of Standing Order 97-01 (East and West Tank Farms 1997) and is required per the Basis for Interim 0peration (LMHC 1997b). This analysis meets the requirements of Administrative Control (AC) 5.15, Moisture Controls, for interim stabilization as identified in LMHC 1997c and is further defined in LMHC 1997a. This analysis deals with the issue of salt well pumping, specifically for the purpose of interim stabilization. The organic end-state analysis can also be applied to the evaluation of tanks that require emergency pumping in response to tank leaks.

Tank Waste Remediation System facilities that are not SSTs and evaluations of proposed changes in the ventilation system of conditionally safe tanks are not within the scope.

\subsection{DEFINITIONS}

Combustion. This term and the phrase "condensed-phase propagating reaction" are often used at Hanford in place of deflagration (see definition).

Deflagration. A release of energy caused by the propagation of a chemical reaction in which the reaction front advances into the unreacted substance at a rate less than sonic velocity. Depending on the substance, propagation rates can vary from very slow $(1 \mathrm{~mm} / \mathrm{min})$ to very fast $(1000 \mathrm{~m} / \mathrm{s})$.

Organic end-state analysis. Anatys is of available information and comparison to defined criteria to determine if a tank will not be categorized as unsafe after pumping.

Organic fuel. Energetic organic constituents that could sustain deflagration. This term is used in describing complexants, which are reactive, and is conservatively assumed to be represented by the total organic carbon. The term "organic fuel" does not describe oxalate or process extractants 
LOCKHEED MARTIN HANFORD CORPORATION

END-STATE ORGANIC ANALYSIS METHODOLOGY (SINGLE-SHELL TANKS) APPLICABILITY: FOR CONPLIANCE
Manual

Section

Page

Effective Date November 15,1998

(solvents) such as tributyl phosphate and its degradation products or normal paraffinic hydrocarbon. Testing indicates that these species do not contribute to the organic complexant hazard (Meacham et a1. 1997).

Safe tanks. Tanks are categorized as safe with respect to organic fue] content when they contain waste judged to be non-combustible without consideration of moisture content (i.e., even if the waste was dried out, it would not be combustible).

Conditionally safe tanks. Tanks are categorized as conditionally safe with respect to organic fuel content when they contain waste judged to pose a smal1 risk when moisture content is considered, but they are judged to pose a significant risk if the waste was dried out.

Unsafe tanks. Tanks are categorized as unsafe with respect to organic fue 1 content when the waste is judged to pose a significant risk under current conditions.

Unassigned tanks. Tanks are unassigned if they have not been categorized as safe, conditionally safe, or unsafe.

\subsection{BACKGROUND}

An unreviewed safety question for organic salt-nitrate reactions was declared in May 1996 (WHC 1996). Subsequent to the unreviewed safety questions declaration, controls were placed on activities that would reduce the moisture level in tanks.

The moisture control for interim stabilization of SSTs is contained in AC 5.15 of the Tank Waste Remediation System Technical Safety Requirements (LMHC 1997c). The control states:

"Supernatant pumping of excess liquid above the solid WASTE surfaces is acceptable. Salt well pumping of liquids below the solid WASTE surfaces of Safe, Conditionally Safe, Unsafe or Unassigned tanks (HNF-SD-WM-BI0$001)$ is prohibited unless sampling and analysis have shown that the post salt well-pumped condition of the remaining WASTE meets the following safety criteria:

Total organic carbon (TOC)/moisture safety criteria:

- $w t \%$ free $\mathrm{H}_{2} \mathrm{O} \geq 20 \%$

or

- TOC (wt\%) $<4.5+0.17\left(w t \%\right.$ free $\left.\mathrm{H}_{2} \mathrm{O}\right)$

when wt\% free $\mathrm{H}_{2} \mathrm{O}<20 \%$ and $\mathrm{wt} \%$ TOC is the wet basis TOC concentration and wt\% free $\mathrm{H}_{2} \mathrm{O}$ is the moisture content of the WASTE." 
LOCKHEED MARTIN HANFORD CORPORATION

END-STATE ORGANIC ANALYSIS METHODOLOGY (SINGLE-SHELL TANKS) APPLICABILITY: FOR CONPLIANCE
Manual

Section

Page

Effective Date
HNF-SD-WM-PROC-021

20.0, REV 2

3 of 10

November 15, 1998

The benefits of pumping Tiquids from a tank must be weighed against the possibility of negative consequences. The removal of liquids from tanks that are no longer in service helps to protect the environment and to reduce worker exposure and lowers waste storage costs. The environment is protected because liquids removed from a SST will not leak into the soil column.

Approximately 65 of the 149 SSTs are assumed leakers, and 117 SSTs have been interim stabilized. A11 SSTs are beyond their design 1 ife and may leak in the future. After a tank is interim stabilized, other steps are taken to isolate the tank and automate monitoring functions. The waste can be safely stored, with minimal worker intervention, until it is removed for treatment and disposal. This reduces the exposure to workers and lowers the cost of maintaining the waste in storage.

\subsection{BASIS}

The criteria for ensuring that a tank will remain in a safe condition are based on the fuel and moisture concentration in the waste. If a tank has a low organic fuel concentration, its waste cannot support combustion and the tank is categorized as safe. If a tank contains fuel, but its waste is too wet to sustain combustion, the tank is categorized as conditionally safe. If a tank contains sufficient fuel and its waste is dry, the tank is categorized as unsafe. In order to allow salt well pumping to proceed in a tank, the organic end-state analysis must show that waste in the tank will not be categorized as unsafe after salt well pumping.

\subsection{EVALUATION}

The preponderance of evidence must demonstrate that salt well pumping will not place a tank into an unsafe condition. Determination of the organic end-state is based on information available. The main sources of information, which lead to understanding the fuel and moisture content of waste in a tank, are process knowledge, analytical data, and modeling. If information is inadequate to make a decision, additional sampling, additional analysis of existing samples, and/or evaluation through statistical methods and models may be required.

Figure 1 shows the decision logic used to perform organic end-state analysis. If a decision block is answered "Yes," pumping can proceed without further evaluation. If a decision block is answered "No," the evaluation proceeds to the next decision block and its associated inputs.

Section 6.1 discusses the types of inputs used in an organic end-state analysis, Section 6.2 the decision criteria, and Section 6.3 the actions to be taken if the organic end-state analysis shows that the tank cannot be pumped. 


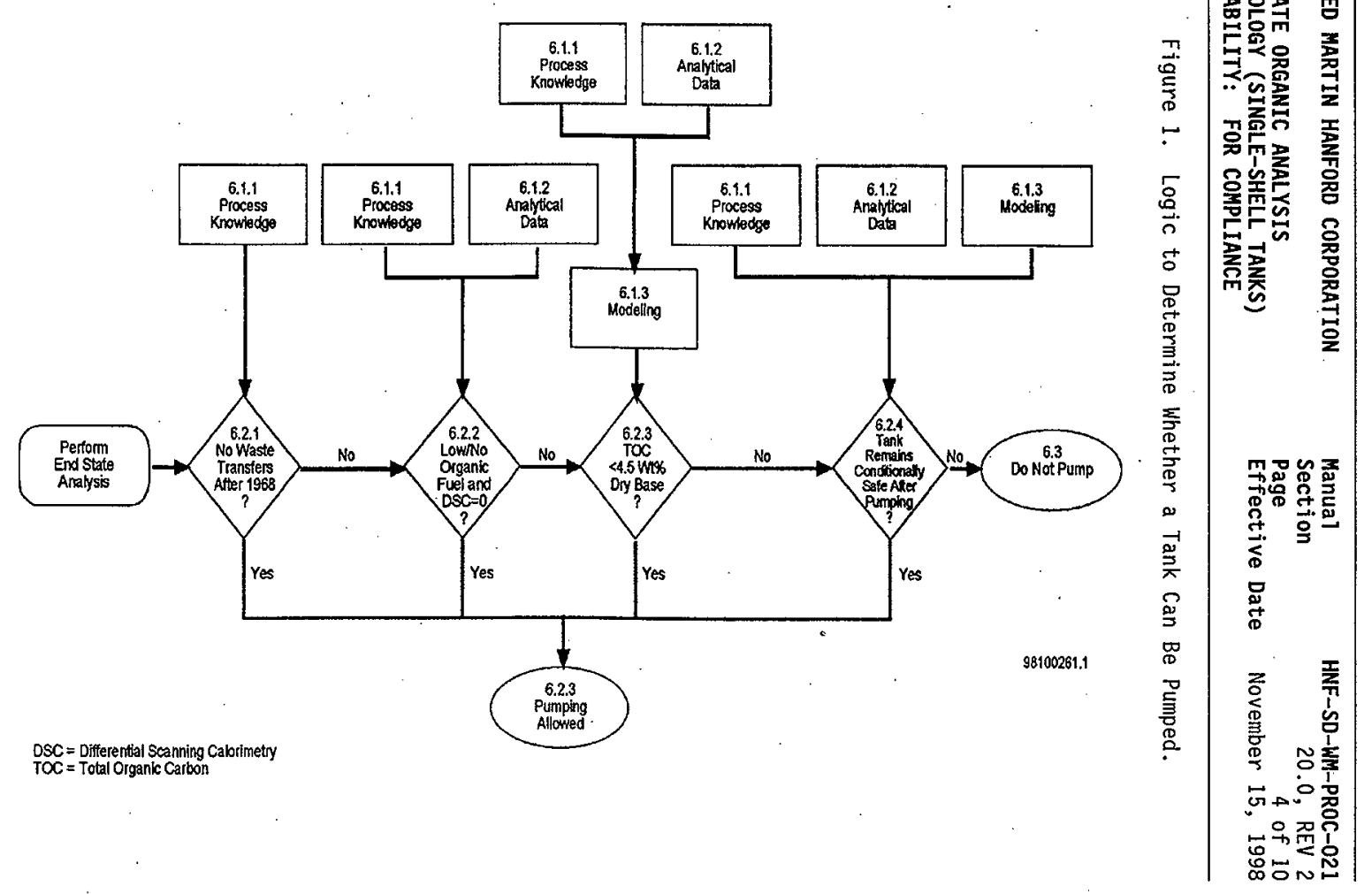


LOCKHEED MARTIN HANFORD CORPORATION

END-STATE ORGANIC ANALYSIS

METHODOLOGY (SINGLE-SHELL TANKS)

APPLICABILITY: FOR CONPLIANCE
Manual

Section

Page

Effective Date
HNF-SD-WM-PROC-021

20.0, REV 2

5 of 10

November 15,1998

\subsection{Inputs to the Evaluation}

This section discusses three main types of input: process knowledge, analytical data, and modeling. These input types provide information on which decisions are based.

\subsubsection{Process Knowledge}

The process history of a tank provides a great deal of information about the type of waste currently in a tank. Knowledge about the waste type in a tank can provide information about the possible existence of certain organic species in the tank. Information is available about tank service history, the transfers of waste into and out of tanks, and when tanks were removed from service.

\subsubsection{Analytical Data}

Sample data provide information about the conditions of the waste at the time the sample was taken. In most instances, the data can be used to predict the composition of the waste now and into the future. In general, information derived from solid samples provides a better understanding of the waste that will remain in the tank. Liquid samples provide good information about the liquid waste being removed through pumping.

Sample analysis data that provide information about the combustibility of the waste include:

- Enthalpy data, such as energetics from differential scanning calorimetry (DSC), the reactive system screening tool (RSST), and the propagating RSST (PRSST).

- Organic content data, such as total organic carbon (TOC) and organic species information.

- Moisture content data, generally in the form of water as a weight percent (wt\%) by thermogravimetric analys is (TGA).

\subsubsection{Modeling}

Modeling is a tool for understanding the distribution of waste properties within a tank and for extrapolating information from tanks with data to tanks with 1 imited or no data. Statistical analyses methods are treated as models for purposes of this discussion. The models that have been or will be used to determine the organic end-state of tanks include:

- The Hanford Defined Waste model (Agnew et a1. 1996)

- The Analysis of Variance (ANOVA) (Meacham 1997). 
Additionally, a calculational model for the drainage of wastes is required to determine the organic and moisture conditions of wastes following interim stabilization. The calculational approach uses the best combination of available waste information as inputs to compute the post salt well pumped condition of a tank. The ANOVA results from Meacham (1997) provide an estimate of the initial TOC and moisture content the bulk waste saltcakes. An important assumption is that salt well pumping will not affect the bounding distributions of either TOC or moisture.

\subsection{Decision Criteria}

Each decision block shown in Figure 1 represents different criteria by which the organic end-state is determined. These decision blocks and their inputs are discussed below.

\subsubsection{No Waste Transfer Into the Tank After 1968}

Processes that produced waste containing organic fuel were not used at Hanford before 1968. Any tank that was removed from service before 1968, and any tank that received no incoming transfers of waste after 1968, would not have received organic complexant fuel. Tanks that meet this criterion do not require further evaluation, and can be pumped.

The process history described by Anderson (1990) and Agnew et a.1. (1996) and other sources that vary tank to tank provide the input to this decision criterion.

\subsubsection{Low or No Organic Fuel and Differential Scanning Calorimetry Show No Exothermic Energy}

Wastes that may contain organic fuel were added to a number of tanks after 1968. The process history (Agnew et a1. 1996) is used to determine whether energetic organic species are expected to be in a tank and in what concentrations. In this context, tanks are low in organic fuel if they have less than 0.53 wt\% TOC (Meacham 1997). Differential scanning calorimetry data must demonstrate that exothermic energy was not found in any sample from a tank. Tanks that meet both the process history and the energetics criteria, do not require further evaluation, and they can be pumped.

\subsubsection{Total Organic Carbon is Less Than 4.5 Weight Percent Dry Basis}

An ANOVA analysis was performed using analytical data to determine whether TOC in tanks is less than the limit of $4.5 \mathrm{wt} \%$ dry basis at the 95 percentile with a .95 percent confidence (Meacham 1997). As data from new sampling become 
LOCKHEED MARTIN HANFORD CORPORATION

END-STATE ORGANIC ANALYSIS METHODOLOGY (SINGLE-SHELL TANKS) APPLICABILITY: FOR COMPLIANCE
Manual

Section

Page

Effective Date
HNF-SD-WM-PROC-021

20.0 , REV 2

7 of 10

November 15, 1998

available, additional ANOVA analyses may be completed. Tanks that meet this criterion do not require further evaluation, and they can be pumped.

The ANOVA model is the input to this decision criterion. Process knowledge and analytical data are inputs to the ANOVA. Process knowledge impacts the groupings of tanks for the ANOVA along with the actual TOC data from tank sampling and analysis.

\subsubsection{Tank Remains Conditionally Safe After Pumping}

According to the Tank Waste Remediation System Basis for Interim Operation (LMHC - 1997b):

"The conservative combustion criterion developed from theory and test results is

$$
\text { wt\% TOC (wet basis) }<4.5+17 x_{w}
$$

where wt\% TOC is the total organic carbon in the waste calculated as the energy equivalent of sodium acetate and $x_{w}$ is the weight

fraction of moisture in the tank, up to 0.20 . Above 0.20 (20 wt\% water) the relationship no longer holds..."

Salt well pumping removes large masses of liquid from a tank and generally changes the mass balances between liquid and bulk waste phases. Due to these mass changes, it is appropriate to calculate changes in waste properties based on mean values of parameters because these means are mass weighted. The median values of bulk waste TOC and moisture as predicted by ANOVA in Meacham (1997) will be converted to mean values for this calculation.

The organic salt nitrate evaluations (Meacham 1997) show that only certain organic complexants are of concern. For example, oxalate and solvents will not participate in the reaction. Where reliable information about the bulk waste oxalate and solvent concentrations are available, the equivalent TOC could be subtracted from the buik ANOVA TOC estimates or core sampie analysis results to provide an "adjusted TOC" to use in further computations. Where such information is not available, the base ANOVA TOC estimates will be used. This basic procedure assumes that accurate information about "nonparticipating TOC" is not avaiTable and that all TOC is considered to be reactive.

The properties of waste tank liquids are assumed to be uniform throughout a tank. On this basis, the most recent liquid grab samples from the tank are expected to be most representative of tank liquids. Therefore, the average or mean value of TOC and moisture liquid grab samples will be used to represent the mean values of these properties for all liquids in the tank being evaluated. 
LOCKHEED MARTIN HANFORD CORPORATION

END-STATE ORGANIC ANALYSIS

METHODOLOGY (SINGLE-SHELL TANKS)

APPLICABILITY: FOR COMPLIANCE
Manual

Section

Page

Effective Date
HNF-SD-WM-PROC-021

20.0 , REV 2

8 of 10

November 15, 1998

The changes in TOC and moisture within the bulk waste are computed based upon mean values. The computed value for TOC $\left(X_{\text {TOCB }}^{\prime}\right)$ is given by the following equation. A similar equation will be used for computing $\% \mathrm{H}_{2} \mathrm{O}$.

$$
X_{\mathrm{TOCB}}^{\prime}=\frac{X_{\mathrm{TOCB}} M_{B}-X_{\mathrm{TOCL}} \Delta M_{\mathrm{L}}}{M_{B}-\Delta M_{\mathrm{L}}}
$$

$X_{\text {TOCB }}=$ Mass fraction of TOC in the in bulk waste after pumping, mean value.

$X_{\text {TOCB }}=$ Mass fraction of TOC in the tank initially in bulk waste, mean value. This value is derived from the median value.

$X_{\text {TOCL }}=$ Liquid waste TOC, mass fraction, mean value. This is typically from analysis of a grab sample of the liquid to be pumped.

$M_{B}=$ Total mass of bulk waste initial, mean value. This is found by taking the volume of waste in Hanion (current issue) $\left(V_{B}\right)$ and multiplying by a bulk density. The bulk density will be taken from knowledge or a value of $1.5 \mathrm{gm} / \mathrm{mL}$ will be used. $M_{B}=V_{B}$ * Density

$\Delta M_{L}=$ Mass of liquid pumped. This is found by taking the pumpable volume of waste in Hanlon (current issue) $\left(V_{p}\right)$ and multiplying by the density of the liquid. The liquid density is determined by a grab sample of Tiquid. $\Delta M_{L}=V_{p}$ * density of liquid.

The adjusted mean values for TOC and $\mathrm{wt}_{\mathrm{C}} \mathrm{H}_{2} \mathrm{O}$ are calculated from the previous step, and the values are transformed back to median values in the $10 \mathrm{~g}$ normal distribution. The procedure described in Appendix $F$ of Meacham (1997) is then applied to estimate the distribution of TOC and $\mathrm{H}_{2} \mathrm{O}$ concentrations for the new condition of the waste after pumping. The results of that procedure are to be interpreted as the fraction of the waste which is combustible after salt well pumping. If greater than 5 percent of the post pumping waste volume is combustible, the waste would be classified as unsafe, and pumping is not a) lowed. If less than 5 percent of the post pumping waste volume is combustible, the waste would be classified as safe or conditionally safe, and pumping is allowed.

\subsubsection{Tank Remains Conditionally Safe After a Period of Dryout}

For tanks shown to be conditionaliy safe after pumping, it is important to understand whether dryout will lead to the tank becoming unsafe in an unacceptably short time. Wastes that are higher in fuel content and lower in moisture could eventually become unsafe if a portion of the waste dries out to a combustible condition. The rate at which the surface of the waste could dry 
LOCKHEED MARTIN HANFORD CORPORATION

END-STATE ORGANIC ANALYSIS METHODOLOGY (SINGLE-SHELL TANKS) APPLICABILITY: FOR COHPLIANCE
Manua 1

Section

Page

Effective Date
HNF-SD-WM-PROC-021

20.0 , REV 2

9 of 10

November 15,1998

to potentially unsafe conditions depends on the physical characteristics of the waste, the fuel concentration, the moisture concentration, the waste temperature, and the ventilation flow rates through the tank.

The dryout rate will be estimated from specific waste and tank data (where available) or from more generalized data. Changes in the surface 1ayer of waste will be computed and compared to criteria as in Section 6.2 .4 to determine whether a significant increase in combustible waste volume would occur in the next five (5) years. The dryout estimate will be weighed with other factors to determine whether salt well pumping should be performed at the present time or whether other actions should be taken first. These actions might include securing more measurements to determine more precisely the waste fuel content and moisture values or taking offsetting measures such as frequent moisture tracking.

\subsection{Tanks That Do Not Meet the Decision Criteria}

Any tank that does not meet the criteria as shown in Figure 1 and described in Section 6.2 cannot be pumped. As additional information becomes available, a tank can be reevaluated using the criteria.

\subsection{DOCUMENTATION OF ORGANIC END-STATE ANALYSIS}

Using the methodology outlined in this document, an organic end-state analysis will be performed before salt well pumping can proceed. The organic end-state analysis will be documented in a supporting document.

\subsection{REFERENCES}

1. Agnew, S. F., R. Corbin, J. Boyer, T. Duran, K. Jurgensen, T. Ortiz, B. Young, 1996, History of Organic Carbon in Hanford HLW Tanks: HDW Model Rev. 3, LA-UR-96-989, Los Alamos National Laboratory, Los Alamos, New Mexico.

2. Anderson, J. D., 1990, A History of the 200 Area Farms, WHC-MR-0132, Westinghouse Hanford Company, Richland, Washington.

3. East and West Tank Farms, 1997, Compensatory Actions for Open Discovery Unreviewed Safety.Questions (USQS), Standing Order 97-01, Lockheed Martin Hanford Corporation, Richland, Washington.

4. LMHC, 1997a, Tank Farms Operations Administrative Controls, HNF-IP-1266, Rev. 0, Lockheed Martin Hanford Corporation for Fluor Daniel, Inc., Richland, Washington. 
5. LMHC, 1997b, Tank Waste Remediation System Basis for Interim operation, HNF-SD-WM-BI0-001, Rev. 0, Lockheed Martin Hanford Corporation for Fluor Daniel, Inc., Richland, Washington.

6. LMHC, 1997C, Tank Waste Remediation System Technical Safety Requirements, HNF-SD-WM-TSR-006, Rev. 0, Lockheed Mart in Hanford Corporation for Fluor Daniel, Inc., Richland, Washington.

7. Meacham, J. E., A. B. Webb, N. W. Kirch, J. A. LecheTt, D. A. Reynolds, G. S. Barney, D. M. Camaioni, F. Gao, R. T. Hallen, and P. G. Heasler, 1997, Organic Complexant Topical Report, HNF-SD-WM-CN-058, Rev. 1A, DE\&S Hanford, Inc. for Fluor Daniel, Inc., Richland, Washington.

8. WHC, 1996, Condensed-Phase Organic Nitrate Reactions, USQ Tracking No. TF-95-0096, Rev. 1, Westinghouse Hanford Company, Richland, Washington. 
LOCKHEED MARTIN HANFORD CORPORATION

TWRS PROCESS ENGINEERING

INSTRUCTION MANUAL
Manual

Section

Page

Effective Date

Organization
HNF-SD-WM-PROC-021

21.0, REV 2

1 of 8

November 15, 1998

TWRS Process

Engineering
TITLE:

BEST-BASIS INVENTORY

CHANGE CONTROL BOARD - CHARTER

APPLICABILITY: FOR COMPLIANCE
Approved by

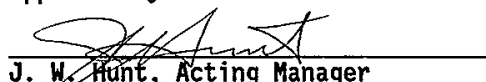

TWRS Process Engineering

\subsection{CHARTER}

The Best-Basis Inventory Change Control Board is chartered to evaluate and approve revisions to the best-basis inventory data set. The best-basis inventory (also referred to as the standard inventory) is the Hanford Site underground waste storage tank baseline for the global and tank-specific chemical and radionuclide inventory. This database contains the official reference inventory for Hanford tank waste and is intended for use in al1 documentation wherein reference to inventory data is made in support of waste management and disposal activities.

The best-basis inventory was initially estab]ished in August 1997 and is being maintained in the Tank Characterization Database (TCD) under strict configuration control. Proposed revisions to the best-basis inventory must be evaluated and approved by the Best-Basis Inventory Change Control Board (hereafter referred to as the CCB) in accordance with this procedure or subsequent revisions thereto.

\subsection{MEMBERSHIP}

The CCB members shall be familiar with: 1) the processes that produced the Hanford Site underground tank wastes; 2) the Tank Characterization Report (TCR) content and preparation process; 3 ) the Hanford Defined Waste (HDW) model content, waste definitions, and treatment of radionuclides; and 4) the methodology for preparing the best-basis inventory documentation (refer to Section 8.0 and Appendix $J$ of Kupfer et a1. [1997]).

The CCB shall consist of at least four (4) members and may function as part of the existing Process Engineering Data Review Committee or as a separate entity. Appointment of membership to the CCB will be by the Manager of the Models and Inventory group. The Manager of the Models and Inventory group will also appoint one board member to the position of CCB Administrator. (The CCB Administrator duties are discussed in Section 4.2.)

Subject matter experts may also participate in meetings of the CCB as deemed necessary by the CCB. A quorum of the CCB consists of a11 appointed members or their designees. Designees shall be appointed by the Manager of the Models and Inventory group as needed. 


\begin{tabular}{llr}
\hline LOCKHEED MARTIN HANFORD CORPORATION & Manua1 & HNF-SD-WM-PROC-02I \\
BEST-BASIS INVENTORY & Section & 21.0, REV 2 \\
CHANGE CONTROL BOARD - CHARTER & Page & 2 of 8 \\
APPLICABILITY: FOR COMPLIANCE & Effective Date & November 15, 1998
\end{tabular}

\subsection{RESPONSIBILITIES}

In order for the best-basis inventory to remain current and useful, new sample analys is results, modeling data, and other information which could influence the global or tank-specific inventory must be evaluated as it becomes

available. It is the responsibility of the respective tank coordinators or their designees to propose revisions to the best-basis inventory as dictated during the preparation of new or revised TCRs. Other revisions to the global and tank-specific inventory data or methodology will. likely be initiated by Process Engineering staff members; however, others may propose best-basis inventory changes to the CCB if they believe the changes are warranted.

The CCB is responsible for:

1. Providing methodology guidance to those preparing inventory or methodology revisions

2. Approving changes to the best-basis inventory methodology

3. Approving changes to the best-basis inventory values

4. Approving changes to the best-basis inventory content (e.g., addition of soluble/insoluble fraction inventories, addition of inventories by waste layer, addition of uncertainty estimates, subtraction or addition of analytes to the best-basis inventory list)

5. Approving changes to source data which may influence one or more tank-specific inventory values (and consequently the global inventory generated by summing the individual tank inventories)

6. Maintaining review and approval records

7. Assuring that approved revisions are reflected in the TCD

8. Correcting known errors in inventory values

9. Assuring the quality of the best-basis inventory in the TCD and in published form by verifying inventory assessment calculations, verifying data quality after it has been loaded into the TCD, and performing queries on the data set to expose anomalies.

The Administrator of the CCB is responsible for administering the Change Controt Operation which is detailed in Section 4.0 .

\subsection{CHANGE CONTROL OPERATION}

Figure 1 is a schematic of the Best-Basis Inventory Change Control Operation. The following sections discuss each element of this process. 


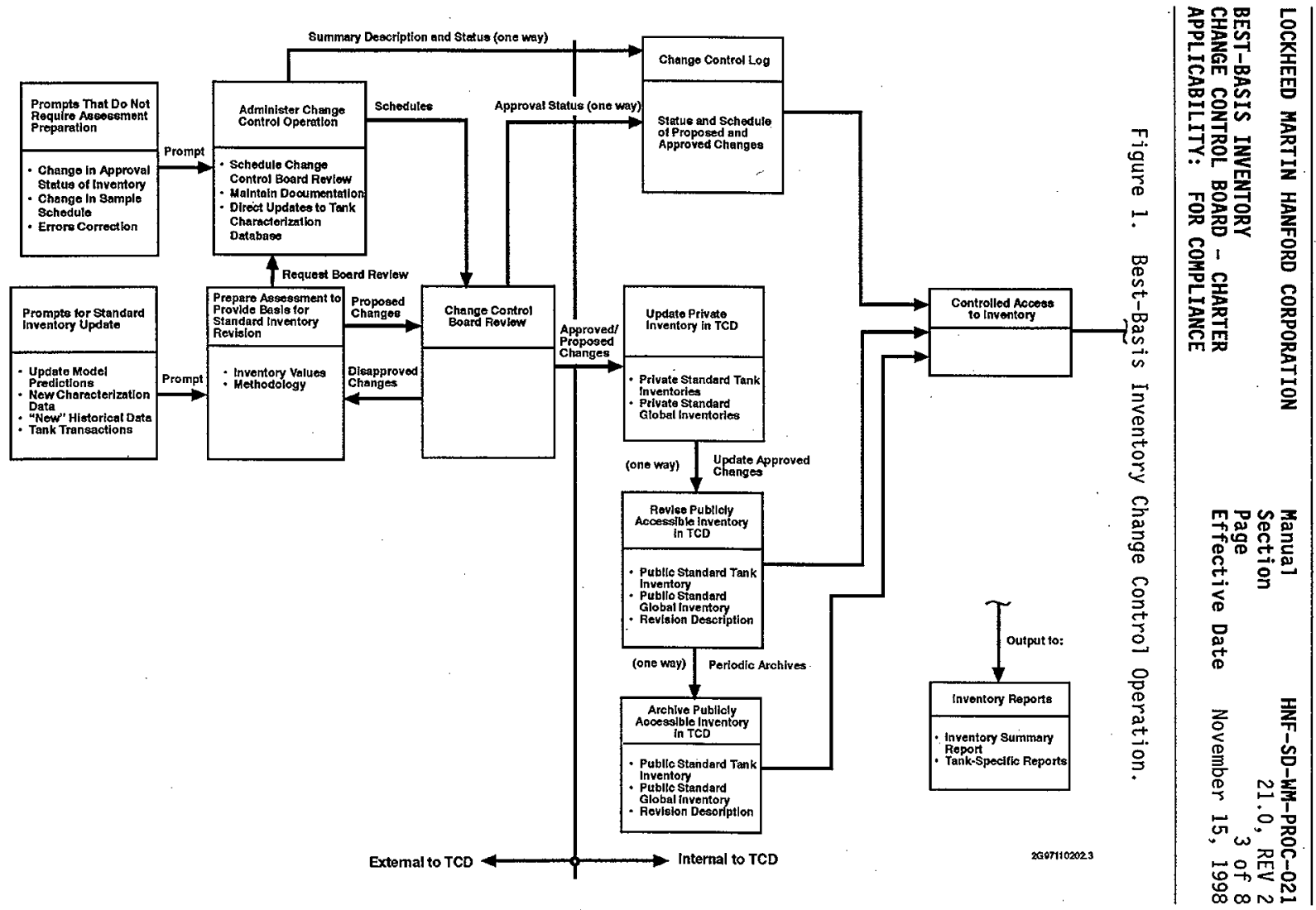


LOCKHEED MARTIN HANFORD CORPORATION

BEST-BASIS INVENTORY

CHANGE CONTROL BOARD - CHARTER

APPLICABILITY: FOR CONPLIANCE
Manua 1

Section

Page

Effective Date
HNF-SD-WM-PROC-021

21.0, REV 2

4 of 8

November 15, 1998

\subsection{Prompts for Best-Basis Inventory Updates}

Updated model predictions, new characterization data, additional historical data (e.g., revised process flowsheets), revised source data (e.g., tank volume revisions, waste type template changes), or tank waste transfers serve as prompts for preparing assessments to review and update the best-basis inventory. Discovery of calculational errors, typographical errors, or data loading errors will also necessitate updates to. the best-basis inventory.

\subsection{Administer Change Control Board Operation}

A CCB Administrator will be appointed by the Manager of the Models and Inventory group to oversee CCB operations. The CCB Administrator will be responsible for recognizing the need for best-basis inventory updates; scheduling reviews of best-basis inventory revisions by the CCB; maintaining CCB meeting minutes, assessment documentation, and other records of CCB decisions; and directing updates to the best-basis inventory maintained in the TCD. This individual will also maintain a change control log (see Section 4.3).

\subsection{Change Control Log}

The change control $\log$ is used to provide inventory users a summary of updates and anticipated changes to the best-basis inventory. It informs users of possible changes to the best-basis inventory baseline and summarizes approved changes that have occurred to the best-basis inventory as a result of CCB decisions. This $\log$ will include a brief description of each activity which may result in changes to inventory values (e.g., TCR revision or reconciliation task), the schedule for this activity, the effected tank inventories, and the CCB approval status (pending, approved, disapproved).

\subsection{Best-Basis Inventory Revisions}

As discussed in Section 4.1 , updated model predictions, new characterization data, additional historical data, revised source data, or tank waste transfers are prompts for preparing assessments to review and update the best-basis inventory. The approved results of such assessments are typically published in new or revised TCRs. Therefore, the preparation of such assessments will be the responsibility of the appropriate tank coordinator or their designee.

The author of the best-basis inventory revisions shall review the new and revised data and the existing best-basis inventory assessment. Using the principles described in Section 8.0 and Appendix $J$ of Kupfer et aT. (1997), revised best-basis inventory documentation shall be prepared for the tank contents.

The revised tank inventory documentation shall be peer reviewed by knowledgeable member(s) of the Process Engineering organization and be submitted to the ССВ for their review and approval. The validity of the 
Manual

Section

Page

BEST-BASIS INVENTORY

CHANGE CONTROL BOARD - CHARTER

APPLICABILITY: FOR COMPLIANCE
Effective Date
HNF-SD-WM-PROC-021

21.0 , REV ?

5 of 8

November 15,1998

technical approach (e.g., derivation of inventories from "basis" tank analyses) and new or revised data shall be reviewed. The CCB shall ensure that the revised best-basis inventory conforms to the prescribed inventory preparation guidelines mentioned above. The author of the best-basis inventory revisions shall formally disposition CCB review comments and finalize the assessment.

After comment incorporation, the author shall submit the best-basis inventory documentation to the CCB for final approval. If the CCB has outstanding issues or concerns, the CCB may request that the author of best-basis inventory revisions appear before the CCB to respond to questions and comments. Even if the assessment does not result in revisions to the bestbasis inventory, the author is still required to have the best-basis inventory assessment reviewed and approved by the CCB.

Methodology changes or other revisions to the best-basis inventory (e.g., correction of calculational, typographical, or data loading errors) will not require a complete formal assessment but will require the comparison of the former inventory (or method) to the proposed inventory (or method), the concise description of the pedigree, and the validity bases for the new data (or method) used. Appropriate change documentation shall be prepared and issued by the author proposing the change.

Changes to inventory approval status (e.g., CCB, U.S. Department of Energy, or Washington State Department of Ecology approval) or to the change control log (see Section 4.3) do not require formal CCB approval. Such changes can be directed by the CCB Administrator and will be reflected in the standard inventory portion of the Tank Waste Information Network System (TWINS/TWINS2), (PNL 1994).

\subsection{Change Control Board Review}

In general, proposed best-basis inventory changes resulting from the preparation of new or revised TCRs shall be handled through the normal peer review process. The tank coordinators shall ensure that members of the CCB are included in the TCR peer review process. The CCB will convene to discuss their comments on the best-bas is inventory contained in the TCRs. The author of the best-basis inventory revisions may be asked to appear before the CCB to address questions concerning the proposed revisions. The author may also be asked to present the best-basis inventory assessment documentation to the CCB and show how it supports the need for the proposed revisions.

The CCB shall discuss and decide the disposition of the proposed inventory or methodology revisions by consensus. The disposition may include:

- Agreement and approval of the revision.

- Agreement that the bases and revision are correct, but that the inventory change is within the accuracy/reliability limits; therefore, a complete modification is not warranted at this time. 
LOCKHEED MARTIN HANFORD CORPORATION

BEST-BASIS INVENTORY

CHANGE CONTROL BOARD - CHARTER

APPLICABILITY: FOR COMPLIANCE
Manual

Section

Page

Effective Date
HNF-SD-WM-PROC-021

21.0, REV 2

6 of 8

November 15, 1998

- Disagreement with the revision bases and/or its application to the best-basis inventory. In this case, the CCB shal1 provide the author of proposed best-bas is inventory revisions with its reasons for rejection and suggest follow-on work to produce an acceptable assessment.

The CCB's decision will be documented and retained by the CCB Administrator (along with the assessment and summary documentation) in CCB hard copy records. The associated approval status and TCD revisions will be incorporated in the change control $10 \mathrm{~g}$ and in the TCD, respectively.

\subsection{Maintain the Best-Basis Inventory in the Tank Characterization Database}

The best-basis inventory values and source data will be maintained in the TCD for ease of access and data management. The changes will initially be reflected in the private inventory of the TCD where they can be verified and retained until they are upleveled to the publicly accessible portion of the TCD.

The private sector of the TCD is a restricted access area of the database which is accessible to TCD administrators, the CCB, and others that are authorized. Given the interdependent nature of the inventories (one tank's inventory may serve as source data for other tank inventories containing similar wastes), the private sector of the TCD may actually be used to evaluate the effect of changes to certain inventory values before CCB approval.

Upleveling of data to the publicly accessible portion of the TCD will occur at the direction of the CCB Administrator after inventory changes have been approved by the CCB, and the associated documentation has been issued. Updates to the inventory associated with TCR revisions and correction of obvious errors will be incorporated promptly into the TCD following CCB approval and associated document issuance. Annual updates to the best-bas is inventory data set will also occur to reflect changes associated with more comprehensive efforts such as the reconciliation of individual tank inventories to the global inventory.

Once the data is upleveled from the private to the publicly accessible portion of TCD, users can access the best-basis inventory through the reporting features contained in the TWINS/TWINS2 interface. 


\subsection{REFERENCES}

1. Kupfer, M. J., A. L. Boldt, B. A. Higley, K. M. Hodgson,

L. W. Shelton, B. C. Simpson, and R. A. Watrous, S. L. Lambert, and

D. E. Place, R. M. Orme, G. L. Borsheim, N. G. Colton.,

M. D. LeClair, R. T. Winward, and W. W. Schulz, 1997, Standard

Inventories of Chemicals and Radionuclides in Hanford Site Tank Wastes, HNF-SD-WM-TI-740, Rev. 0, Lockheed Martin Hanford

Corporation for Fluor Daniel Hanford, Inc., Richland, Washington.

2. PNL, 1994, TWINS User Guide Tank Waste Characterization Information Network System Version 4.0, PNL-8824-2, Pacific Northwest Laboratory, Richland, Washington. 
LOCKHEED MARTIN HANFORD. CORPORATION

BEST-BASIS INVENTORY

CHANGE CONTROL BOARD - CHARTER

APPLICABILITY: FOR COMPLIANCE
Manua1

Section

Page

HNF-SD-WM-PROC-021

21.0, REV 2

8 of 8
Effective Date November 15, 1998

This page intentionally left blank. 
LOCKHEED MARTIN HANFORD CORPORATION

TWRS PROCESS ENGINEERING

INSTRUCTION MANUAL
Manua]

Section

Page

Effective Date

Organization
HNF-SD-WM-PROC-021

22.0, REV 2

1 of 2

November 15, 1998

TWRS Process

Engineering

\section{TITLE:}

SAVING WORK FROM LOSS

APPLICABILITY: FOR COMPLIANCE

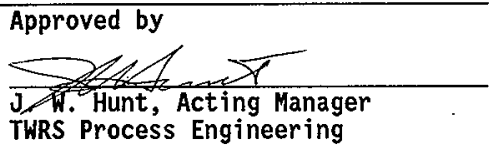

\subsection{OBJECTIVE AND PURPOSE}

The purpose of this section is to provide employees instructions for saving desktop work from loss by performing a nightly backup. The objective is to reduce rework and loss of time to the greatest extent practicable by providing a consistent, effective, and easy method for saving and backing-up work created on the desktop. Specifically, use of this procedure will:

- Allow another employee to complete a document without having to access the hard disk of the author's computer, should the author be absent

- Protect the files from loss because the network backs up the files every night

- Conserve space on the author's hard disc

- Provide a step toward a future a11-electronic document preparation and release process.

\subsection{PROCEDURAL REQUIREMENTS}

A common network share area has been created for authors, editors, and other employees of TWRS Process Engineering to post their most recent document files as they are created. Use of this share area will provide a nightly backup, assure access to the files in the event employee is incapacitated or absent for an extended period, and will provide an orderly and controlled procedure for editing and storing work in progress.

Authors and employees, including subcontracted and matrixed employees, shall use the share area for posting all files needed to complete a document including word processing and graphics files or, as an alternative, the " $U$ " drive, or another share area authorized by management. The share area name that is recommended is IIAP012\CHARDOCS. This network share area, "U" drive or other share area shall be used for al1 documents, graphics, spreadsheets, etc., into which more than eight hours of work have been invested. Examples of documents that need to be protected on an ongoing basis include Data Quality Objectives (DQO), Tank Sampling and Analysis Plans, Tank Characterization Reports (TCR), planning documents, and other similar documents prepared by the TWRS Process Engineering organization. 
A filing structure has been established for use in CHARDOCS. Each document release shall be $\mathrm{placed}$ in its own subdirectory. For documents that apply to more than one tank such as DQOs, a subdirectory \MULTITANK\DQO sha11 be used. For documents that apply to one tank such as TCRs, use the directory allocated to the tank number and document type (e.g.; ISY \103\TCR). One new subdirectory shall be created for each document posted. To make it clear what the revision sequence is within a series, the date is incorporated in the subdirectory name (YYMMDD) with an extension of up to three characters following the decimal to define the version number (if any). Drafts are saved in subdirectories with the format DATE.DFT. For example, a draft version of a TCR for tank 241-SY-103 posted September 23, 1995, would be stored as: ISY $\backslash$ 103\TCR\950923.DFT. If a version 2 were created on October 3, 1995, with

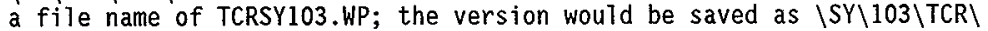
951003.02\TCRSY103.WP. 
LOCKHEED MARTIN HANFORD CORPORATION

TWRS PROCESS ENGINEERING

INSTRUCTION MANUAL
Manual

Section

Page

Effective Date

Organization
HNF-SD-WH-PROC-021

23.0, REV 2

1 of 44

November 15, 1998

TWRS Process

Engineering
TITLE:

PROCESS ENGINEERING CALCULATIONS FOR

TANK 241-C-106 SLUICING AND RETRIEVAL APPLICABILITY: FOR COMPLIANCE
Approved by

J. W. Hunt, Acting Hanager

TWRS Process Engineering

\subsection{PURPOSE}

This document defines and presents the method for calculating the engineering material balance for tank 241-C-106 leak detection and for the mass transfer during the tank 241-C-106 sluicing process. This document also presents the calculations used to make judgments on the extent of gas retention in tank 241-AY-102 following each campaign of the tank 241-C-106 retrieval. The material balance satisfies the requirements of Administrative Control 5.12, Transfer Controls, located in the Technical Safety Requirements (TSR) (Noorani 1998a) and the requirements of Addendum I of the Basis for Interim 0perations (BI0) (Noorani 1998b). The controls to prevent a possible flammable gas deflagration during siujce batches are in Section 2.5.2.2.3 (Flammable Gas Process Control) of Addendum I of the BIO (Noorani 1998b).

\subsection{SCOPE}

This document applies to the sluicing and waste retrieval of tank 241-C-106. The material balance in section 3.0 will be used as a secondary means of leak detection for tank 241-C-106. The material balance in Section 4.0 will be used as a means of determining the mass and volume of sludge received to tank 241-AY-102 and of estimating the heat load in the transferred waste. The flammable gas calculations in Section 5.0 will be used to make judgments on the extent of gas retention in tank $241-A Y-102$ following each campaign of the retrieval.

\subsection{LEAK DETECTION DETERMINATION}

\subsection{Requirements}

This material balance will be performed once every 24 hours during active sluicing; the 24-hour period begins when a sluice batch is initiated. Process Engineering will perform a material balance as a verification of the material balance T0-320-003 performed by 0perations. The data used to calculate the material balance will be averaged over the previous seven days. The results will be communicated to the shift manager with a telephone call followed by an. e:majl within the 24-hour period. After the sluicing is complete, the mass balance calculations will be documented in a supporting document. 


\subsection{Methods of Leak Detection}

Leak detection instrumentation will be monitored during all phases of the sluicing process. Waste leakage could occur from tank 241-C-106, tank 241-AY-102, or the interfarm piping between the two tanks. Each of these systems has specific leak detection capabilities to provide early warning of a leak.

Leakage from tank 241-C-106 will be determined using a combination of liquid level measurements, dry well measurements, and material balance estimates. The liquid level measurements and the dry well measurements provide information that is specific to tank 24l-c-106. The material balance algorithm collects data from the entire sluicing process and determines an overal] indication of potential leakage. The Teak detection systems for tank 241-AY-102 and the transfer pipeline are highly reliable, and any potential leakage identified from the material balance can be assumed to be from tank 241-C-106.

Liquid Level Monitoring. The primary leak detection method for tank 241-C-106 during the sluicing process is to monitor the Tiquid level using the ENRAF ${ }^{1}$ level gauge. The liquid level will be measured continuously during periods between sluice batches to prevent damaging the gauge.

Dry Well Monitoring. In addition to the in-tank level measurement, eight dry wells located in the soil surrounding tank 241-C-106 will be monitored to detect a possible leakage plume. A leakage plume that migrates within detection range of the dry wells will be caught by this method. The monitoring uses radiation probes to detect a change in the radiation profile over the length of the dry well when compared with a baseline profile. The wells will be monitored monthly to determine radiation profiles for the soil within several inches of the outer surface of the well. Because of the low percentage of soil intercepted and the long timeframe required for leaks to migrate within range of the dry wells, immediate detection of a small leakage volume is beyond the capabilities of the dry well system. However, the system would provide confirming information for the occurrence of a small leak given sufficient time or of a larger leak. Dry well monitoring data are al so useful in assessing the extent and direction of plume movement.

Material Balance. A cumulative material balance will be kept during the sluicing process to monitor the progress of the sluicing operations and to provide a secondary indication of a potential leak from tank 241-C-106.

This cumulative material balance will be kept current by performing a material balance. for each sluice batch and monitoring period.

This material balance may only be applicable as a leak detection method during the first sluicing campaign (i.e., retrieval of the first two feet of sludge) and at the end of the retrieval operation. The uncertainty in the tank 241-C-106 waste volume becomes too great after the first campaign for the 
material balance method to be useful for leak detection. The solids that accumulate in the "no-sluice zone" next to the tank wall during the retrieval process cannot be measured and may account for up to approximately 190,000 L $(50 \mathrm{kgal})$ of waste. After the walls are sluiced at the end of the last campaign, the material balance will provide an indication whether tank 241-C-106 leaked during the sluicing operations.

It is possible that the material balance method may apply during the intervening period if only a small amount of material clings to the tank wall during sluicing operations. In this latter case, Process Engineering will evaluate the applicability of the material balance method and make recommendations to the Technical Review Group (TRG) and/or the Waste Retrieval STuicing System (WRSS) Operations Manager, as required.

\subsection{Criteria for Continuing Sluicing Operations}

When the material balance method is applicable for leak detection, previous and current material balance estimates will be combined with other process data to predict the expected tank 1 iquid levels. Inconsistencies between the predicted level values and actual levels will be evaluated as potential indications of leakage. The actual waste volumes in tanks 241-C-106 and 241-AY-102 are obtained from the ENRAF ${ }^{T M}$ level gauge measurements.

A material balance will be determined immediately following each sluice batch once the baseline level measurement in tank 241-C-106 has been established. The material balance will cover the time period between completion of the previous material balance and establishing the current tank baseline level. The material balance will compare the current measured total volume in tanks 241-C-106 and 241-AY-102 with a calculated total volume for the tanks. The material balance criteria are as follows:

1. If $V_{m}-V_{c a l-c}>-8,000 \mathrm{gal}$, continue sluicing operations and set $V_{\text {cal-p }}$ $=V_{\text {cal }-c} \cdot$

$V_{m}=$ current measured total volume in tanks

$V_{\text {cal-c }}^{m}=$ current calculated total volume in tanks

$V_{\text {cal-p }}^{c a l-c}=$ previous calculated total volume in tanks.

2. If $V_{m}-V_{c a l-c} \leq-8,000 \mathrm{gal}$, stop sluicing operations and initiate a leak investigation.

The 8,000 gallon criterion was developed in the Environmental Assessment Tank 241-C-106 Past-Practices Sluicing Waste Retrieval (D0E 1995). 


\subsubsection{Calculation of Material Balance}

The material balance equation to calculate $V_{c a l-c}$ is given below:

$$
\begin{aligned}
& V_{\text {cal-c }}=V_{c a l-p}+V_{6 C-\text { in }}+V_{6 C-m}+V_{2 A Y-\text { in }}+V_{2 A Y-m}-V_{6 C-\text { out }}-V_{2 A Y-\text { out }}+\Delta V_{G C-T}+ \\
& \Delta V_{2 A Y-T}+\Delta V_{2 A Y-\text { sol }}
\end{aligned}
$$

where

$$
\begin{aligned}
& V_{6 c-i n}=\text { volume of water entering tank } 241-C-106 \text { in vapor streams and } \\
& \text { water flushes } \\
& V_{6 c-m}=\text { volume of other materials added to tank 241-C-106 } \\
& V_{2 A Y-i n}=\text { volume of water entering tank 24I-AY-102 in vapor streams and } \\
& \text { water flushes } \\
& V_{2 A Y-m}=\text { volume of other materials added to tank 241-AY-102 } \\
& V_{6 c-o u t}=\text { volume of water discharged from tank 241-C-106 in vapor } \\
& \text { streams } \\
& V_{2 A Y-o u t}=\begin{array}{l}
\text { volume of water discharged from tank } 241-A Y-102 \text { in vapor } \\
\text { streams }
\end{array} \\
& \Delta \mathrm{V}_{\mathrm{GC}-\mathrm{T}} \quad=\text { change in current volume of tank 241-C-106 waste caused by } \\
& \text { temperature effect on solution density } \\
& \Delta \mathrm{V}_{2 \mathrm{AY}-\mathrm{T}}=\text { change in current volume of tank 241-AY-102 waste caused by } \\
& \text { temperature effect on solution density } \\
& \Delta V_{2 A Y-s o l}=\begin{array}{l}
\text { change in current volume of tank } 241-A Y-102 \text { waste caused by } \\
\text { solubility effects on solution density }
\end{array}
\end{aligned}
$$

Note that at the beginning of sluicing operations, $V_{c a i-g}$ is equal to $V_{m}$, the initial measured total volume in tanks $241-C-106$ and $241-A Y-102$. Each of the material balance parameters are defined in the following sections.

\subsection{1 $V_{6 C-\text { out }}$}

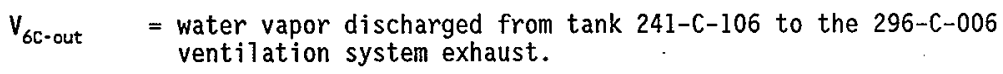

The calculational sequence for this determination is as follows:

1. Obtain the average volumetric flow rate downstream of condenser $H X-1361$ (after the exhaust recirculation and ventilation duct junction). 
2. Calculate the molar flow rate of water vapor in the air stream.

3. Calculate the volumetric flow of water out of the stack during the material balance period.

(1) Average volumetric flow rate downstream of $\mathrm{HX}-1361$.

$$
P_{1}=P_{\text {cond in }}+\Delta P_{H X-1361}
$$

where

$$
\begin{aligned}
& P_{1}=\begin{array}{l}
\text { average absolute pressure after junction downstream of } \\
H X-1361 \text {, psia. }
\end{array} \\
& P_{\text {cond-in }}=\text { average pressure upstream of } H X-1361 \text {, psia } \\
& \Delta P_{H X-1361}=\text { average pressure differential across } H X-1361 \text {, psia } \\
& \qquad V_{1}=\frac{T_{1} P_{\text {STD }} V_{\text {STK }}}{T_{\text {STD }} P_{1}}
\end{aligned}
$$

where

$$
\begin{aligned}
& V_{1}=\begin{array}{l}
\text { average volumetric flow rate after junction downstream of } \\
H X-1361, \text { cfm }
\end{array} \\
& T_{1}=\begin{array}{l}
\text { average absolute temperature after junction downstream of } \\
H X-1361, \text { Rankine }\left({ }^{\circ}+460\right)
\end{array} \\
& P_{1}=\begin{array}{l}
\text { average absolute pressure after junction downstream of } H X-1361, \\
\text { psia (from previous equation) }
\end{array} \\
& P_{\text {STD }}=\text { standard pressure, } 14.696 \text { psia } \\
& T_{\text {STD }}=\text { standard temperature, } 492^{\circ} \mathrm{R} \\
& V_{\text {STK }}=\text { average volumetric flow rate at stack, scfm }
\end{aligned}
$$

Measured variables:

- Volumetric flow rate at stack (FI-3627A, recorded once per shift, V6yymmdd) ${ }^{2}$

- Pressure upstream of HX-1361 (PI-13611, recorded once per shift, roundsheet) 
- Pressure differential across HX-1361 (PDISH-13611, recorded once per shift, roundsheet)

- Temperature downstream of HX-1361 (TISH-13621, recorded once per shift, roundsheet)

(2) Calculate the molar flow rate of water vapor in the air stream.

$$
y_{H_{2} \mathrm{O}}=\frac{P_{H_{2} \mathrm{O}}^{*}}{P_{1}}
$$

where

$y_{\mathrm{H}_{2} \mathrm{O}}=$ mole fraction of water vapor in saturated air at junction.

$\mathrm{P}_{\mathrm{H}_{2} \mathrm{O}}^{*}=$ vapor pressure of water at the temperature of the air downstream of $\mathrm{HX}-1361$ as Tisted in "vapor pressure of water" table, psia.

$P_{1}$ from (1)

where

$$
n_{\mathrm{H}_{2} \mathrm{O}}=y_{\mathrm{H}_{2} \mathrm{O}} \times \frac{P_{1} V_{1}}{R T_{1}}
$$

$$
\begin{aligned}
& n_{H_{2} O}=\text { molar flow rate of water through junction, } 1 \mathrm{~b}-\text { mole/min } \\
& R=\text { gas constant; } 10.73 \frac{\mathrm{ft}^{3} \cdot \mathrm{psia}}{\left[\mathrm{b}-\mathrm{mol}^{\circ} \mathrm{R}\right.} \\
& \mathrm{P}_{1}, V_{1}, T_{1} \text { from (1). }
\end{aligned}
$$

(3) Calculate the volumetric flow of water out of the stack during the material balance period.

$$
\dot{m}_{\mathrm{H}_{2} \mathrm{O}}=n_{\mathrm{H}_{2} \mathrm{O}} \times M_{\mathrm{H}_{2} \mathrm{O}}
$$

where

$$
\begin{aligned}
& \dot{m}_{\mathrm{H}_{2} \mathrm{O}}=\text { mass flow rate of water, } 1 \mathrm{~b} / \mathrm{min} \\
& \mathrm{MW}_{\mathrm{H}_{2} \mathrm{O}}=\text { molecular weight of water }(18 \mathrm{lb} / 1 \mathrm{~b}-\mathrm{mol}) \\
& \mathrm{n}_{\mathrm{H}_{2} \mathrm{O}} \text { from (2) }
\end{aligned}
$$




$$
V_{\mathrm{H}_{2} \mathrm{O}(\mathrm{L})}=\left[\frac{\dot{\mathrm{m}}_{\mathrm{H}_{2} \mathrm{O}}}{62.4 \mathrm{lb} / \mathrm{ft}^{3}}\right]\left(7.481 \mathrm{gal} / \mathrm{ft}^{3}\right)
$$

where

$$
\begin{aligned}
V_{\mathrm{H}_{2} \mathrm{O}(\mathrm{L})}= & \text { volumetric flow rate of water exiting tank } 241-\mathrm{C}-106 \text { out of } \\
& \text { the stack, gal } / \mathrm{min}
\end{aligned}
$$

The total volume of water $\left(V_{6 C-o u t}\right)$ discharged from tank 241-C-106 to 296-C-006 ventilation system exhaust (in gallons):

where

$$
V_{O C \text {-out }}=V_{\left.\mathrm{H}_{2} \mathrm{OCL}\right)} \times \mathrm{t}_{\mathrm{E}} \times 60 \mathrm{~min} / \mathrm{hr}
$$

$t_{E}=\begin{aligned} & \text { total elapsed time between the previous material balance and the } \\ & \text { current material balance in hours }\end{aligned}$

\subsection{2 $V_{6 C-\text { in }}$}

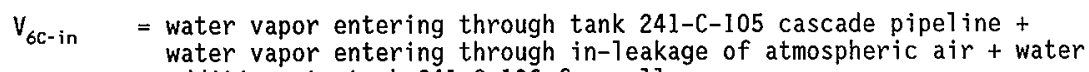
additions to tank $241-C-106$ from al1 sources

\subsubsection{Calculation for Water Vapor Entering Tank 241-C-106 Through the Cascade Pipeline from Tank 241-C-105 $\left(V_{5 c}\right)$}

If the tank 241-C-105 breather filter valve is closed, the assumption is that the volumetric air flow rate through the cascade pipeline is negligible. Consequently, no water vapor is assumed to be entering tank 241-C-106 through the cascade pipeline. In this case, skip to step 3.4.2.2. Otherwise, continue with step 3.4.2.1 as follows.

The calculational sequence for this determination is as follows:

1. Calculate the average volumetric air flow rate through the cascade pipeline.

2. Determine the resulting pressure drop across the $241-C-105$ inlet HEPA filter.

3. Use this pressure drop to calculate a new cascade pipeline air flow rate. 
LOCKHEED MARTIN HANFORD CORPORATION

OBJECTIVE AND PURPOSE:

APPLICABILITY: FOR COMPLIANCE
Manual

Section

Page

Effective Date
HNF-SD-WM-PROC-021

23.0, REV 2

8 of 44

November 15,1998

4. Repeat steps 2 and 3 until the air flow rate and the inlet pressure drop converge.

5. Convert volumetric air flow rate to a molar flow rate.

6. Calculate the molar flow rate of water vapor in the air stream.

7. Calculate the volumetric inflow of water during the material balance period.

(1) Average volumetric air flow rate from tank 241-C-105 to 241-C-106 through cascade line.

This equation is Equation 1-7a from Flow of Fluids Through Valves, Fittings, and Pipe (Crane Co. 1988).

where

$$
q_{h}^{\prime}=114.2 \sqrt{\frac{\left(P_{1}^{\prime}\right)^{2}-\left(P_{2}^{\prime}\right)^{2}}{f L_{m} S_{g}^{T}} \times d^{5}}
$$

$q_{h}^{\prime}=$ air flow rate through cascade Tine from $c-105$ to $c-106$, scfh

$\mathrm{P}_{\mathfrak{i}}^{\prime} \quad=$ average absolute dome pressure in $\mathrm{C}-105$, psia

$P_{2}^{\prime}=$ average absolute dome pressure in $\mathrm{C}-106$, psia

$\mathrm{d}=$ internal diameter of pipe, inches: $3.068 \mathrm{in}$. (3 in. sched 40)

f $\quad=\frac{0.032}{\sqrt[3]{d}}=0.0220$

$\mathrm{L}_{\mathrm{m}}=$ length of cascade pipe, miles: $\frac{30 \mathrm{ft} .}{5,280}=0.00568 \mathrm{mi}$.

$\mathrm{T}=$ average absolute dome temperature in $\mathrm{C}-105$, Rankine $\left({ }^{\circ} \mathrm{F}+460\right)$

$\mathrm{S}_{\mathrm{g}} \quad$ = ratio of molecular weight of gas relative to air (for this case $\mathrm{S}_{\mathrm{g}}=1$ )

Assumptions: For the initial calculation, $C-105$ dome pressure $(P)$ is equal to $14.674 \mathrm{psia}$. For later calculations, use the P calculated during the previous 24-hour period.

Measured variables:

- C-106 dome pressure (PI-1361, recorded every 10 minutes, SyymmddH) 
LOCKHEED MARTIN HANFORD CORPORATION

OBJECTIVE AND PURPOSE:

APPLICABILITY: FOR CONPLIANCE
Nanual

Section

Page

Effective Date November 15, 1998

- C-105 dome temperature, (number of TMACS measurements vary, RAWDATA, C105-TI-R001-06)

- Barometric pressure (recorded once per hour, Hlyymmdd).

(2) Determine the pressure drop required across the $241-C-105$ HEPA filter to achieve this flow rate.

Convert the flow rate to atmospheric conditions:

where

$$
V=\frac{q_{h}^{\prime} T_{\text {atm }} P_{\text {std }}}{60 T_{\text {std }} P_{\text {atm }}}
$$

$V_{1}=$ air flow in $\mathrm{cfm}$ at average atmospheric temperature

$q_{h}^{\prime}=$ volumetric flow rate from (1) above, scfh

$\mathrm{T}^{\mathrm{h}}$ = average absolute atmospheric temperature, ${ }^{\circ} \mathrm{R}$

$\mathrm{T}^{\mathrm{atm}}=$ absolute temperature at standard conditions, $492{ }^{\circ} \mathrm{R}$

$\mathrm{P}_{\mathrm{atm}}^{\mathrm{std}}=$ average absolute atmospheric pressure, $\mathrm{psia}$

$P_{\text {std }}^{\text {atm }}=$ absolute pressure at standard conditions, 14.696 psia

Measured variables:

- Atmospheric temperature (recorded once per hour, Hlyymmdd)

- Barometric pressure (recorded once per hour, Hlyymmdd).

Determine pressure drop for the calculated flow rate (V) from following chart (this chart is for a CC-F filter size). Interpolate if necessary.

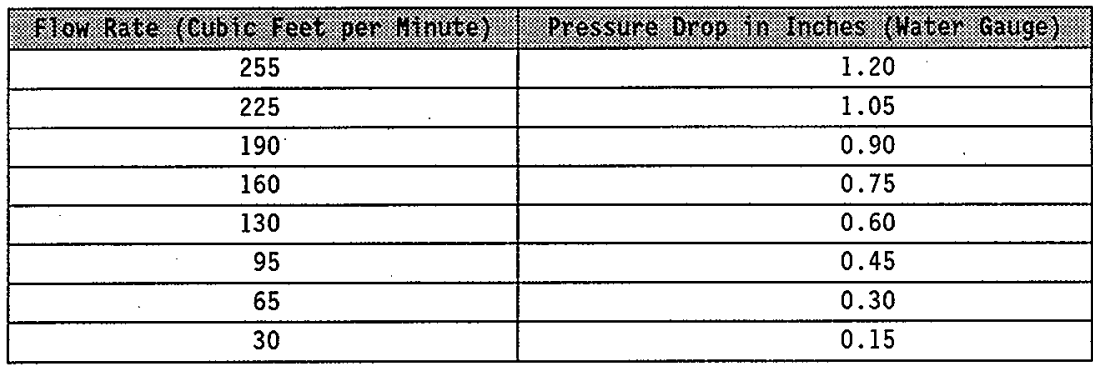


LOCKHEED MARTIN HANFORD CORPORATION

OBJECTIVE AND PURPOSE:

APPLICABILITY: FOR COMPLIANCE
Manual

Section

Page

Effective Date
HNF-SD-WM-PROC-021

23.0, REV 2

10 of 44

November 15,1998

(3) Use this pressure drop to calculate a new cascade pipeline air flow rate.

Convert the pressure drop to a new 241-C-105 dome pressure, psia (mu1tiply by 0.036 and subtract from 14.696)

Substitute this pressure for $P_{1}^{\prime}$ in step (1).

(4) Repeat steps 2 and 3 until the air flow rate and the inlet pressure drop converge.

(5) Convert the final cascade pipe volumetric flow rate to vapor molar flow rate.

$$
n_{\text {air }}=\frac{17 b-m o 1}{359.05 \mathrm{ft}^{3}} \times q_{h}^{\prime}
$$

where

$n_{\text {air }}=$ molar flow rate of air at standard conditions, $1 \mathrm{~b}-\mathrm{mol} / \mathrm{hr}$

(6) Molar flow rate of water vapor in air stream.

where

$$
y_{H_{2} \mathrm{O}}=\frac{P_{H_{2} \mathrm{O}}^{*}}{P_{1}^{\prime}}
$$

$$
\begin{aligned}
& \mathrm{y}_{\mathrm{H}_{2} \mathrm{O}}=\text { mole fraction of water vapor in saturated air at average pressure } \\
& P \text { and average temperature } T \text { of } 241-\mathrm{C}-105 \text { dome space } \\
& \mathrm{P}_{\mathrm{H}_{2} \mathrm{O}}^{*}=\text { vapor pressure of water at average temperature } \mathrm{T} \text { as listed in } \\
& \text { "vapor pressure of water" table, psia } \\
& \mathrm{P}_{1}^{\prime} \text { from step (4) }
\end{aligned}
$$

Assumption: Inlet air from $\mathrm{C}-105$ dome space is saturated.

Measured variables: Same as for (1) above.

where

$$
n_{\mathrm{H}_{2} \mathrm{O}}=y_{\mathrm{H}_{2} \mathrm{O}} \times n_{\text {air }}
$$

$n_{\mathrm{H}_{2} \mathrm{O}}=$ molar flow rate of water into $\mathrm{C}-106,1 \mathrm{~b}-\mathrm{mole} / \mathrm{hr}$ 
LOCKHEED MARTIN HANFORD CORPORATION

OBJECTIVE AND PURPOSE:

APPLICABILITY: FOR COMPLIANCE
Manual

Section

Page

Effective Date
HNF-SD-WM-PROC-021

23.0, REV 2

11 of 44 November 15,1998

$n_{\text {air }}=$ molar flow rate of saturated air into C-106 from (5) above, 1b-mol/hr

(7) Volumetric inflow of water during material balance period.

$$
\dot{\mathrm{m}}_{\mathrm{H}_{2} \mathrm{O}}=\mathrm{n}_{\mathrm{H}_{2} \mathrm{O}} \times M_{\mathrm{H}_{2} \mathrm{O}}
$$

where

$$
\begin{aligned}
& \dot{\mathrm{m}}_{\mathrm{H}_{2} \mathrm{O}}=\text { mass flow rate of water, } 1 \mathrm{~b} / \mathrm{hr} \\
& \mathrm{MW}_{\mathrm{H}_{2} \mathrm{O}}=\text { molecular weight of water }(18 \mathrm{lb} / 1 \mathrm{~b}-\mathrm{mo} 7) \\
& \mathrm{n}_{\mathrm{H}_{2} \mathrm{O}} \text { from }(6) \\
& \qquad V_{\left.\mathrm{H}_{2} \mathrm{OCL}\right)}=\left[\frac{\dot{\mathrm{m}}_{\mathrm{H}_{2} \mathrm{O}}}{62.4 \mathrm{lb} / \mathrm{ft}^{3}}\right]\left(7.481 \mathrm{gal} / \mathrm{ft}^{3}\right)
\end{aligned}
$$

where

$$
\begin{aligned}
V_{\mathrm{H}_{2} \mathrm{O}(\mathrm{L})}= & \text { volumetric flow rate of water entering tank } 241-\mathrm{C}-106 \text { from } \\
& \operatorname{tank} 241-\mathrm{C}-105, \mathrm{gal} / \mathrm{hr}
\end{aligned}
$$

The total volume of water $\left(V_{5 c}\right)$ added from the tank $241-C-105$ vapor stream, in gal1ons:

where

$$
V_{5 C}=V_{H_{2} O(L)} \times t_{E}
$$

$t_{E}=$ total elapsed time between the previous material balance and the current material balance in hours.

\subsubsection{Calculation for Volume of Water Vapor Entering 241-C-106 from Air In-leakage $\left(V_{6 c-a i r}\right)$}

The calculated sequence for this determination is as follows:

1. Calculate the volumetric flow rate of air entering 241-C-106 from air in-leakage and convert it to atmospheric conditions.

2. Calculate the volume of water entering 241-C-106 from air inleakage.

(1) Calculate the volumetric flow rate of air entering $241-C-106$ from air inleakage and convert it to atmospheric conditions.

$$
V_{\text {air }}=V_{\text {sTK }}-V_{\text {cascade }}
$$


where

$$
\begin{aligned}
& V_{\text {air }}=\text { average volumetric flow rate of air entering 241-C-106 from air } \\
& \text { in-leakage at standard conditions, scfm } \\
& V_{\text {STK }}=\text { average volumetric flow rate of air out of the 241-C-106 stack } \\
& \text { at standard conditions (calculated once per day) from Section } \\
& 3.4 .1 \text {, step (1), scfm } \\
& V_{\text {cascade }}=\text { volumetric flow rate of air entering } 241-C-106 \text { from the } \\
& \text { 241-C-105 cascade pipeline at standard conditions (calculated } \\
& \text { once per day), scfm [ } q_{h} \text { from section 3.4.2.1, step (4); } \\
& \left.\left(\mathrm{q}_{\mathrm{h}}^{\prime} /(60 \mathrm{~min} / \mathrm{hr})\right)\right]
\end{aligned}
$$

Convert $V_{\text {air }}$ to atmospheric conditions:

where

$$
V_{\text {ATM }}=\frac{P_{\text {STD }} V_{\text {air }} T_{\text {ATM }}}{P_{\text {ATM }} T_{\text {STO }}}
$$

$$
\begin{aligned}
& \mathrm{V}_{\text {ATM }}=\begin{array}{l}
\text { average volumetric flow rate of air entering } 241-\mathrm{C}-106 \text { from air } \\
\text { in-leakage at atmospheric conditions, cfm }
\end{array} \\
& \mathrm{T}_{\text {ATM }}=\text { average absolute atmospheric temperature, Rankine } \\
& \mathrm{P}_{\text {ATM }}=\text { average absolute atmospheric pressure, psia } \\
& \mathrm{P}_{\text {STD }}=\text { pressure at standard conditions, } 14.696 \mathrm{psia} \\
& \mathrm{T}_{\text {STD }}=\text { temperature at standard conditions, } 492^{\circ} \mathrm{R} \\
& \mathrm{V}_{\text {air }} \text { from (1) }
\end{aligned} .
$$

Measured variables:

- Atmospheric temperature (recorded once per hour, Hlyymmdd)

- Atmospheric pressure (recorded once per hour, Hlyymmdd)

(2) Calculate the volumetric flow of water entering 241-C-106 from air inleakage.

$$
P_{v}=\frac{R H * P_{v}^{*}}{100 \%}
$$

where

$$
\begin{aligned}
& P_{v}=\text { average partial pressure of water in the atmosphere, psia } \\
& R H=\text { average relative humidity, } \%
\end{aligned}
$$


$P_{v}^{*}=$ vapor pressure of water at average atmospheric temperature $\left(T_{A T M}\right)$ as listed in "vapor pressure of water" table, psia

Measured variable: Relative humidity of ambient air (recorded once per hour, Hlyymmdd)

Calculate mole fraction of water vapor:

where

$$
y_{v}=\frac{P_{v}}{P_{\text {ATM }}}
$$

$y_{v}=$ mole fraction of water vapor in air

$P_{V}^{v}$ from above

$P_{\text {AIM }}$ from step (1)

Ca7culate molar flow rate of water entering 241-C-105 from air in-leakage:

where

$$
n_{\text {air }}=\frac{P_{A T M} V_{A T M}}{R T_{A T M}}
$$

$$
\begin{aligned}
& \mathrm{R}=\text { gas constant; } 10.73 \frac{\mathrm{ft}^{3} \cdot \mathrm{psia}}{1 \mathrm{~b}-\mathrm{mol}^{\circ} \mathrm{R}} \\
& \mathrm{P}_{\mathrm{ATM}}, \mathrm{V}_{\mathrm{ATM}}, \mathrm{T}_{\mathrm{ATM}} \text { from (1) } \\
& n_{\mathrm{air}}=\text { molar flow rate of air in-leakage, } 1 \mathrm{~b}-\mathrm{mol} / \mathrm{min} \\
& \mathrm{n}_{\mathrm{H}_{\mathrm{Z}} \mathrm{O}}=y_{\mathrm{V}} \mathrm{n}_{\mathrm{air}}
\end{aligned}
$$

where

$$
\begin{aligned}
& n_{H_{z} \mathrm{O}}=\text { molar flow rate of water from air in-leakage, } 1 \mathrm{~b}-\mathrm{mol} / \mathrm{min} \\
& n_{\mathrm{air}}, y_{v} \text { from above }
\end{aligned}
$$

Converting molar flow rate to volumetric flow rate:

$$
\dot{m}_{\mathrm{H}_{2} \mathrm{O}}=n_{\mathrm{H}_{2} \mathrm{O}} \times M_{\mathrm{H}_{2} \mathrm{O}}
$$

where

$$
\begin{aligned}
& n_{\mathrm{H}_{2} \mathrm{O}} \text { from above } \\
& \dot{\mathrm{m}}_{\mathrm{H}_{2} \mathrm{O}}=\text { mass flow rate of water, } 1 \mathrm{~b} / \mathrm{min} \\
& \mathrm{MW}_{\mathrm{H}_{2} \mathrm{O}}=\text { molecular weight of water }(18 \mathrm{lb} / 7 \mathrm{~b}-\mathrm{mol})
\end{aligned}
$$




$$
V_{\mathrm{H}_{2} \mathrm{O}(\mathrm{L})}=\left[\frac{\dot{\mathrm{m}}_{\mathrm{H}_{2} \mathrm{O}}}{62.41 \mathrm{~b} / \mathrm{ft}^{3}}\right]\left(7.481 \mathrm{gal} / \mathrm{ft}^{3}\right)
$$

where

$$
\begin{aligned}
V_{\mathrm{H}_{2} \mathrm{O}(\mathrm{L})=} & \text { volumetric flow rate of water entering tank } 241-\mathrm{C}-105 \text { from } \\
& \text { air in-leakage, gal/min }
\end{aligned}
$$

The total volume of water entering 241-C-106 from air in-leakage:

where

$$
V_{S C \text {-air }}=V_{\left.\mathrm{H}_{2} \mathrm{OCL}\right)} \times t_{\mathrm{E}} \times 60 \mathrm{~min} / \mathrm{hr}
$$

$$
\begin{aligned}
& t_{E}=\text { total elapsed time between the previous material balance and the } \\
& \begin{aligned}
& V_{6 c-a i r}= \text { total volume of water entering } 241-C-106 \text { from air in-leakage, } \\
& \text { gal. }
\end{aligned}
\end{aligned}
$$

\subsubsection{Water Additions to Tank 241-C-106 from All Sources}

Water additions include the following point sources:

- FQI-1361A; determined by difference in totalizer readings

- SN-200 flush water additions from 241-AY-02E Sluice Pit

- SN-100 flush water additions from 241-AY-02A Pump Pit

- ENRAF ${ }^{T M}$ level gauge (riser 1) flush water additions

- HX-1361 Condenser shell side water/cleaning solution flushes

- Chilled water supply drainage to 241-C-91 Process Building Seal Pot drain; determined by difference in LG-1366 level gauge readings

- 241-C-06C Sluice Pit water flushes/maintenance activities

- 241-C-06A Pump Pit water flushes/maintenance activities

- All other water additions made to tank 241-C-106.

These additions must be summed and inciuded in $V_{6 c-i n}$. 
LOCKHEED MARTIN HANFORD CORPORATION

OBJECTIVE AND PURPOSE:

APPLICABILITY: FOR COMPLIANCE
Manual

Section

Page

Effective Date
HNF-SD-WM-PROC-021

23.0, REV 2 15 of 44

\section{$3,4.3 V_{6 c-m}$}

$$
\begin{aligned}
V_{6 c-m}= & \text { volume of any chemical additions or other materials added to } \\
& \operatorname{tank} 241-C-106 ; \text { nominally }=0
\end{aligned}
$$

\section{$3,4.4 V_{2 A Y-o u t}$}

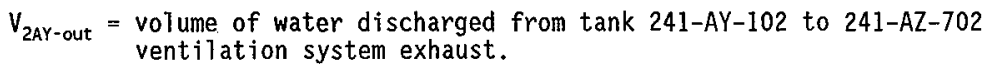

The calculational sequence for this determination is as follows:

1. Convert the measured volumetric tank 241-AY-102 exhaust flow rate to a molar flow rate.

2. Calculate the moles of water present in the exhaust gas.

3. Calculate the volumetric flow rate of water leaving the tank 241-AY-102 exhaust.

(1) Convert the measured volumetric tank 241-AY-102 exhaust flow rate to a molar flow rate.

where

$$
\dot{n}=\frac{\dot{V}}{359 \mathrm{ft}^{3} / \mathrm{lb}-\mathrm{mol}_{\mathrm{T}}}
$$

$\dot{n}=$ average molar flow rate of exhaust gas, $1 \mathrm{~b}-\mathrm{mol} / \mathrm{min}$.

$\dot{V}=$ average volumetric flow rate of tank 241-AY-102 exhaust, scfm

Measured variables: 241-AY-102 exhaust air flow (FI-AY2KI-2, recorded once every 2 minutes, VyymmddH)

(2) Calculate the moles of water present in the exhaust gas.

where

$$
P_{v}=\frac{R H * P_{v}^{*}}{100 \%}
$$

$P_{v} \quad=$ average partial pressure of water in the exhaust gas, psia

$\mathrm{P}_{\mathrm{v}}^{*} \quad$ = vapor pressure of water at the average exhaust air temperature as listed in the "vapor pressure of water" table, psia

$\mathrm{RH}=$ average relative humidity of exhaust gas, $\%$ 
LOCKHEED MARTIN HANFORD CORPORATION

OBJECTIVE AND PURPOSE:

APPLICABILITY: FOR COYPLIANCE
Manual

Section

Page

Effective Date
HNF-SD-WM-PROC-021

23.0 , REV 2 16 of 44

November 15,1998

Measured variable:

- Relative humidity in 241-AY-102 exhaust (AI-0623, recorded once every 2 minutes, VyymmddH)

- Air temperature in 241-AY-102 exhaust (TI-AY2K48-1B, recorded once every two minutes, VyymmddH)

$$
y_{v}=\frac{P_{v}}{P}
$$

where

$y_{v}=$ mole fraction of water in the exhaust gas

$P^{v}=$ absolute average pressure at the 241-AY-102 tank exhaust, psia

$P_{v}$ from above

Assumption: Pressure in tank exhaust line is equal to pressure in the tank dome

Measured variable: Pressure in 241-AY-102 tank dome (PI-AY2-K1-1, recorded once per shift, roundsheet)

where

$$
n_{H_{2} \mathrm{O}}=y_{v} \dot{n}
$$

$\mathrm{n}_{\mathrm{H}_{2} \mathrm{O}}=$ molar flow rate of water in exhaust gas, 1b-mol/min

$\dot{n}$ from (1)

$y_{v}$ from above

(3) Calculate the volumetric flow rate of water leaving the 241-AY-102 exhaust.

$$
\dot{\mathrm{m}}_{\mathrm{H}_{2} \mathrm{O}}=\mathrm{n}_{\mathrm{H}_{2} \mathrm{O}} \times M_{\mathrm{H}_{2} \mathrm{O}}
$$

where

$$
\begin{aligned}
& \dot{\mathrm{m}}_{\mathrm{H}_{2} \mathrm{O}}=\text { mass flow rate of water leaving the tank 241-AY-102 exhaust, } \\
& 1 \mathrm{~b} / \mathrm{min} \\
& \mathrm{MW}_{\mathrm{H}_{2} \mathrm{O}}=\text { molecular weight of water, } 18 \frac{1 \mathrm{~b}}{1 \mathrm{~b}-\mathrm{mo}]} \\
& n_{\mathrm{H}_{2} \mathrm{O}} \text { from (2) }
\end{aligned}
$$


where

$$
V_{\mathrm{H}_{2} \mathrm{O}(\mathrm{L})}=\left[\frac{\dot{\mathrm{m}}_{\mathrm{H}_{2} \mathrm{O}}}{62,41 \mathrm{~b} / \mathrm{ft}^{3}}\right]\left(7.481 \mathrm{gal} / \mathrm{ft}^{3}\right)
$$

$$
\begin{aligned}
\dot{\mathrm{m}}_{\mathrm{H}_{2} \mathrm{O}} \text { from above } & \\
\mathrm{V}_{\mathrm{H}_{2} \mathrm{O}(\mathrm{L})=} & \text { average volumetric flow rate of water leaving the 241-AY-102 } \\
& \text { tank exhaust, } \mathrm{gal} / \mathrm{min}
\end{aligned}
$$

The total volume of water leaving in the tank 241-AY-102 exhaust in gallons $\left(V_{2 A Y-o u t}\right)$ :

$$
V_{2 A Y-\text { out }}=V_{\mathrm{H}_{2} \mathrm{O}(\mathrm{L})} \times t_{\mathrm{E}} \times 60 \mathrm{~min} / \mathrm{hr}
$$

where

$t_{E}=$ total elapsed time between the previous material balance and the current material balance in hours.

\subsection{5 $\quad V_{2 A Y-i n}$}

$V_{2 A Y-i n}=$ volume of water entering through in-leakage of atmospheric air + water additions to tank 24l-AY-102 from all sources

\subsubsection{Water Vapor Entering Through In-leakage of Atmospheric Air $\left(V_{2 A Y-a i r}\right)$}

1. Calculate how much of the gas exiting the tank 241-AY-102 exhaust stack is dry air.

2. Calculate the molar flow rate of water in the inlet air.

3. Convert the molar flow rate to a volumetric flow rate.

(1) Calculate how much of the gas exiting the exhaust is dry air.

where

$$
n_{\mathrm{air}}=\dot{\mathrm{n}}-\mathrm{n}_{\mathrm{H}_{2} \mathrm{O}}
$$

$n_{\mathrm{air}}=$ molar f1ow rate of air at 241-AY-102 exhaust, 1b-mol/min

$\dot{\mathrm{n}}=$ total molar flow rate at $241-\mathrm{AY}-102$ exhaust, $1 \mathrm{~b}-\mathrm{mol} / \mathrm{min}$ from Section 3.4.4, step (1) 
(2) Calculate the molar flow rate of water in the inlet air.

where

$$
P_{v}=\frac{R H * P_{v}^{*}}{100 \%}
$$

$P_{v} \quad=$ average partial pressure of water in the inlet air, psia

$\mathrm{RH} \quad=$ average relative humidity, $\%$

$P_{v}^{*}=$ vapor pressure of water at average inlet air temperature as listed in the "vapor pressure of water" table, psia

Measured variable: Atmospheric relative humidity (recorded once per hour, Hlyymmdd)

where

$$
y_{v}=\frac{P_{v}}{P_{A T M}}
$$

$y_{v}=$ mole fraction of water in the inlet air

$P_{v}$ from above

$P_{\text {ATM }}^{V}=$ average absolute atmospheric pressure, psia

Measured variable: Atmospheric pressure (recorded once per hour, Hiyymmdd)

$$
n_{\text {water }}=\frac{y_{v} n_{\text {air }}}{1-y_{v}}
$$

where

$$
n_{\text {water }}=\underset{\text { molar flow rate of water into } 241-A Y-102 \text { carried with the inlet }}{\text { air, } 1 \mathrm{~b}-\mathrm{mole} / \mathrm{min}}
$$

(3) Convert the molar flow rate to a volumetric flow rate.

$$
\dot{m}_{\mathrm{H}_{2} \mathrm{O}}=n_{\text {water }} \times \mathrm{MW}_{\mathrm{H}_{2} \mathrm{O}}
$$

where

$$
\begin{aligned}
\dot{\mathrm{m}}_{\mathrm{H}_{2} \mathrm{O}}= & \text { mass flow rate of water entering } 241-\mathrm{AY}-102 \text { in the inlet air, } \\
& 1 \mathrm{~b} / \mathrm{min}
\end{aligned}
$$


$M W_{H_{2} \mathrm{O}}=$ molecular weight of water, $18 \frac{1 \mathrm{~b}}{1 \mathrm{~b}-\mathrm{mol}}$

$n_{\text {water }}$ from (2)

$$
V_{\mathrm{H}_{2} \mathrm{O}(\mathrm{L})}=\left[\frac{\dot{\mathrm{m}}_{\mathrm{H}_{2} \mathrm{O}}}{62.4 \mathrm{lb} / \mathrm{ft}^{3}}\right]\left(7.481 \mathrm{gal} / \mathrm{ft}^{3}\right)
$$

where

$V_{\mathrm{H}_{2} \mathrm{O}(\mathrm{L})}=$ average volumetric flow rate of water entering 241-AY-102 from the inlet air, gal/min

$$
V_{2 A Y-a i r}=V_{H_{2} O(L)} \times t_{E} \times 60 \mathrm{~min} / \mathrm{hr}
$$

where

$$
\begin{aligned}
t_{E}= & \text { total elapsed time between the previous material balance and } \\
& \text { the current material balance in hours }
\end{aligned}
$$

\subsubsection{Water Additions to Tank 241-AY-102 from All Sources}

Water additions include the following point sources:

- ENRAF $^{T M}$ level gauge (riser 22A) flush water additions

- ENRAF ${ }^{T M}$ densitometer (riser 15S) flush water additions

- 241-AY-02E Sluice Pit water flushes/maintenance activities

- 241-AY-02A Pump Pit water flushes/maintenance activities

- All other water additions made to tank 241-AY-102.

These additions must be summed and included in $V_{2 A Y-i n}$.

\subsection{6 $\quad V_{2 A Y-m}$$$
\begin{aligned}
V_{2 A Y-m}= & \text { volume of any chemical additions or other materials added to } \\
& \operatorname{tank} 241-A Y-102 ; \text { nominally }=0
\end{aligned}
$$

3.4.7 $\Delta \mathbf{V}_{6 \mathrm{C}-\mathrm{T}}$

$$
\Delta V_{6 C-T}=\left[(2,750)\left(\text { ENRAF }_{6 C-c}\right)+12,500\right]\left(1-D_{c f-c} / D_{c f-p}\right)_{6 C}
$$


where

$$
\begin{aligned}
& \text { ENRAF }_{6 C-c}=\begin{array}{l}
\text { current tank } 241-C-106 \text { liquid level from the riser } 1 \text { ENRAF } \\
\text { level gauge }
\end{array} \\
& \left(D_{c f-c}\right)_{6 c}=\text { density correction factor at current tank 241-C-106 } \\
& \text { average waste temperature determined from Figure 4-7 of } \\
& \text { Process Control Plan } \\
& \left(D_{c f-p}\right) 6 C=\text { density correction factor at previous material balance } \\
& \text { tank 241-C-106 average waste temperature determined from } \\
& \text { Figure 4-7 of Process Control PTan }
\end{aligned}
$$

\subsection{8 $\Delta \mathbf{V}_{2 A Y-T}$}

$$
\Delta V_{2 A Y-T}=(2,750)\left(E_{N R A F} 2 A Y-c\right)\left(1-D_{c f-c} / D_{c f-p}\right)_{2 A Y}
$$

where

$$
\begin{aligned}
& \text { ENRAF }_{2 A Y-c}=\text { current tank 241-AY-102 liquid level from the riser } 22 \mathrm{~A} \\
& \text { ENRAF }^{\mathrm{TM}} \text { level gauge (LI-602C) } \\
& \left(D_{c f-c}\right)_{2 A Y}=\text { density correction factor at current tank 241-AY-102 average } \\
& \text { waste temperature determined from Figure 4-7 of Process } \\
& \text { Control Plan } \\
& \left(D_{c f-p}\right)_{2 A Y}=\text { density correction factor at previous material balance } \\
& \text { tank 241-AY-102 average waste temperature determined from } \\
& \text { Figure 4-7 of Process Control Plan }
\end{aligned}
$$

\subsection{9 $\Delta \mathrm{V}_{2 \mathrm{AY}-\mathrm{sot}}$}

$$
\Delta V_{2 A Y-s o l}=\left[(2,750)\left(E N_{R A F} F_{2 A Y-c}\right)-22,000\right]\left[1-\left(\operatorname{ENRAF}_{d m-c}\right)\left(D_{c f-p} / D_{c f-c}\right)_{2 A Y} / E N_{R A F}\right]
$$

where

$$
\begin{aligned}
\text { ENRAF }_{\mathrm{dm}-\mathrm{c}}= & \begin{array}{l}
\text { current tank 241-AY-102 supernatant density from the } \\
\text { riser } 15 S \text { ENRAF }
\end{array} \\
\text { ENRAF }_{\mathrm{dm}-\mathrm{p}}= & \begin{array}{l}
\text { previous material balance tank } 241-\mathrm{AY}-102 \text { supernatant } \\
\text { density from the riser } 15 \mathrm{SNRAF}^{\mathrm{TM}} \text { densitometer (DI-602A-X) }
\end{array}
\end{aligned}
$$


LOCKHEED MARTIN HANFORD CORPORATION

OBJECTIVE AND PURPOSE:

APPLICABILITY: FOR COMPLIANCE
Manual

Section

Page

Effective Date
HNF-SD-WM-PROC-021

23.0, REV 2

21 of 44

November 15, 1998

\subsection{MASS TRANSFER AND HEAT LOAD CALCULATIONS}

\subsection{Requirements}

Administrative Control (AC) 5.12 and Addendum $I$ of the BIO require that material balance calculations be performed every 24 hours during sluicing to ensure that $\mathrm{planned}$ transfer parameters are consistent with existing tank conditions. The material balance shall include (a) total material. transferred, (b) heat generation rate, and (c) solids loading calculation. The 24-hour period begins when a sluice batch is initiated. Process Engineering will perform the required calculations. The results of the initial material balance will be communicated to the shift manager with a telephone ca11. The call will be followed by a cc:mail to the shift manager, the TRG, and Process Engineering manager within the 24-hour period. A final material balance for each batch will be determined once all of the data have been received. After the sluicing is complete, the calculations will be documented in a supporting document.

\subsection{Methods of Determining Mass Transfer and Heat Load}

Upon completion of each batch, monitoring takes $p l a c e$ and verification requirements are met before the next sluice batch is performed. The performance of the slurry pipeline mass flowmeter is verified and an estimate of the heat load in the transferred waste is determined after every batch, whether or not the batch corresponds to the completion of an increment or campaign.

The primary focus of this post-batch evaluation is to obtain an independent measure of the mass and volume of sludge received by tank 241-AY-102 during the batch. The primary mass transfer verification method uses the ENRAF ${ }^{\text {TM }}$ densitometer installed on riser 15-E of tank 241-AY-102. Grab samples taken from riser 15-N supplement the ENRAF ${ }^{\mathrm{TM}}$ results. Additionally, the Multifunction Instrument Tree (MIT) (fixed elements and validation probe) will be monitored to provide supporting evidence of the liquid-solid interface.

The heat generation rate will be determined using the mass of solids transferred and the cesium-137 (Cs-137) and strontium-90 (Sr-90) concentrations analyzed from grab samples. An initial heat generation rate will be calculated from the mass flowmeter measurement and the grab sample results from previous batches. After the analyses are received from the grab samples for the current batch, the final heat generation rate can be determined.

The monitoring period between batches is a minimum of three days after each batch; the nominal duration varies from five to twelve days. A distinct supernatant-sludge interface is expected to form during the initial three-day settling period. Follow-on measurements with the ENRAF ${ }^{T M}$ densitometer and the MIT validation probe, and data evaluation extend the monitoring an additional one or two days. Concurrent grab sampling and analysis and a TRG review and 
concurrence of subsequent sluicing plans will extend for nine days early on during the sluicing (i.e., sluice batches making up the first increment). As sluicing becomes more routine, the need for confirmatory grab sample results before restarting sluicing and the frequency of TRG reviews of mass transfer results are anticipated to diminish. However, confirmatory grab sample results and a TRG review are required between campaigns (Carothers et al. 1998).

Mass Flowmeter. The 241-AY-02A pit mass flowmeter has been installed as the principal solids loading process control instrument. This instrument indicates the slurry mass flow rate and average slurry density at the receiver tank end of the transfer line. The slurry solids mass loading can be determined from the output of the mass flowmeter. Knowledge of the carrier solution density (i.e., tank 241-AY-102 supernatant density), the solids particulate density, and the measured slurry density are required to determine slurry solids loading. This parameter is displayed in the M0-211 control room and can be monitored to control solids loading during a sluicing batch (Carothers et al. 1998).

Uncertainty in mass transfer has been determined for the mass flowmeter. The accuracy of the flowmeter at the nominal process solids loading (10 to 20 wt\%) and volumetric flow rate $(300$ to $330 \mathrm{gal} / \mathrm{min})$ is estimated at $\pm 0.11 \%$ (Carothers et a1. 1998).

The uncertainty in the solids volume fraction in the slurry as measured by the mass flowmeter was determined to be \pm 3 vol\% based on the derivation for the standard deviation and applicable parameter values. This volume fraction uncertainty translates into a mass fraction uncertainty of approximately $\pm 7 w t \%$. Consequently, the uncertainty in the mass flowmeter is acceptable for the flowmeter to be useful in controlling the slurry solids loading to the $30 \mathrm{wt} \%$ 1imit. At the nominal 10 to $20 \mathrm{wt} \%$ operating range, the solids loading will remain below the safety limit (Carothers et al. 1998).

The mass flowmeter measures the mass of the slurry transferred thereby enabling the control of the total amount of solids. The device is configured to measure mass flow rate and density. It is equipped with a "net flow" computer that converts instrument measurements into a total mass of solids transferred through the slurry line (Carothers et al. 1998).

The mass flowmeter has an uncertainty of 40 to $50 \%$ in determining the solids mass transfer at a solids loading of less than 10 wt\% (equivalent to 4 vol\%). Consequently the flowmeter should not be used as the primary mass transfer measurement during the first campaign or when solids loading of a batch averages $<10$ vol\%. When the batch solids loading is from 10 to $20 \mathrm{wt} \%$ (4 to 10 vol\%), the mass flowmeter uncertainty will be between 20 to $40 \%$.

Therefore, the mass flowmeter may not be capable of serving as the primary measurement method for determining mass transfer for each sluicing batch.

ENRAF Densitometer. The ENRAF ${ }^{\mathrm{TM}}$ densitometer in tank 241-AY-102 is used to obtain two key pieces of information: the density profile of the waste below the supernatant surface and the level of the supernatant-sludge interface. In 
Manual

Section

OBJECTIVE AND PURPOSE:

APPLICABILITY: FOR COMPLIANCE
Page

Effective Date
HNF-SD-WM-PROC-021

23.0, REV 2

23 of 44

November 15, 1998

addition to obtaining a measure of the clarified supernatant density immediately below the supernatant surface, the density of the settling solids region will be measured until the sludge mechanical strength prohibits further displacer descent (i.e., when neutral buoyancy is reached). For supernatantsolids interface level measurement, the wire tension setting will be maximized to enhance gauge performance and guard against excavating a depression in the solids bed, which would compromise the accuracy of the interface measurement (Carothers et a1. 1998).

The uncertainty in the ENRAF ${ }^{T M}$ densitometer's ability to measure the sludge transferred from tank $241-C-106$ based on measurement taken in tank 241-AY-102 after the transfer has been evaluated. When the solids settling fraction in tank $241-A Y-102$ is $<20 \%$, the uncertainty in the sludge transferred remains below $20 \%$ even with significant nonuniformity in the settled solids level. For intermediate settling fractions and nonuniformity fractions, the uncertainty generally fal7s below $30 \%$. Therefore, the best results are obtained if the densitometer measurement is made immediately after completing each batch when the highest possible fraction of solids is still suspended (Carothers et a7. 1998).

Grab Samples. Grab samples are obtained from the tank to refine the estimated amount of tank 241-C-106 sludge that has been transferred and to estimate the radiogenic heat associated with the sludge. Carothers et al. (1998) discusses the process control sampling requirements and schedule in more detail.

The precision and accuracy of the $C_{s-137}$ analyses are $\leq 20 \%$ and $\pm 20 \%$, respectively. The precision and accuracy of the $S r-90$ analyses are $\leq 20 \%$ and $\pm 25 \%$, respectively (Sasaki 1998).

Uncertainty in determining the solids mass transfer from grab sample data is very high largely due to uncertainties in the analytical data and those from the assumptions made in the mass transfer calculation. Assumptions that must be made include: the average starting sludge level is uniform across the tank, the new sludge level is the same over the cross-section of the tank, the physical properties of the sludge are uniform throughout, and the grab samples taken in the sludge are representative of the sludge that was transferred.

Multifunction Instrument Tree. The MIT provides a second measurement of the supernatant-sludge interface in tank 241-AY-102. In addition to the stationary thermocouples that measure temperature at 22 elevations, the MIT is equipped with a validation temperature probe that can be positioned at any elevation. Establishing the initial stages of a parabolic temperature profile that identifies the nonconvective layer will require at least a few weeks once sluicing starts. The MIT provides a vertical temperature profile through the waste. The approximate elevation of the interface is determined by monitoring fixed thermocouples to detect the different temperature profiles between the solid and liquid phases. Monitoring the temperatures between fixed thermocouples using the validation probe enables a more accurate identification of the interface elevation using changes in the slope of the 
temperature profile data. Even so, the layer depth cannot be determined with sufficient precision from the temperature profile to quantify a small volume of solids transfer (Carothers et aT. 1998).

\subsection{Criteria for Determining Completion of WRSS}

The primary objectives of the tank 241-C-106 WRSS operation are to eliminate the radiogenic high-heat safety issue and to demonstrate a technology for retrieval of single-shell tank wastes. Therefore, the WRSS process will be considered complete when the following conditions are met (Carothers et al. 1998).

1. Sufficient heat-generating waste has been transferred from tank 241-C-106 to tank 241-AY-102 to permit water additions to tank 241-C-106 to be discontinued. Removing the first $0.6 \mathrm{~m} \mathrm{(2} \mathrm{ft.)} \mathrm{of}$ sludge from tank $241-C-106$ is anticipated to meet this criterion.

2. The maximum feasible amount of waste has been removed from tank 241-C-106. A series of goals defining this criterion are:

- Remove sufficient waste so that tank 241-C-106 may be considered stabilized. This requires that less than $18,900 \mathrm{~L}(5,000 \mathrm{gal}$. of supernatant and less than $189,000 \mathrm{~L}(50,000 \mathrm{gal}$.$) of$ interstitial Tiquid remain in the tank.

- Remove sufficient waste to reduce the heat load to less than $7.6 \mathrm{~kW}(26,000 \mathrm{Btu} / \mathrm{hr})$ which will. eliminate the need for ventilation and remove the high heat tank designation. It is estimated that removal of $1.6 \mathrm{~m}(5.2 \mathrm{ft}$.) of sludge from tank 241-C-106 will satisfy this goal.

- Remove $95 \%$ of the waste from tank 241-C-106.

\subsection{Calculation of Sludge Transferred}

\subsubsection{Initial Material Balance Estimate}

An initial estimate of the volume of sludge transferred will be done to satisfy the AC 5.12 24-hour requirement. The only data available within 24 hours will be the mass flowmeter data. A final mass transfer estimate will be determined once all of the data have been received.

The 241-AY-02A pit mass flowmeter is used to determine the siurry mass flow rate and the average slurry density at the receiver tank end of the transfer line. The flowmeter parameters are calculated and recorded every ten minutes in the Data Acquisition System (DAS) file for WRSS slurry data. 


\section{Mass of Solids Transferred}

$$
M_{S D+F}=C_{M} M_{S}
$$

where:

$$
\begin{aligned}
& M_{S D-F}=\text { Mass of solids based on the flowmeter, } 1 \mathrm{~b} . \\
& C_{M}=\begin{array}{l}
\text { Average mass fraction of solids in slurry (see calculation } \\
\text { in Section } 4.5, \text { calculated and recorded by DAS) }
\end{array} \\
& M_{S}=\text { Mass of slurry transferred, } 1 \mathrm{~b} .
\end{aligned}
$$

Measured variables:

- Total mass transferred, reset for each batch (DQ1-0621B, recorded every 10 minutes, SyymmddH)

Convert mass of solids to mass of sludge

$$
M_{S L+}=\frac{M_{S D+}}{1-\left(\frac{W_{6 C S L}}{W_{6 C I L}}\right)}
$$

where:

$$
\begin{aligned}
& M_{S L-F}=\text { Mass of sludge transferred based on flowmeter, } 1 \mathrm{~b} \text {. } \\
& W_{6 \mathrm{CsL}}=\begin{array}{l}
\text { Weight percent water in tank } 241-\mathrm{C}-106 \text { sludge, } 47.2 \% \\
\text { (Carothers et al. 1998) }
\end{array} \\
& W_{6 C I L}=\text { Weight percent water in tank 241-C-106 interstitial liquid, }
\end{aligned}
$$

Convert mass of sludge to volume of sludge

where:

$$
v_{\mathrm{SL}+}=\frac{M_{\mathrm{SL}+}}{\rho_{6 \mathrm{cSL}}}\left[\frac{453,593 \mathrm{~g}}{\mathrm{~Tb}}\right]\left(\frac{\mathrm{ft}^{3}}{28,317 \mathrm{~mL}}\right)
$$

$$
\begin{aligned}
& V_{\mathrm{SL}-\mathrm{F}}=\text { Volume of sludge transferred based on flowmeter, } \mathrm{ft}^{3} \\
& \begin{aligned}
& \rho_{\text {6csL }}= \text { Bulk density of tank } 241-\mathrm{C}-106 \mathrm{~s} 1 \text { udge, } 1.55 \mathrm{~g} / \mathrm{mL} \text { (Carothers } \\
& \text { et al. 1998) }
\end{aligned}
\end{aligned}
$$


LOCKHEED MARTIN HANFORD CORPORATION

OBJECTIVE AND PURPOSE:

APPLICABILITY: FOR COMPLIANCE
Manua 1

Section

HNF-SD-WM-PROC-021

Page

Effective Date
23.0, REV 2 26 of 44 November 15,1998

\subsubsection{Material Balance Based on ENRAF Densitometer}

The measurements taken with the ENRAF ${ }^{T M}$ densitometer are used to determine the amount of sludge transferred from tank 241-C-106 to 241-AY-102. This estimate cannot be completed within 24 hours because the formation of the supernatantsludge interface is expected to take up to three days. ENRAF ${ }^{\mathrm{TM}}$ densitometer measurements will be obtained once per shift over this three-day period.

Mass of Sludge Removed from Tank 241-C-106

$$
\Delta H_{60} \rho_{6 \mathrm{CSL}}=\left(\mathrm{H}_{\mathrm{S}}-\mathrm{H}_{0}\right) \rho_{\mathrm{S}}+\left(\mathrm{H}_{\mathrm{w}}-\mathrm{H}_{\mathrm{S}}\right) \rho_{\mathrm{LS}}-\left(\mathrm{H}_{\mathrm{WO}}-\mathrm{H}_{0}\right) \rho_{\mathrm{LO}}
$$

where:

$$
\begin{aligned}
& \Delta \mathrm{H}_{6 \mathrm{C}} \quad=\text { Depth of sludge removed from tank 241-C-106 during transfer, } \\
& \text { inches } \\
& \mathrm{H}_{\mathrm{s}}=\text { Average height of settled solids layer in tank 241-AY-102 after } \\
& \text { transfer, inches } \\
& \mathrm{H}_{0} \quad=\text { Average height of original sludge layer before transfer, inches } \\
& \rho_{\mathrm{s}} \quad=\text { Bulk density of the newly settled solids, } \mathrm{g} / \mathrm{mL} \\
& \rho_{\mathrm{LS}} \quad=\text { Density of the slurry suspended solids after transfer, } \mathrm{g} / \mathrm{mL} \\
& \rho_{\text {Lo }} \quad=\text { Initial liquid density (without suspended solids) before } \\
& \text { transfer, } \mathrm{g} / \mathrm{mL} \\
& \mathrm{H}_{\mathrm{W}} \quad=\text { Waste level in tank 241-AY-102 after batch is transferred, }
\end{aligned}
$$

Assumptions:

- the ENRAF ${ }^{\mathrm{TM}}$ density profile in tank 241-AY-102 wi1l be taken quickly after completing the batch, therefore there is no significant solids settling $\left(\mathrm{H}_{\mathrm{s}}=\mathrm{H}_{0}\right)$.

- density of slurry suspended solids after sluicing $\left(\rho_{L S}\right)$ is the average density of slurry suspended solids after batch is complete.

Therefore:

$$
\Delta \mathrm{H}_{60} \rho_{6 \mathrm{CSL}}=\left[\left(\mathrm{H}_{\mathrm{W}}-\mathrm{H}_{0}\right) \rho_{\mathrm{LS}}-\left(\mathrm{H}_{\mathrm{LO}}-\mathrm{H}_{0}\right) \rho_{\mathrm{LO}}\right]\left[\frac{2,750 \mathrm{gal}}{\text { inch }}\right)\left(\frac{1 \mathrm{~b}}{453.493 \mathrm{~g}}\right)\left(\frac{3,785 \mathrm{~mL}}{\mathrm{gal}}\right)
$$


Measured variables:

- Average height of originat sludge layer before transfer ( 8 inches for first batch, Carothers et a1. 1998), sludge layer measured by densitometer (DI-602A-1 through DI-602A-N, recorded after each batch, D2yymmdd)

- Riser 22A ENRAF TM level indicator before and after transfer (LI-062C, recorded every 10 minutes, SyymmddH)

- Density of liquid (without suspended solids) before transfer (estimate from densitometer and grab sample data, recorded after each batch)

- Density of the slurry suspended solids after sluicing (DI-602A-1 through DI-602A-N, recorded after each batch, D2yymmdd)

Calculate volume of sludge removed from tank $241-C-106$

$$
\left.V_{S L E}=\frac{\Delta H_{6 C_{6 C L L}}}{\rho_{6 \mathrm{CSL}}}\left[\frac{453.593 \mathrm{~g}}{1 \mathrm{~b}}\right] \cdot \frac{\mathrm{ft}^{3}}{28,317 \mathrm{~mL}}\right]
$$

where:

$V_{\mathrm{SL}-\mathrm{E}}=\underset{\substack{\mathrm{ft}^{3} \\ \text { Volume of sludge transferred based on ENRAF }}}{\mathrm{TM}}$ densitometer,

\subsubsection{Material Balance Based on Grab Samples}

Grab samples are obtained from the tank to refine the estimated amount of tank 241-C-106 sludge that has been transferred. The following analyses will be done on grab samples taken after each batch.

- \% settled solids in slurry

- density in slurry

- \% centrifuged solids

- density of centrifuged solids

- density of decantate 
Mass of S7udge Transferred

$$
\Delta \mathrm{H}_{6 \mathrm{C}} \rho_{6 \mathrm{CSL}}=\frac{\left(\mathrm{H}_{\mathrm{s}}-\mathrm{H}_{0}\right) \rho_{\mathrm{s}}-\left(\mathrm{H}_{\mathrm{S}}-\mathrm{H}_{0}\right)\left[1-\frac{\%_{\mathrm{CS}}}{100}\right] \rho_{\mathrm{IL}}}{1-\left(\frac{\mathrm{W}_{\text {GCSL }}}{\mathrm{W}_{\text {GCIL }}}\right]}\left[\frac{2,750 \mathrm{gal}}{\text { inch }}\right]\left[\frac{1 \mathrm{~b}}{453.493 \mathrm{~g}}\right)\left[\frac{3,785 \mathrm{~mL}}{\mathrm{gal}}\right]
$$

where:

$$
\begin{aligned}
& \%_{\mathrm{CS}} \quad=\text { Percent centrifuged solids } \\
& \rho_{\mathrm{IL}} \quad=\text { Density of interstitial liquid, } \mathrm{g} / \mathrm{mL}
\end{aligned}
$$

Measured variables:

- Average height of sludge layer measured by densitometer (DI-602A-I through DI-602A-N, recorded after each batch, D2yymmdd)

- Average bulk density of settled solids (no tag number, sample taken after each sluice batch, lab report)

- Percent centrifuged solids in the slurry (no tag number, sample taken after each sluice batch, 1 ab report)

- Density of decantate (no tag number, sample taken after each sluice batch, lab report)

Assumptions:

- Density is uniform throughout newly settled solids.

- Average starting sludge level is uniform across the tank.

- New sludge level is the same over the cross-section of the tank.

- Grab samples taken in the sludge are representative of the sludge that was transferred.

Convert mass of sludge to volume of sludge

$$
V_{\text {SL }-G}=\frac{\Delta H_{60} \rho_{6 \mathrm{CSL}}}{\rho_{6 \mathrm{CSL}}}\left[\frac{453.593 \mathrm{~g}}{1 \mathrm{~b}}\right]\left[\frac{\mathrm{ft}^{3}}{28,317 \mathrm{~mL}}\right]
$$

where:

$V_{\text {sL-G }}=$ Volume of solids transferred based on grab samples, $\mathrm{ft}^{3}$ 
LOCKHEED MARTIN HANFORD CORPORATION

OBJECTIVE AND PURPOSE:

APPLICABILITY: FOR COMPLIANCE
Manual

Section

HNF-SD-WM-PROC-021

Page

23.0, REV 2 29 of 44

Effective Date November 15,1998

\subsubsection{Material Balance Based on Solid/Liquid Interface}

The solid/liquid interface is determined from the MIT temperature profile (fixed and validation probe). Once the height of the sludge is determined, the amount of sludge transferred to tank 241-AY-102 can be calculated.

$$
V_{\mathrm{SL}-\mathrm{I}}=\frac{1}{\mathrm{~F}}\left(\mathrm{H}_{\mathrm{s}}-\mathrm{H}_{0}\right)\left(\frac{2,750 \mathrm{ga}]}{\text { inches }}\right)\left(\frac{\mathrm{ft}^{3}}{7.4805 \mathrm{gal}}\right)
$$

where:

$\mathrm{V}_{\mathrm{SL}-\mathrm{I}}=\mathrm{Vol}_{\mathrm{ft}^{3}}$ ume of sludge transferred based on solid/liquid interface,

F $=$ Fluffing factor.

Measured variables:

- MIT validation probe temperatures (manual measurements, minimum of one profile before start of next batch, V2yymmdd)

\section{Calculate Fluffing Factor}

$$
\mathrm{F}=\frac{\rho_{6 \mathrm{CSL}}-\rho_{\mathrm{L} 0}}{\rho_{\mathrm{S}}-\rho_{\mathrm{L} 0}}
$$

Measured variables:

- Density of liquid (without suspended solids) before transfer

(estimate from densitometer and grab sample data, recorded after each batch)

- Bulk density of the settled solids after sluicing (no tag number, sample taken after each sluice batch, lab report)

\subsection{Slurry Solids Loading Calculation}

The slurry solids loading is calculated using parameters from the 241-AY-02A pit mass flowmeter. The slurry solids loading results are recorded in file SyymmddH in DAS (tag number DI-0621B). The following equation is used by DAS to calculate the slurry solids loading (Carothers et a1. 1998). 
where:

$$
C_{\mathrm{N}}=100\left[\frac{\rho_{\mathrm{p}}\left(\rho_{\mathrm{m}}-\rho_{f}\right)}{\rho_{\mathrm{m}}\left(\rho_{\mathrm{p}}-\rho_{f}\right)}\right]
$$

$$
\begin{array}{ll}
\mathrm{C}_{\mathrm{M}} & =\text { Mass fraction of solids in slurry, } \% \\
\rho_{\mathrm{p}} & =\text { Solids particulate density, } \mathrm{g} / \mathrm{mL} \\
\rho_{\mathrm{f}} & =\text { Carrier solution density, } \mathrm{g} / \mathrm{mL} \\
\rho_{\mathrm{m}} & =\text { Slurry density measured by mass flowmeter, } \mathrm{g} / \mathrm{mL}
\end{array}
$$

\subsection{Calculation of Tank 241-C-106 Heat Load Transferred}

An estimate of the heat load in the transferred waste is determined after every batch.

\subsubsection{Initial Heat Load Estimate - Based on Mass Flowmeter Output}

An initial estimate of the heat load will be made to satisfy the 24-hour AC 5.12 requirement.

\section{Batch 1.1.1}

The Cs-137 and Sr-90 concentrations for the first batch of sluicing will be determined from the initial estimate of s7udge transferred and existing tank 241-C-106 pre-s7uicing grab sample results. The average Cs-137 and $\mathrm{Sr}-90$ concentrations in the sludge will be used for the calculation.

$Q_{S L}=M_{S L+}\left[[C S-137]_{6 C}\left[\frac{0.0161 B t u / h r}{C i}\right]+[S r-90]_{6 C}\left[\frac{0.0229 \mathrm{Btu} / \mathrm{hr}}{C i}\right]\right]\left[\frac{\mathrm{Ci}}{1 \mathrm{E}+6 \mathrm{CCi}}\right]\left(\frac{453.593 \mathrm{~g}}{\mathrm{lb}}\right)$ where:

$$
\begin{aligned}
& \mathrm{Q}_{\mathrm{SL}}=\text { Heat load in sludge transferred, Btu/hr } \\
& M_{\text {SL-F }}=\text { Mass of sludge transferred based on flowmeter (calculated in } \\
& {[\mathrm{Cs}-137]_{6 \mathrm{C}}=\text { Concentration of } \mathrm{Cs}-137 \text { in tank } 241-\mathrm{C}-106 \text { sludge, } 230 \mu \mathrm{Ci} / \mathrm{g}} \\
& \text { (Carothers et a1. 1998) } \\
& {[\mathrm{Sr}-90]_{6 \mathrm{C}}=\text { Concentration of } \mathrm{Sr}-90 \text { in tank } 241-\mathrm{C}-106 \text { sludge, } 4,100 \mu \mathrm{Ci} / \mathrm{g}} \\
& \text { (Carothers et al. 1998) }
\end{aligned}
$$


LOCKHEED MARTIN HANFORD CORPORATION

OBJECTIVE AND PURPOSE:

APPLICABILITY: FOR CONPLIANCE
Manual

Section

Page

HNF-SD-WM-PROC-021

23.0, REV 2

31 of 44

Effective Date November 15, 1998

\section{Subsequent Batches}

The Cs-137 and Sr-90 concentrations for all subsequent batches will be determined from the average concentrations in the tank 241-AY-102 solids analyzed for the previous batch samples taken.

$$
Q_{S D}=M_{S D+}\left[[C s-137]_{A V G}\left(\frac{0.0161 B t u / h r}{C i}\right)+[S r-90]_{A V G}\left(\frac{0.0229 B t u / h r}{C i}\right)\right]\left[\frac{C i}{1 E+6 u C i}\right)\left(\frac{453.593 g}{l b}\right)
$$

where:

$$
\begin{aligned}
& \mathrm{Q}_{\mathrm{SD}} \quad=\text { Heat load of solids transferred, Btu/hr } \\
& M_{S D-F}=\text { Mass of solids transferred based on flowmeter (calculated } \\
& \text { in Section 4.4.1), 1b } \\
& {[\mathrm{Cs}-137]_{\text {AVG }}=\text { Average concentration of } \mathrm{Cs}-137 \text { in solids from previous }} \\
& \text { batch samples, } \mu \mathrm{Ci} / \mathrm{g} \\
& {[\mathrm{Sr}-90]_{\mathrm{AVG}}=\text { Average concentration of } \mathrm{Sr}-90 \text { in solids from previous }} \\
& \text { batch samples, } \mu \mathrm{Ci} / \mathrm{g}
\end{aligned}
$$

Assumption:

- Head load of solids fraction is representative of the heat load of the transferred sludge.

Measured variables:

- Concentration of Cs-137 in centrifuged solids (no tag number, sample taken after each sluice batch, lab report)

- Concentration of Sr-90 in centrifuged solids (no tag number, sample taken after each sluice batch, lab report)

\subsubsection{Sludge Heat Load Calculations Based on Batch Grab Samples}

The final heat load calculations will be calculated using the grab samples taken from the corresponding batch. The concentration of $\mathrm{Cs}-137$ in the solid and liquid fractions will not be measured for every batch, nor will the concentration of $\mathrm{Sr}-90$ in the 1iquid fraction be measured for every batch. In these cases the ratio of $\mathrm{Cs}-137$ to $\mathrm{Sr}-90$ in the solids will be assumed to be the same as prior samples. Also, the distribution of $\mathrm{Cs}-137$ and $\mathrm{Sr}-90$ between the fractions will be assumed to be the same as that of prior samples.

Calculating $\mathrm{Cs}-137$ concentration in solids if not analyzed

1) Calculate $\mathrm{Cs}-137 / \mathrm{Sr}-90$ ratio in previous batches from solid samples analyses. 
2) Average the ratios.

$$
[\mathrm{Cs}-137]_{\mathrm{ECS}}=\mathrm{r}_{\mathrm{AVG}}[\mathrm{Sr}-90]_{\mathrm{CS}}
$$

where:

$$
\begin{aligned}
& r_{\mathrm{AVG}}=\underset{\text { average } \mathrm{Cs}-137 / \mathrm{Sr}-90 \text { ratio in solids fraction (based on }}{\text { previous samples) }} \\
& {[\mathrm{CS}-137]_{\mathrm{ECS}}=\underset{\mu \mathrm{Ci} / \mathrm{g}}{\text { estimated concentration of } \mathrm{Cs}-137 \text { in centrifuged solids, }}} \\
& {[\mathrm{Sr}-90]_{\mathrm{CS}}=\text { concentration of } \mathrm{Sr}-90 \text { in centrifuged solids, } \mu \mathrm{Ci} / \mathrm{g}}
\end{aligned}
$$

Measured variable:

- Concentration of $\mathrm{Sr}-90$ in centrifuged solids sample (no tag number, sample taken after each sluice batch, 1 ab report)

Heat load of transferred solids

$$
Q_{s 0}=V_{s L} \rho_{\text {SCSL }}\left(1-\frac{W_{6 C S L}}{W_{G C I L}}\right)\left[[C s-137]_{c s}\left(\frac{0.0161 B t u / h r}{C i}\right)+[S r-90]_{c s}\left(\frac{0.02298 t u / h r}{C i}\right)\right]\left[\frac{C i}{I E+6 u C i}\right)\left(\frac{28,317 \mathrm{~mL}}{\mathrm{ft}^{3}}\right)
$$

where:

$$
\begin{array}{ll}
V_{\mathrm{SL}} & =\begin{array}{l}
\text { best estimate of volume of sludge transferred (ca]culated } \\
\text { in Section } 4.7), \mathrm{ft}^{3}
\end{array} \\
{[\mathrm{Cs}-137]_{\mathrm{CS}}=} & \begin{array}{l}
\text { measured or estimated concentration of } \mathrm{Cs}-137 \text { in } \\
\text { centrifuged solids, } \mu \mathrm{C} \dot{\mathrm{i}} / \mathrm{g}
\end{array}
\end{array}
$$

Measured variables:

- Concentration of Cs-137 in centrifuged solids sample (no tag number, sample taken after each sluice batch, lab report)

- Concentration of $5 r-90$ in centrifuged solids sample (no tag number, sample taken after each sluice batch, lab report)

Heat load of settled sludge from transfer

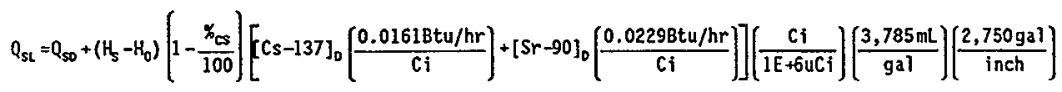


where:

$$
\begin{aligned}
& {[\mathrm{Cs}-137]_{D}=\text { concentration of } \mathrm{Cs}-137 \text { in decantate, } \mu \mathrm{Ci} / \mathrm{mL}} \\
& {[\mathrm{Sr}-90]_{D}=\text { concentration of } \mathrm{Sr}-90 \text { in decantate, } \mu \mathrm{Ci} / \mathrm{mL}}
\end{aligned}
$$

Measured variables:

- Concentration of Cs-137 in decantate sample (no tag number, sample taken after each sluice batch, lab report)

- Concentration of $5 r-90$ in decantate sample (no tag number, sample taken after each sluice batch, Tab report)

\subsubsection{Supernatant Heat Load Calculations Based on Batch Grab Samples Calculate $\mathrm{Cs}-137$ concentration in liquids if not analyzed} Assumptions:

- Ratio of Cs-137/Sr-90 in solids is the same as prior samples (calculated from Section 4.6.2).

- Distribution for Cs-137 between phases is the same as prior samples.

- Liquid fraction of grab samples is representative of the tank supernatant.

Calculate [Cs-137] in liquid fraction:

1) Calculate the ratio between the concentrations of Cs-137 in the solids and the liquid fraction (based on previous samples).

2) Average the ratios to use in the calculation.

$$
\begin{gathered}
r_{\mathrm{Cs}-137}=\frac{[\mathrm{Cs}-137]_{\mathrm{CS}} \rho_{\mathrm{IL}}}{[\mathrm{Cs}-137]_{\mathrm{E} 2 \mathrm{AYS}}} \\
{[\mathrm{Cs}-137]_{\mathrm{E} 2 \mathrm{AYS}}=r_{\mathrm{CS}-137}[\mathrm{Cs}-137]_{\mathrm{CS}} \rho_{\mathrm{IL}}}
\end{gathered}
$$

where:

$$
\begin{aligned}
{[\mathrm{Cs}-137]_{\mathrm{E} 2 \mathrm{AYS}}=} & \begin{array}{l}
\text { estimated concentration of } \mathrm{Cs}-137 \text { in } \operatorname{tank} 241-\mathrm{AY}-102 \\
\text { liquid fraction, } \mu \mathrm{Ci} / \mathrm{mL}
\end{array} \\
r_{\mathrm{Cs}-137} & \begin{array}{l}
\text { ratio of } \mathrm{Cs}-137 \text { in the solids to } \mathrm{Cs}-137 \text { in the } \\
\text { liquid fraction }
\end{array}
\end{aligned}
$$


Measured variables:

- Concentration of $\mathrm{Cs}_{\mathrm{S}}-137$ in centrifuged solids sample (no tag number, sample taken after each sluice batch, lab report)

Calculate $5 r-90$ concentration in liquids if not analyzed

Assumptions:

- Distribution for $5 r-90$ between phases is the same as prior samples.

- Liquid fraction of grab samples is representative of the tank supernatant.

Calculate $[5 r-90]$ in liquid fraction:

1) Calculate the ratio between the concentration of $5 r-90$ in the solids and the liquid fraction (based on previous samples).

2) Average the ratios to use in the calculation.

$$
\begin{gathered}
r_{S r \rightarrow O}=\frac{[S r-90]_{\mathrm{CS}} \rho_{\mathrm{IL}}}{[S r-90]_{\mathrm{E} 2 \mathrm{AYS}}} \\
{[S r-90]_{\mathrm{E} 2 \mathrm{AYS}}=r_{\mathrm{Sr} \rightarrow 0}[S r-90]_{\mathrm{CS}} \rho_{\mathrm{IL}}}
\end{gathered}
$$

where:

$$
\begin{aligned}
& {[S r-90]_{\text {EZAYS }}=} \text { estimated concentration of Sr-90 in tank } 241-\mathrm{AY}-102 \\
& \text { liquid fraction, } \mu \mathrm{Ci} / \mathrm{mL} \\
& r_{\mathrm{Sr}-90}= \text { ratio of } \mathrm{Sr}-90 \text { in the solids to } \mathrm{Sr}-90 \text { in the 1iquid } \\
& \text { fraction }
\end{aligned}
$$

Measured variables:

- Concentration of Sr-90 in centrifuged solids sample (no tag number, sample taken after each sluice batch, lab report)

\section{Heat load of liquid fraction from transfer}

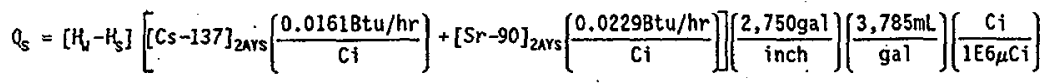


LOCKHEED MARTIN HANFORD CORPORATION

OBJECTIVE AND PURPOSE:

APPLICABILITY: FOR COMPLIANCE
Manua]

Section

Page

Effective Date
HNF-SD-WM-PROC-021

23.0, REV 2

35 of 44

November 15,1998

where:

$Q_{S}=$ heat load of supernatant transferred, Btu/hr

$[\mathrm{Cs}-137]_{2 \mathrm{AYS}}=$ measured or estimated concentration of $\mathrm{Cs}-137$ in tank 241-AY-102 supernatant, $\mu \mathrm{Ci} / \mathrm{mL}$

$[\mathrm{Sr}-90]_{2 \mathrm{AYS}}=$ measured or estimated concentration of Sr-90 in tank 241 $A Y-102$ supernatant, $\mu \mathrm{Ci} / \mathrm{mL}$

\subsubsection{Comparison of Cs-137 Concentrations in Tank 241-AY-102 Liquids}

The concentration of $\mathrm{Cs}-137$ in the tank 241-AY-102 liquids wit1 be calculated following each batch. The concentration of the current batch will be compared to the concentration in previous batches to determine if $\mathrm{Cs}_{\mathrm{s}}-137$ is being redistributed from the solids fraction to the liquid phase.

\section{Calculate amount of $\mathrm{Cs}-137$ in pre-sluicing supernatant}

$$
\mathrm{CS}-137_{2 A Y S}=[\mathrm{Cs}-137]_{\text {2AYS }}\left(\mathrm{V}_{2 \mathrm{AYS}}\right)\left(\frac{3785 \mathrm{~mL}}{\mathrm{gaT}}\right)\left[\frac{\mathrm{C} i}{1 \mathrm{E} 6 \mu \mathrm{Ci}}\right)
$$

where:

$\mathrm{Cs}-137_{2 \mathrm{ArS}}=$ amount of $\mathrm{Cs}-137$ in pre-sluicing supernatant, $\mathrm{Ci}$

$V_{2 A Y S}=$ volume of supernatant in tank 241-AY-102, gallons

Measured variables:

- Concentration of $\mathrm{Cs}-137$ in tank 241-AY-102 supernatant (no tag number, pre-sluicing samples, lab report)

- Volume of tank 241-AY-102 supernatant

Ca]culate amount of $\dot{C} s-137$ after each batch

where:

$$
\mathrm{Cs}-137_{2 \mathrm{AYS}}=[\mathrm{Cs}-137]_{\text {2AYS }}\left[\mathrm{H}_{\mathrm{W}}-\mathrm{H}_{\mathrm{s}}\right]\left(\frac{2,750 \mathrm{gaT}}{\text { inch }}\right)\left(\frac{3,785 \mathrm{~mL}}{\mathrm{gal}}\right)\left(\frac{\mathrm{Ci}}{1 \mathrm{E} 6 \mu \mathrm{Ci}}\right)
$$

$\mathrm{H}_{W}=$ height of waste in tank 241-AY-102, inches

$\mathrm{H}_{\mathrm{s}}=$ average height of settled solids layer in tank 241-AY-102 after transfer, inches 


\begin{tabular}{llr}
\hline LOCKHEED MARTIN HANFORD CORPORATION & Manual & HNF-SD-WM-PROC-021 \\
OBJECTIVE AND PURPOSE: & Section & 23.0, REV 2 \\
APPLICABILITY: FOR COMPLIANCE & Page & 36 of 44 \\
\hline
\end{tabular}

Measured variables:

- Tank 241-AY-102 waste leve1 (LI-602C, recorded every 10 minutes, SyymmddH)

- Average height of sludge 1 ayer measured by densitometer (DI-602A-1 through DI-602A-N, recorded after each batch, D2yymmdd)

\subsection{Evaluation of Mass Transfer and Heat Load}

Process Engineering will evaluate the data and the results of the calculations to determine the best estimate of the amount of sludge transferred to tank 241-AY-102 and the heat load of the sludge. Process Engineering will provide recommendations for the next batch of sludge to be transferred. The results of the calculations will be given to the WRSS Data Administrator. The results will also be included in the Review of Waste Retrieval S7uicing System Operations and Tank Data for 241-C-106 and 241-AY-102 from [reporting period start date] to [reporting period end date] in accordance with Section 24.0, "Data Management Reporting for Tank 241-C-106 Sluicing and Retrieval," of this manual.

\subsection{FLAMMABLE GAS CALCULATIONS}

\subsection{Requirements}

A minimum waiting time of 30 days between campaigns is necessary before initiating further sluicing. During this monitoring period, flammable monitoring will be focused on determining if excessive gas retention is occurring in tank 241-AY-102. The decision maps based on hydrogen concentration and level data are shown in Carothers et. al. (1998). The values calculated in this document will be used with these decision maps to determine if sluicing can proceed.

\subsection{Methods of Determining Flammable Gas Parameters}

The proposed process control logic uses the monitoring data to make judgments on the extent of gas retention in tank 241-AY-102 following each campaign of the retrieval. The logic, described in Section 4.4 of Carothers et al. (1998), is based on the level rise of the waste, the rate of level rise, the hydrogen concentration in the dome space, and rate of change in the hydrogen concentration.

Level Rise. The level rise refers to the increase in the waste level starting from the waste level immediately after completion of a campaign. This measurement must be obtained using ENRAF ${ }^{T M}$ data, and the baseline must be established when the potential surface motion and intermediate foaming stop (within 1 day of completion of campaign) (Carothers et al. 1998). 
LOCKHEED MARTIN HANFORD CORPORATION

OBJECTIVE AND PURPOSE:

APPLICABILITY: FOR COMPLIANCE
Manual

Section

Page

Effective Date
HNF-SD-WM-PROC-021

23.0 , REV 2 37 of 44

November 15, 1998

Rate of Level Rise. The rate of level rise is expressed in inches per day and must be averaged over 10 days. Thus, the rate-of-level-rise computations become meaningful after the first 10 days of the monitoring period. After that, the computations must continue using the values from the previous 10 days. The 1 eve1 and rate-of-level-rise computations must account for the level changes resulting from evaporation (Carothers et al. 1998).

Hydrogen Concentration. The hydrogen concentration in the tank 241-AY-102 dome space must be baselined before the start of the first sluicing batch (1.1.1) (Carothers et a. 1998).

Rate of Change in Hydrogen. Concentration. The rate of change in the hydrogen concentration is a daily value expressed in parts per million per day and can be obtained using the daily average values between two consecutive days (Carothers et al. 1998).

Release Rates. The amount of hydrogen released in tanks $241-A Y-102$ and 241-C-106 can be estimated using the tank ventilation rates and the hydrogen concentrations.

\subsection{Calculation of Flammable Gas Parameters}

\subsubsection{Level Rise of Waste}

The equation to calculate the level rise of the waste caused by retained gas is given below:

where:

$$
\Delta L=L_{F}-L_{1}+L_{2 A Y-o u t}-V_{2 A Y-i n}\left(\frac{\text { inch }}{2,750 \text { ga } ~}\right)
$$

\footnotetext{
$\Delta \mathrm{L}=$ level rise of tank 241-AY-102 waste caused by retained gas, inches

$L_{F} \quad=$ final tank 241-AY-102 waste, inches

$\mathrm{L}_{1}=$ initial tank 241-AY-102 waste, inches

$\mathrm{L}_{\text {2AY-out }}=$ amount of waste discharged from tank 241-AY-102 to tank 241-AZ-702 ventilation system exhaust

$V_{2 A Y-i n}=$ volume of water entering through in-leakage of atmospheric air + water additions to tank 241-AY-102 from all sources, calculated in Section 3.4 .5 , gallons
}

Measured variable:

- Tank 241-AY-102 riser 22A ENRAF ${ }^{\mathrm{TM}}$ Tevel indicator (LI-602C, recorded every 10 minutes, SyymmddH) 
LOCKHEED MARTIN HANFORD CORPORATION

OBJECTIVE AND PURPOSE:

APPLICABILITY: FOR COMPLIANCE
Manual

Section

Page

Effective Date November 15,1998

Calculate $L_{2 A Y-o u t}$

The calculational sequence for this determination is as follows:

1. Convert the measured volumetric tank 241-AY-102 exhaust flow rate to a molar flow rate.

2. Calculate the moles of water present in the exhaust gas.

3. Calculate the volumetric flow rate of water leaving the tank 241-AY-102 exhaust.

4. Calculate amount water leaving the tank 241-AY-102 exhaust in inches.

(1) Convert the measured volumetric tank 241-AY-102 exhaust flow rate to a molar flow rate.

$$
\dot{\mathrm{n}}=\frac{\dot{\mathrm{v}}}{359 \mathrm{ft} \mathrm{t}^{3} / 7 \mathrm{~b}-\mathrm{mol}}
$$

where:

n = average molar flow rate of exhaust gas, $1 \mathrm{~b}-\mathrm{mol} / \mathrm{min}$.

$\dot{v}=$ average volumetric flow rate of tank 241-AY-102 exhaust, scfm Measured variable:

- 241-AY-102 exhaust air flow (FI-AY2K1-2, recorded once every 2 minutes, VyymmddH)

(2) Calculate the moles of water present in the exhaust gas.

$$
P_{v}=\frac{R H * P_{v}^{*}}{100 \%}
$$

where:

$P_{v} \quad=$ average partial pressure of water in the exhaust gas, psia

$\mathbf{P}_{\mathrm{V}}{ }^{*} \quad=$ vapor pressure of water at the average exhaust air temperature as listed in the "vapor pressure of water" table, psia

RH = average relative humidity of exhaust gas, \% 
LOCKHEED MARTIN HANFORD CORPORATION

OBJECTIVE AND PURPOSE:

APPLICABILITY: FOR COMPLIANCE
Manual

Section

Page

Effective Date
HNF-SD-WM-PROC-021

23.0, REV 2

39 of 44

November 15,1998

Measured variables:

- Relative humidity in 241-AY-102 exhaust (AI-0623, recorded once every 2 minutes, VyymmddH)

- Air temperature in 241-AY-102 exhaust (TI-AY2K48-1B, recorded once every 2 minutes, VyymmddH)

$$
y_{v}=\frac{P_{v}}{P}
$$

where:

$$
\begin{array}{ll}
y_{v} & =\text { mole fraction of water in the exhaust gas } \\
P & =\text { absolute average pressure at the } 241-A Y-102 \text { tank exhaust, psia } \\
P_{v} & =\begin{array}{l}
\text { average partial pressure of waster in the exhaust gas, psia } \\
\text { (calculated above) }
\end{array}
\end{array}
$$

Assumption:

- Pressure in tank exhaust line in equal to pressure in the tank dome.

Measured variable:

- Pressure in 241-AY-102 tank dome (PI-AY2-K1-1, recorded once per shift.

$$
\mathrm{n}_{\mathrm{H}_{2} \mathrm{O}}=\mathrm{y}_{\mathrm{V}} \dot{\mathrm{n}}
$$

where:

$$
\begin{aligned}
\mathrm{n}_{\mathrm{H} 2 \mathrm{O}} & =\text { molar flow rate of waster in exhaust gas, } 1 \mathrm{~b}-\mathrm{mole} / \mathrm{min} \\
\dot{\mathrm{n}} & =\text { from }(1) \\
y_{\mathrm{V}} & =\text { calculated above }
\end{aligned}
$$

(3) Calculate the volumetric flow rate of water leaving the 241-AY-102 exhaust.

$$
\dot{\mathrm{m}}_{\mathrm{H}_{2} \mathrm{O}}=\mathrm{n}_{\mathrm{H}_{2} \mathrm{O}} \times \mathrm{MW}_{\mathrm{H}_{2} \mathrm{O}}
$$

where:

$$
\dot{\mathrm{m}}_{\mathrm{H}_{2} \mathrm{O}}=\underset{1 \mathrm{~b} / \mathrm{min}}{\text { mass flow rate of water leaving the tank } 241-\mathrm{AY}-102 \text { exhaust, }}
$$


$M W_{H 2 O}=$ molecular weight of water, $18 \mathrm{lb} / 1 \mathrm{~b}-\mathrm{mo} 7 \mathrm{e}$

$n_{\mathrm{H} 2 \mathrm{O}}=$ from

$$
V_{\mathrm{H}_{2} \mathrm{O}(\mathrm{L})}=\left[\frac{\dot{\mathrm{m}}_{\mathrm{H}_{2} \mathrm{O}}}{62.4 \mathrm{lb} / \mathrm{ft}^{3}}\right]\left(7.482 \mathrm{gal} / \mathrm{ft}^{3}\right)
$$

where:

$\mathrm{V}_{\mathrm{H} 2 \mathrm{O}(\mathrm{L})}=$ average volumetric flow rate of water leaving the 241-AY-102 tank exhaust, gal/min.

(4) Calculate amount water leaving the tank 241-AY-102 exhaust in inches.

where:

$$
L_{2 A Y-\text { out }}=V_{H_{2} O(L)} \times t_{E}\left[\frac{60 \mathrm{~min}}{\mathrm{hr}}\right]\left[\frac{\text { inch }}{2,750 \mathrm{gal} 7}\right]
$$

$\begin{aligned} & t_{E}= \text { total elapsed time between the final and the initial tank } \\ & \text { waste level measurements in hours }\end{aligned}$

\subsubsection{Rate of Level Rise}

$$
i_{N}=\frac{L_{N}-L_{N-1}+L_{2 A Y-o u t(N)}-V_{2 A Y-i n}\left(\frac{\text { inch }}{2,750 \text { gal }}\right)}{\text { day }}
$$

where:

$$
\begin{aligned}
L_{N} .= & \text { rate of level rise on day } N \text { caused by retained gas, inches/day } \\
L_{N}= & \text { level at } 2400 \text { hours on day } N \text {, inches } \\
L_{N-1}= & \text { final level at } 2400 \text { hours on day } N-1 \text {, inches } \\
L_{2 A Y-o u t(N)=}= & \begin{array}{l}
\text { level change due to discharge of waste from tank } \\
\end{array} \\
& \begin{array}{l}
241-A Y-102 \text { to tank } 241-A Z-702 \text { ventilation system } \\
\text { exhaust, inches (use calculation method in section 5.3.1) }
\end{array}
\end{aligned}
$$

Measured variables:

- Tank 241-AY-102 riser 22A ENRAF ${ }^{T M}$ level indicator (LI-602C, recorded every 10 minutes, SyymmddH) 


\subsubsection{Hydrogen Concentration in the Dome Space}

where:

$$
\left[\% H_{2}\right]_{2 A Y}=\left[H_{2}\right]\left(\frac{1 \%}{10,000 p p m}\right)
$$

$\left[\begin{array}{ll}\% & \mathrm{H}_{2}\end{array}\right]_{2 \mathrm{AY}}=$ hydrogen concentration in the dome space, $\%$

$\left[\mathrm{H}_{2}\right]=$ hydrogen concentration in the dome space, $\mathrm{ppm}$

Measured variables:

- Riser $15 \mathrm{C}_{2}$ concentration from gas chromatograph (no tag name, recorded every 10 minutes)

\subsubsection{Rate of Change of Hydrogen Concentration}

$$
\left[\dot{\mathrm{H}}_{2}\right]_{\mathrm{N}}=\frac{\left[\overline{\mathrm{H}}_{2}\right]_{\mathrm{N}}-\left[\overline{\mathrm{H}}_{2}\right]_{\mathrm{N}-1}}{\text { day }}
$$

where:

$$
\begin{aligned}
& {\left[\ddot{\mathrm{H}}_{2}\right]_{\mathrm{N}}=\text { rate of change of }\left[\mathrm{H}_{2}\right] \text { for day } \mathrm{N} \text {, ppm/day }} \\
& {\left[\overline{\mathrm{H}}_{2}\right]_{\mathrm{N}-1}=\text { average }\left[\mathrm{H}_{2}\right] \text { for day } \mathrm{N}-1, \mathrm{ppm}} \\
& {\left[\overline{\mathrm{H}}_{2}\right]_{\mathrm{N}}=\text { average }\left[\mathrm{H}_{2}\right] \text { for day } \mathrm{N}, \mathrm{ppm}}
\end{aligned}
$$

\subsubsection{Hydrogen Gas Release Rate in Tank 241-AY-102}

$$
R_{2 A Y}=V_{2 A Y} \frac{\left[\% H_{2}\right]_{2 A Y}}{100}\left[\frac{1,440 \min }{\text { day }}\right]
$$

where:

$$
\begin{aligned}
& R_{2 A Y}=\text { rate of hydrogen released in tank } 241-A Y-102, \mathrm{ft}^{3} / \text { day } \\
& V_{2 A Y}=\text { tank } 241-A Y-102 \text { ventilation rate, scfm }
\end{aligned}
$$


Measured variables:

- Tank 241-AY-102 exhaust air flow rate (FI-AY2K-2, recorded every 2 minutes, VyymmddH)

\subsubsection{Hydrogen Gas Release Rate in Tank 241-C-106}

$$
R_{6 C}=V_{6 c} \frac{\left[\mathrm{H}_{2}\right]_{6 C}\left(\frac{1 \%}{10,000 \mathrm{ppm}}\right)}{100}\left[\frac{1,440 \mathrm{~min}}{\text { day }}\right) .
$$

where:

$\mathrm{R}_{b c}=$ rate of hydrogen released in tank $241-\mathrm{C}-106, \mathrm{ft}^{3} / \mathrm{day}$

$V_{6 c}=$ tank $241-C-106$ ventilation rate, $\mathrm{scfm}$

$\left[\mathrm{H}_{2}\right]_{6 \mathrm{C}}=$ hydrogen concentration, ppm

Measured variables:

- Tank 241-C-106 exhaust air flow rate (tag name FI-13627A, recorded once or twice a shift)

- Riser $\mathrm{R}-2 \mathrm{H}_{2}$ concentration from gas chromatograph (no tag name, recorded every 10 minutes)

\subsection{REFERENCES}

1. Carothers, K. G., S. D. Estey, N. W. Kirch, L. A. Stauffer, and J. W. Bailey, 1998, Tank 241-C-106 Waste Retrieval Sluicing System Process Control Plan, HNF-SD-WM-PCP-013, Rev. 1, Lockheed Mart in Hanford Corporation, Richland, Washington.

2. Crane Co., 1988, Flow of Fluids Through Valves, Fittings, and Pipe, Technical Paper No. 410, Crane Co., Joliet, Illinois.

3. DOE, 1995, Environmental Assessment Tank 241-C-106 Past-Practices S7uicing Waste Retrieva7, DOE/EA-0933, U.S. Department of Energy, Richl and, Washington.

4. Leche1t, J. A., 1998, Management of Data for Tank 241-C-106 Retrieval, HNF-2318, Rev. 0, Lockheed Mart in Hanford Corporation, Richland, Washington. 


\section{LOCKHEED MARTIN HANFORD CORPORATION}

OBJECTIVE AND PURPOSE:

APPLICABILITY: FOR CONPLIANCE
Manual

Section

Page

Effective Date
HNF-SD-HM-PROC-021

23.0, REV 2 43 of 44

5. Noorani, Y. G., 1998a, Tank Waste Remediation System Technica7 Safety Requirements, HNF-SD-WM-TSR-006, Rev. 0-L, Fluor Daniel Hanford, Inc., Richland, Washington.

6. Noorani, Y. G., 1998b, Tank Waste Remediation System Basis for Interim operation, HNF-SD-WM-BI0-001, Rev. 0-I, Fluor Daniel Hanford, Inc., Richland, Washington.

7. Reynolds, D. A., 1997, Chemical and Chemically-Related Considerations Associated with S7uicing Tank C-106 to Tank AY-102, HNF-SD-WM-TI-756, Rev. 2, Lockheed Martin Hanford Corporation, Richland, Washington.

8. Sasaki, L. M., 1998, Tank 241-AY-102 Grab Sampling and Analysis P7an for Waste Retrieval S7uicing System Process Contro7, HNF-2958, Rev. 0, Lockheed Martin Hanford Corporation, Richland, Washington. 
LOCKHEED MARTIN HANFORD CORPORATION

OBJECTIVE AND PURPOSE:

APPLICABILITY: FOR COMPLIANCE
Manual

Section

Page

Effective Date
HNF-SD-WM-PROC-021

23.0, REV 2

44 of 44

November 15,1998

This page intentionally left blank. 
LOCKHEED MARTIN HANFORD CORPORATION

TWRS PROCESS ENGINEERING

INSTRUCTION MANUAL
Manual

Section

Page

Effective Date

Organization
HNF-SD-WH-PROC-021

24.0 , REV 2

1 of 16

November 15, 1998

TWRS Process

Engineering

\section{TITLE:}

DATA MANAGEMENT REPORTING FOR TANK 241-C-106 SLUICING AND RETRIEVAL APPLICABILITY: FOR COMPLIANCE

\section{Approved by}

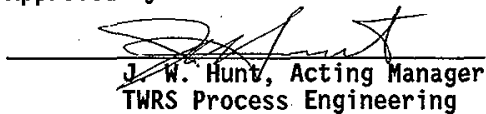

\subsection{PURPOSE}

The purpose of this procedure is to delineate the data archiving, analysis, and reporting by TWRS Process Engineering as required by the Tank 241-C-106 Waste Retrieval Technical Review Group Charter (HNF-IP-0842, Volume I, Section 3.18, Rev. 1). This procedure defines the responsibilities and actions required to prepare a data summary report to the Tank 241-C-106 Waste Retrieval Technical Review Group (TRG) on waste retrieval sluicing system (WRSS) operations.

\subsection{REQUIREMENT SOURCES}

1. "Tank 241-C-106 Waste Retrieval Sluicing System Process Control Plan", HNF-SD-WM-PCP-013, Rev. 1.

2. "Tank 241-C-106 Waste Retrieval Technical Review Group Charter", HNF-IP-0842, Vo1. I, Section 3.18, Rev. 1.

3. "Guidelines for the Technical Review Group on C-106 Sluicing Process Control", HNF-3226, Rev. 0.

4. "Management of Data for Tank 241-C-106 Retrieval", HNF-2318, Rev. 0.

5. "Benchmarking and Basel ining of Project $W-320$ Thermal Hydraulic Mode1s", HNF-3196, Rev. 0.

6. "Process Engineering Calculations for Tank 241-C-106 Sluicing and Retrieval", HNF-SD-WM-PROC-021, Section 23.0, Rev. 1E, 
LOCKHEED MARTIN HANFORD CORPORATION

OBJECTIVE AND PURPOSE:

APPLICABILITY: FOR CONPLIANCE
Manual

Section

Page

Effective Date
HNF-SD-WM-PROC-021

24.0, REV 2

2 of 16

\subsection{RESPONSIBILITIES}

Preparation of the data summary report requires the cooperative effort of a number of individuals and organizations. Data must be collected, administered, and delivered to the report coordinator. It must then be digested, processed into a coherent report, reviewed for technical accuracy, and delivered to the TRG. The specific responsibilities of the various participants are listed in the following subsections.

\subsection{TWRS Process Engineering}

TWRS Process Engineering is ultimately responsible for data reporting for the tank C-106 retrieval operations in accordance with HNF-IP-0842, Volume I, Section 3.13. Rev. 1. As the interpretive and evaluation authority for waste behavior for the TWRS Project, TWRS Process Engineering is responsible for a]l process related aspects of the WRSS operations and serves as the primary interface to Tank Waste Operations for process control issues. Preparation of the data summary report can be delegated, if necessary, to other organizations having unique expertise to support his effort. However, such delegation does not abrogate TWRS Process Engineering of its responsibility. As such, the WRSS data summary report must receive concurrence from Process Control before submitting to the TRG.

\subsection{WRSS Data Administrator}

The WRSS Data Administrator collects relevant data from the WRSS Data Acquisition System (DAS) server, Tank Monitoring and Control System (TMACS), Hanford Meteorological Station (HMS), and other sources according to the data management plan (HNF-2318, Rev. 0) and performs the filtering and processing agreed on with the WRSS data users. The WRSS Data Administrator places the processed data on a file server accessible to the WRSS data users. The WRSS Data Administrator archives the raw data, manually recorded data, and processed data. TWRS Process Engineering personnel are responsible for WRSS data administration.

\subsection{Data Report Contributors}

Contributions include data furnished by TWRS Process Engineering and Numatec Hanford Company (NHC) Process Analysis. The data from TWRS Process Engineering consists of:

- summaries of operations logs

- copies of rounds sheets

- WRSS engineering material balance

- solids transfer mass balance between AY-102 and C-106

- heat load estimate for batch transfers

- integration of daily gas release from AY-102 and C-106

- interpretation of sampling results. 
The data from NHC Process Analysis consists of:

- heat balance for AY-102 and C-106.

Contributors obtain processed data from the WRSS file server and perform calculations in accordance with approved procedures. Contributors transmit results of these calculations electronically in the form of data files to the report coordinator.

\subsection{Data Report Coordinator}

The Data Report Coordinator is responsible for production and content of the WRSS Data Report and acts as the primary point of contact with the TRG for data reporting and interpretation. Pacific Northwest National Laboratory (PNNL) shall appoint a primary Data Report Coordinator with concurrence from TWRS Process Engineering. A representative of TWRS Process Engineering wi1] serve as the alternate Data Report Coordinator. The Data Report Coordinator will be assisted by supporting TWRS Process Engineering and PNNL staff, as needed, to perform the tasks required by this procedure. Major responsibilities are the following:

\subsubsection{Coordinate WRSS Data Report Input}

Establish a schedule to receive data processed by the WRSS Data Administrator and contributions from Data Report Contributors for timely production of the WRSS Data Report. Arrange acceptable data formats, file server access and other details as necessary for efficient information flow. Coordinate with TWRS Process Engineering, WRSS operations and contributors to resolve issues of data quality.

\subsubsection{Prepare, Distribute, and Archive the WRSS Data Report}

In conjunction with TWRS Process Engineering, plot, interpret and explain the data trends and operational items for the reporting period in accordance with this procedure and directions from the TRG. P1 ace the draft report as an HTML file on the WRSS Data Report Web site and announce its availability. Transmit hardcopies of the finalized preliminary report to TWRS Process Engineering manager, TWRS Chief Engineer, Tank Waste Operations Director and others as directed by the TRG. Archive the report and associated data on CD-ROM. The report data archive is distinct from archives performed by WRSS Data Administration.

\subsubsection{Present the WRSS Data Report to the TRG at a Regularly Scheduled Meeting}

Report resolution of TRG review comments. Coordinate with TWRS Process Engineering, WRSS operations and others to develop answers to TRG questions about the data. 
LOCKHEED MARTIN HANFORD CORPORATION

OBJECTIVE AND PURPOSE:

APPLICABILITY: FOR COMPLIANCE
Manual

Section

Page

Effective Date
HNF-SD-WM-PROC-021

24.0 , REV 2

4 of 16

November 15, 1998

\subsection{Technical Review Group}

Review WRSS Data Reports and incorporate the information into the decision-making process in accordance with HNF-SD-WM-PCP-013, HNF-IP-0842 (Volume I, Section 3.18), and HNF-3226. Request additional data, revised data formats or other reporting items and address questions concerning data to the Data Report Coordinator and/or alternate.

\subsection{PROCEDURE}

\subsection{General Instructions}

1. Report frequency. This report is prepared for presentation to the TRG at regularly scheduled meetings. (For example, if the TRG meets weekly, then the report must be prepared each week; if the TRG meets biweekly, then the report must be prepared biweekly, and so on.) The TRG may determine a data report frequency different from the regularly scheduled meeting.

2. Report title. The report title is "Review of Waste Retrieval Sluicing System Operations and Tank Data for 241-C-106 and 241-AY-102 from [reporting period start date] to [reporting period end date]"

3. Reporting period. The report focuses on activities since the last report. Depending on the frequency of TRG meetings, this may be one week, two weeks, and so forth. For continuity and comparison purposes, however, the data is reported for a 4-week period, ending with the closing date of the current reporting period. In addition, some data (as specified in the Report Preparation Procedures below), will be collected and plotted for a 6-month window, ending on the closing date of the current reporting period. The closing date of the current reporting period will be 3 working days before the next scheduled TRG meeting.

4. Report document form. The report will be prepared using the platform, of the report preparer's choice. The word processing software and plotting package used for report preparation will meet with TWRS Process Engineering acceptance. Where practical, the data report should be consistent with the guidelines for document preparation found in HNF-SD-WM-PROC-021, Section 11.0, Sub-section 6.0, "Publication Standards for Preparation of Documents." 
LOCKHEED MARTIN HANFORD CORPORATION

OBJECTIVE AND PURPOSE:

APPLICABILITY: FOR COMPLIANCE
Manual

Section

Page

Effective Date
HNF-SD-WH-PROC-021

24.0, REV 2

5 of 16

November $15 ; 1998$

5. Report transmittal. Timeliness is of the essence in reporting data to the TRG. The report preparer will establish and maintain an internal Hanford web page (i.e., inside the firewall), and post the draft report for general access, to facilitate timely comments by experts and users. An informal peer review of the document will be performed by TWRS Process Engineering and others, as determined by Data Report Coordinator, before distribution of the report to the TRG. Review of the report by the TRG will meet the purpose of an independent review. After presentation to the TRG, an comment resolutions to TRG issues will be incorporated, and the report attached to an Internal Memo issued from the TRG to the WRSS operations Manager. The memo will include any recommendations from the TRG regarding sluicing operations.

6. Report archiving. Reports will be saved in electronic format consistent with Record Inventory Disposition Schedules and in a manner that allows easy access to the reports from earlier reporting periods.

\subsection{Report Preparation Procedure}

\subsubsection{Procedure for Obtaining Data Plots for Report on Waste Transfer Operations}

The following steps will be carried out by the Data Report Coordinator, or supporting staff at the direction of the Coordinator.

1. Obtain data files listed in Tables 1,2 , and 3 below for the current reporting period.

Sources of data:

DAS -- on server \\Ap005\baro\, in folder "WRSS Data", or on server \\WC62613\(aka \|WC62613.r1.gov \), folder |wrs_datal

(NOTE: The raw DAS data is currently stored on these servers in comma separated variable (*.csv) ascii files with approximately 24 hours of data in a given file. The date appears numerically in the file name as yymmdd; the file is named for the day of the last time in the file. For example, for a file with data from 6:00am on $7 / 02 / 98$ to $5: 00$ am on $7 / 03 / 98$, the yymmdd in the file name is 980703.)

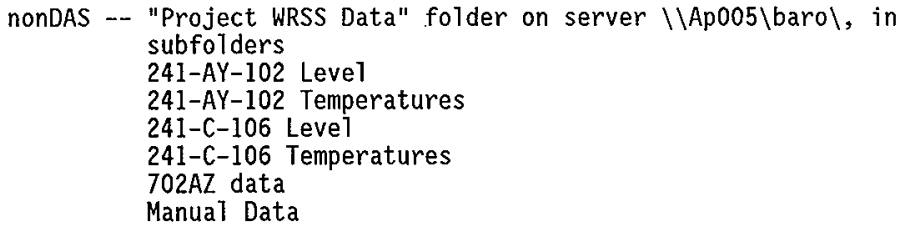




\section{Meteorological Station Parameters SHMS Hydrogen}

(NOTE: Other subfolders may be added, as needed.)

(NOTE: TMACS and SHMS data files are also available on the internal web, at http://twins.pnl.gov:8001/ntbin/TCD/getTable.)

2. Process data files to facilitate manipulation for plotting for a given plot, as follows;

a) Copy daily file(s) for each day of reporting period into a signal file, (NOTE: Refer to Tables 1, 2, and 3 for the appropriate length of each plot file. Some parameters are plotted for a 6-month window, some are plotted for a 1-month window, and the plots in Table 3 are profile plots at a specific date and time.).

b) Evaluate condition of the data; (i.e., \#COM values indicate loss of signal, \#RANGE values indicate out of range of instrument, which usually means instrument is off-line, for some reason).

c) Write a brief summary describing condition of the data, noting time and date of any periods when data was unavailable for longer than an hour from any instrument.

(NOTE: Intermittent occurrences of \#COM or \#RANGE can be ignored, but if either of these signals persist continuously over more than a few hours, report the affected instrument by name, function, and time interval(s) when it shows invalid values).

d) Eliminate all lines with \#COM or \#RANGE values.

e) Filter the temperature data and gas chromatograph data, which is typically in 2-min. or 10-min. intervals, down to approximately 1-hour intervals by taking a linear average of the measurements over the time period.

3. Make plots 1 isted in TabTes 1 and 2, with the following format;

a) After the header row of the plot file (which identifies the data by DAS TAG name or non-DAS identifier code), insert a row providing a more complete description of the instrument (this row should appear in the plot legend, along with the TAG name or identifier).

(NOTE: These expanded labels can be condensed from the instrument descriptions in Appendix A of HNF-2318, Table A.l for the DAS files and from Table A.3 for the nonDAS files.)

b) For all plots in Tables 1 and 2, the x-axis is date-and-time, as recorded in the first two columns of the *.csv files. 
LOCKHEED MARTIN HANFORD CORPORATION

OBJECTIVE AND PURPOSE:

APPLICABILITY: FOR COMPLIANCE
Manual

Section

Page

Effective Date
HNF-SD-WM-PROC-021

24.0, REV 2

7 of 16

November 15,1998

c) For all plots versus date-and-time in Table 1 , the $x$-axis spans a 6-month interval; for all plots in Table 2, the $x$-axis spans

a 4-week (28-day) interval. Both intervals end with the end-date of the reporting period.

d) $Y$-axis scale must be kept consistent from week to week, as far as possible. Even if the end-points must shift to accommodate the data, the difference between max/min values should be kept the same. If this is not possible, expand the scale to fit to nearest multiple of 5 or 10 , and note the change in the report submitted to the Data Report Coordinator.

e) Select 8-pt font for axis values, axis labels and legend, and 10-pt font for the plot title.

4. Make plots listed in Table 3, using the same plot size and font selections as for the plots of data in Tables 1 and 2 .

NOTE: As with the $y$-axis for the time plots, $x$-axis scale for these plots must be kept consistent from week to week, as far as possible. Even if the end-points must shift to accommodate the data, the difference between max/min values should be kept the same. If this is not possible, expand the scale to fit to nearest multiple of 5 or 10 , and note the change in the report submitted to the Data Report Coordinator.)

a) For the Riser 5 MIT temperature profile, plot the profile for the last entry in the data file for the last day of the current reporting period.

b) For the MIT Validation Probe, plot the file containing the most recent operation of the probe, noting the date of the measurement in the plot title.

c) If the most recent operation of the MIT Validation Probe occurred during the current reporting period, include on the same plot a graph of the MIT temperature profile on that date, at a time during (or very close to) the time of operation of the Validation Probe.

5. Deliver written summary (in electronic format) on data condition and any changes in plot format to the Data Report Coordinator and a]ternate, along with hardcopies of all plots. 


\subsubsection{Procedure for Interpreting Data and Data Plots}

1. The Data Report Coordinator shall write a clear and concise narrative summary of the logs and rounds sheets from waste transfer operations during the reporting period, for inclusion in the report. If appropriate, include a bulleted list of significant items or events. Examples of such events would inciude start/end times for s]uicing operations; any modifications, repairs or malfunctions of the tank instrumentation; changes in dome space air cooler or annulus exhaust system.

2. TWRS Process Engineering shall write a summary description of data and observations from any specific sampling activities undertaken during the reporting period, such as headspace grab samples, waste grab samples, or video scans of C-106 and make the results available to the Data Report Coordinator.

3. NHC Process Analyses shall perform energy balance and temperature predictions in accordance with HNF-3196, Rev. 0, "Benchmarking and Baselining of Project W-320 Thermal Hydraulic Models, " for both tanks $C-105$ and $A Y-102$, and make the results available to the Data Report Coordinator.

4. TWRS Process Engineering shall perform the solids transfer mass balance and heat load estimates in accordance with HNF-SD-WM-PROC-021, Section 23.0, Rev. IE, "Process Engineering Calculations for Tank 241-C-106 Sluicing and Retrieval," and make the results available to the Data Report Coordinator.

5. TWRS Process Engineering shall perform the WRSS engineering material balance in accordance with HNF-SD-WM-PROC-021, Section 23.0, Rev. IE, "Process Engineering Calculations for Tank 241-C-106 Sluicing and Retrieval," and results available to the Data Report Coordinator.

6. TWRS Process Engineering shall plot daily hydrogen gas release from AY-102 for the reporting period, by integrating tank exhaust air flow data and head space hydrogen concentration, in accordance with HNF-SD-WM-PROC-021, Section 23.0, Rev. 1E, and make the results available to the Data Report Coordinator.

7. TWRS Process Engineering shall plot daily hydrogen gas release from C-106 for the reporting period, by integrating tank exhaust air flow data and head space hydrogen concentration, in accordance with HNF-SD-WM-PROC-021, Section 23.0, Rev. 1E, and make the results available to the Data Report Coordinator.

8. The Data Report Coordinator and TWRS Process Engineering alternate shall examine the plots produced in steps 3 and 4 of Section 4.2.1, and steps 3 through 6 above, with particular attention to the issues listed in Table 4. Operations information obtained from logs and rounds sheets can be used to help evaluate whether observed changes and data trends are reasonable and understandable. 
LOCKHEED MARTIN HANFORD CORPORATION

OBJECTIVE AND PURPOSE:

APPLICABILITY: FOR COMPLIANCE
Manual

Section

Page

Effective Date
HNF-SD-WM-PROC-021

24.0, REV 2

9 of 16

November 15,1998

9. The Data Report Coordinator shall write a summary report providing as clear a picture as possible of the general behavior trends in the tanks over the reporting period, with particular attention to information on any evidence (or lack of evidence) of flammable gas accumulation in $A Y-102$ or $C-106$, and the rate of heat removal from AY-102. The draft summary report shall be submitted informally to TWRS Process Engineering for concurrence before posting the report on the Hanford web page.

(NOTE: The format of the report is at the discretion of the Data Report Coordinator, but it must suit the needs of the TRG, and facilitate efficient and effective presentation of useful information.)

\subsection{Procedure for Delivery of the Report}

The Report Coordinator and supporting TWRS Process Engineering and PNNL staff shall deliver the report to the TRG, following these steps;

1. Perform an informal peer review on the contents of the report, checking for completeness and engineering reasonableness of the interpretations of observed behavior in the tanks.

2. Upon completion of the internal peer review, obtain TWRS Process Engineering concurrence with the draft report.

3. Post the draft report (including all related plots) to the web site.

4. Present the draft report to the TRG; note all questions, points of discussion, and requests for changes to the presentation of the data or the interpretation of results.

5. Revise the report as appropriate to resolve comments of the TRG, and post the final version to the web site. The posted report will replace the draft version on the web site and will be labeled as "Prel iminary."

6. Copy the report to appropriate electronic storage media for archiving.

7. Make hardcopies (using a color printer or color photocopier for all plots and figures that use color) and disseminate to TWRS Process Engineering manager, TWRS Chief Engineer, Tank Waste Operations Director and others as defined by TRG. 
LOCKHEED MARTIN HANFORD CORPORATION

OBJECTIVE AND PURPOSE:

APPLICABILITY: FOR COMPLIANCE
Manua1

Section

Page

Effective Date November 15, 1998
HNF-SD-WM-PROC-021

24.0, REV 2

10 of 16

\begin{tabular}{|c|c|c|c|c|c|c|c|c|c|c|c|c|c|}
\hline : & 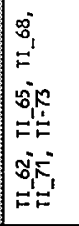 & 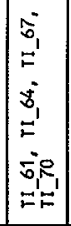 & 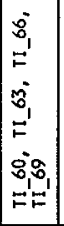 & 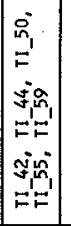 & 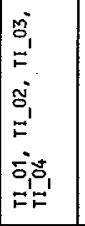 & 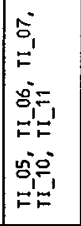 & 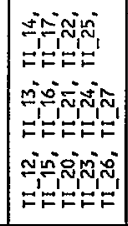 & 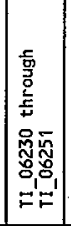 & 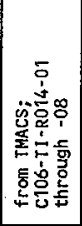 & 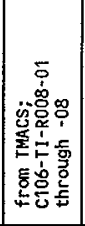 & 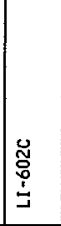 & 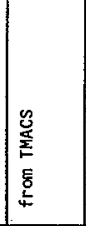 & 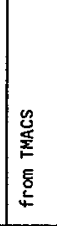 \\
\hline & in & in & 品 & in & \& & 9 & 9 & in & मे & in & : & $\dot{2}$ & 0 \\
\hline & 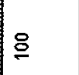 & @ & 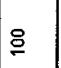 & : & 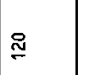 & ฐి & $\approx$ & $\mathrm{g}$ & 品 & 몽 & 㝎 & டू & $\grave{g}$ \\
\hline & 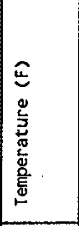 & 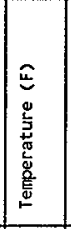 & 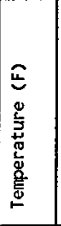 & 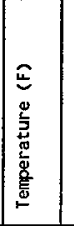 & 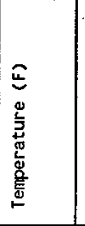 & 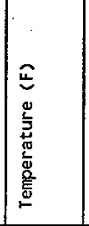 & 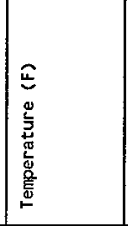 & 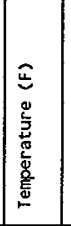 & 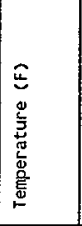 & 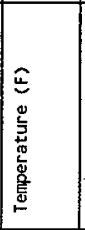 & 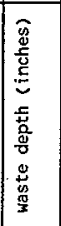 & 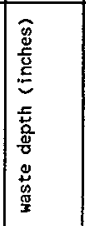 & 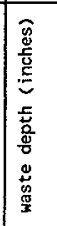 \\
\hline & 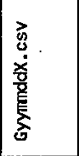 & 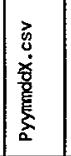 & 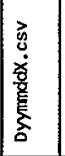 & 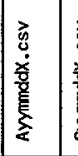 & 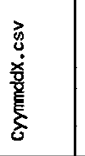 & 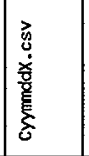 & 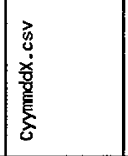 & 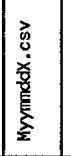 & 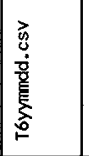 & 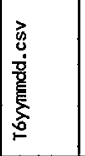 & & 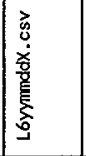 & 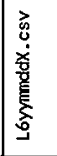 \\
\hline & $\stackrel{\mathscr{2}}{\Delta}$ & \begin{tabular}{|l}
8 \\
\end{tabular} & $\stackrel{0}{\Delta}$ & \begin{tabular}{|l|l}
5 \\
\end{tabular} & 岁 & $\frac{y}{\Delta}$ & $\frac{g}{\partial}$ & \begin{tabular}{|l}
9 \\
\end{tabular} & \begin{tabular}{|l|} 
产 \\
con
\end{tabular} & 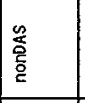 & $\frac{y}{\partial}$ & 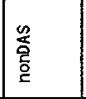 & 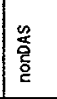 \\
\hline 12 & 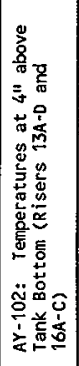 & 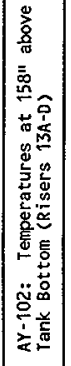 & 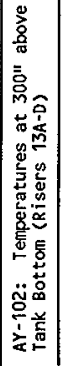 & 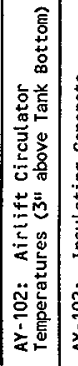 & 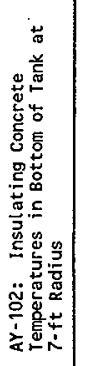 & 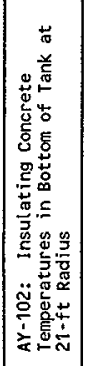 & 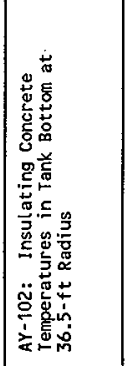 & 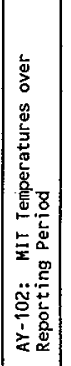 & 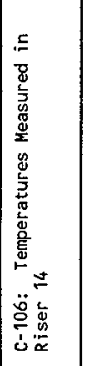 & 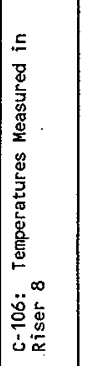 & 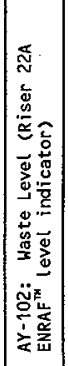 & 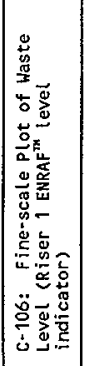 & 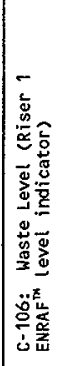 \\
\hline
\end{tabular}




\begin{tabular}{llr}
\hline LOCKHEED MARTIN HANFORD CORPORATION & Manual & HNF-SD-WM-PROC-02I \\
OBJECTIVE AND PURPOSE: & Section & 24.0, REV 2 \\
APPLICABILITY: FOR COMPLIANCE & Page & 11 of 16 \\
\hline
\end{tabular}

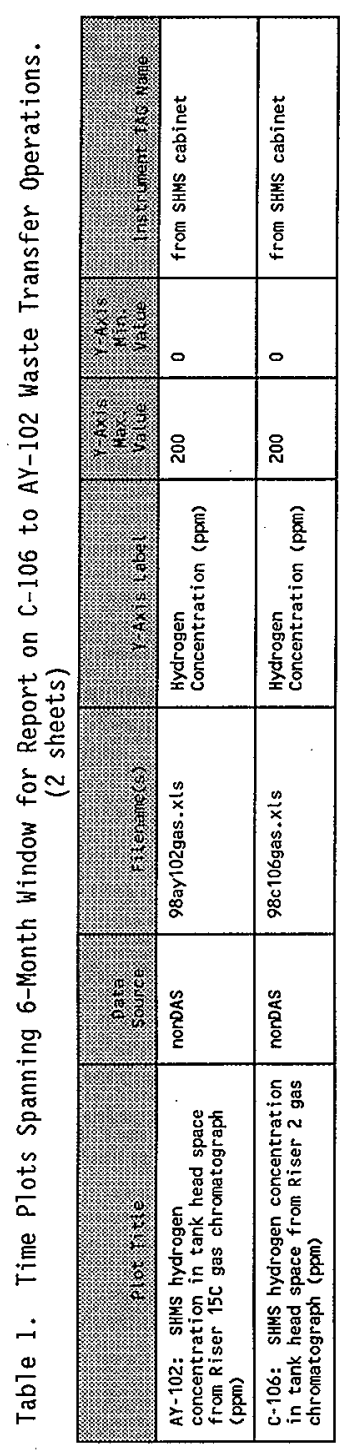




\begin{tabular}{llr}
\hline LOCKHEED MARTIN HANFORD CORPORATION & Manual & HNF-SD-WM-PROC-021 \\
& Section & 24.0, REV 2 \\
OBJECTIVE AND PURPOSE: & Page & 12 of 16 \\
APPLICABILITY: FOR COMPLIANCE & Effective Date & November 1, 1998 \\
\hline
\end{tabular}

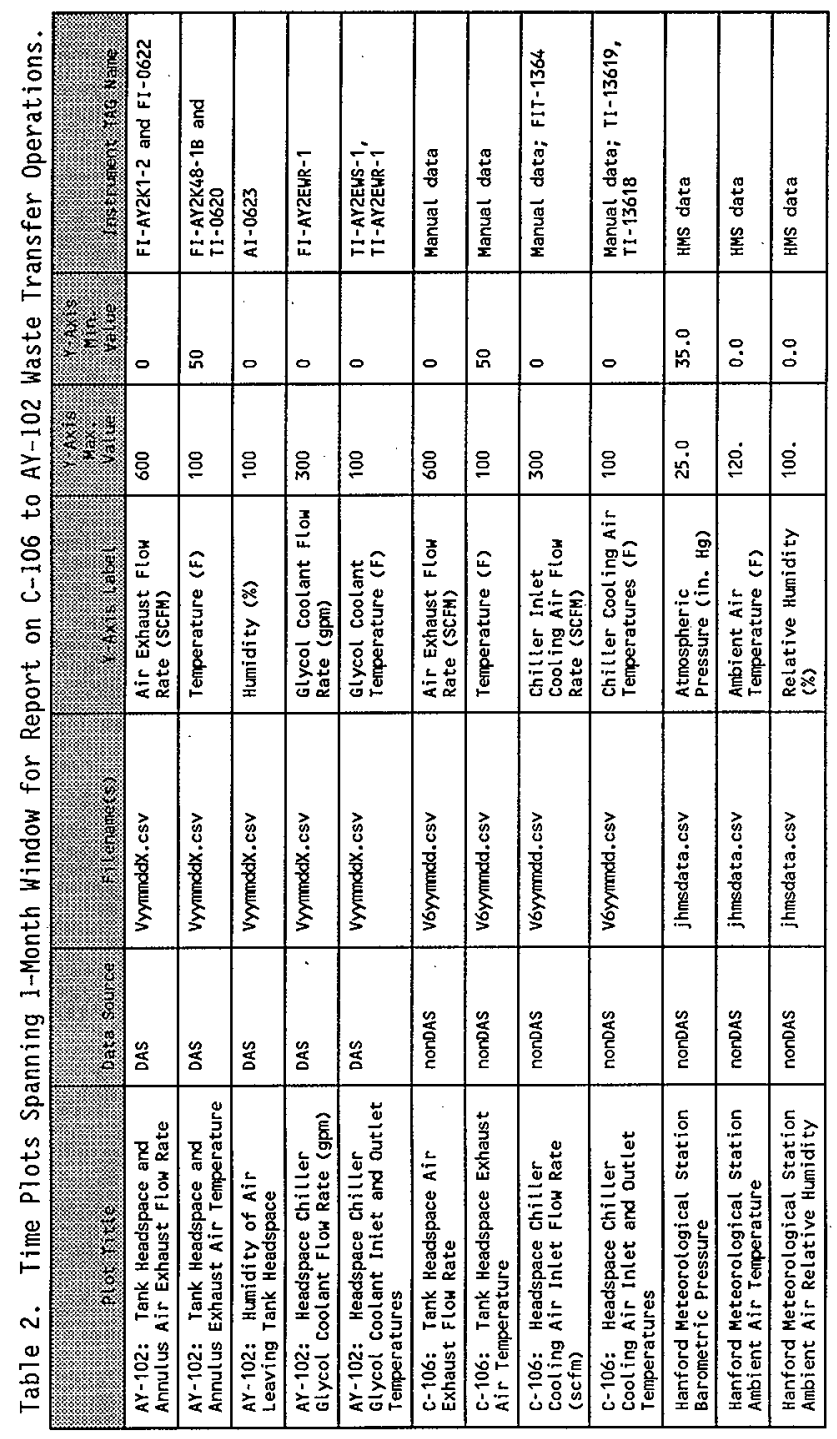




\begin{tabular}{llr}
\hline LOCKHEED MARTIN HANFORD CORPORATION & Manual & HNF-SD-HM-PROC-021 \\
& Section & 24.0, REV 2 \\
OBJECTIVE AND PURPOSE: & Page & 13 of 16 \\
APPLICABILITY: FOR COMPLIANCE & Effective Date & November 15, 1998 \\
\hline
\end{tabular}

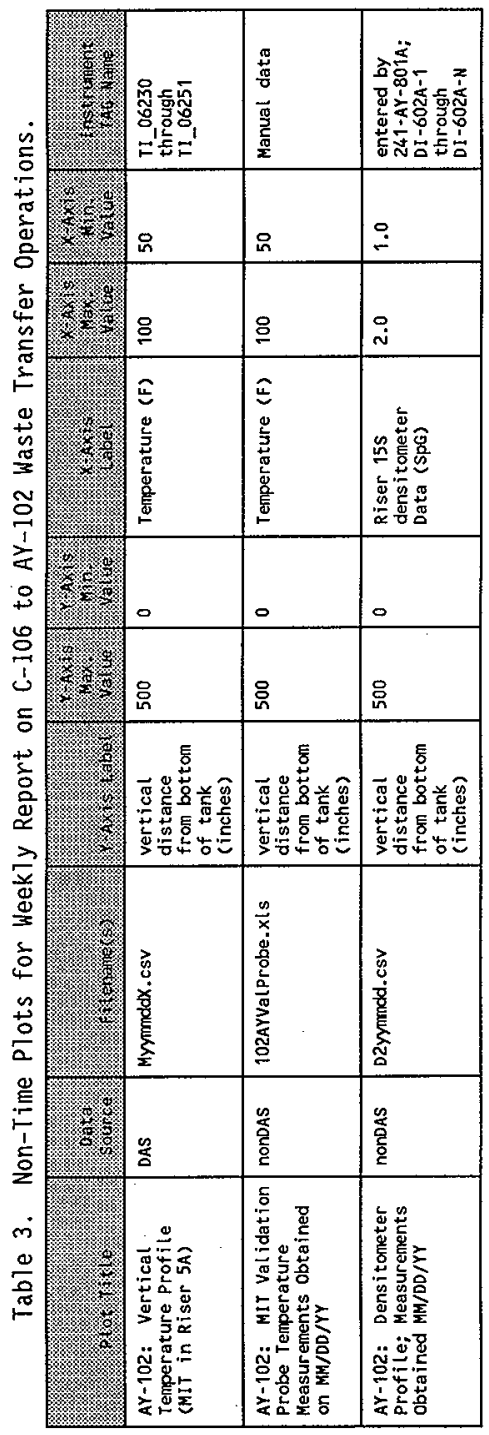


Table 4. Data Interpretation Guidelines. (2 sheets)

\begin{tabular}{|c|c|}
\hline 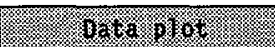 & 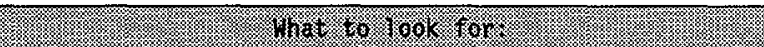 \\
\hline $\begin{array}{l}\text { AY-102 } \\
\text { thermocouples at } \\
4 " \text { from bottom of } \\
\text { tank (Risers } 13 \\
\text { and } 16 \text { ) }\end{array}$ & $\begin{array}{l}\text { Should be sludge temperature; expected to be } \\
\text { relatively uniform, but may vary as mixing proceeds; } \\
\text { may correlate with concrete temperatures, and airl ift } \\
\text { circulator temperatures (which are measured } 3^{11} \text { from } \\
\text { bottom of tank). }\end{array}$ \\
\hline $\begin{array}{l}\text { AY-102 } \\
\text { thermocouples at } \\
\text { I58" from bottom } \\
\text { of tank (Risers } \\
13 \mathrm{~A}-\mathrm{D} \text { ) }\end{array}$ & $\begin{array}{l}\text { Correlate with waste level measurement and ENRAF } \\
\text { densitometer; if TCs are in convective layer, (i.e., } \\
\text { more-or-less liquid supernatant, mainly), expect } \\
\text { temperatures to be essentially uniform; if not } \\
\text { uniform, evaluate possible reasons due to waste } \\
\text { transfer activities, transient mixing, etc. }\end{array}$ \\
\hline $\begin{array}{l}\text { AY-102 } \\
\text { thermocouples at } \\
300^{\prime \prime} \text { from bottom } \\
\text { of tank (Risers } \\
\text { I3A-D) }\end{array}$ & $\begin{array}{l}\text { Correlate with waste Tevel measurement and ENRAF } \\
\text { densitometer; if TCS are submerged, measurements } \\
\text { should be evaluated using the same criteria as at } \\
\text { I58"; if TCS are above the waste level, treat as } \\
\text { headspace air temperature measurements; look for } \\
\text { uniformity, correlate with Riser 5A MIT temperatures } \\
\text { at TC locations near 300", and HMS ambient outside air } \\
\text { daily peak temperatures. }\end{array}$ \\
\hline $\begin{array}{l}\text { AY- } 102 \\
\text { thermocouples in } \\
\text { airlift } \\
\text { circulators }\end{array}$ & $\begin{array}{l}\text { Expected to be essentially uniform; any large } \\
\text { differences should be investigated; correlate with } \\
\text { temperatures from TCs at } 4 " \text { in Risers } 13 A-D \text {, and } \\
\text { concrete temperatures. }\end{array}$ \\
\hline $\begin{array}{l}\text { AY }-102 \\
\text { thermocouples in } \\
\text { concrete }\end{array}$ & $\begin{array}{l}\text { Correlate with internal waste temperature measurements } \\
\text { near bottom of tank (Risers } 13 \text { and } 16 \text { at } 4 " \text {, MIT at } \\
11.2^{\prime \prime} \text {, and airlift circulator temperatures); look for } \\
\text { unusual gradients, or changes in location of hottest } \\
\text { temperatures. }\end{array}$ \\
\hline $\begin{array}{l}\text { AY-102 dome } \\
\text { temperature } \\
\text { compared to HMS } \\
\text { daily max/min } \\
\text { temperatures }\end{array}$ & $\begin{array}{l}\text { Look for consistency; expect some tendency to follow } \\
\text { local seasonal trend; correlate with what is happening } \\
\text { with cooling of annulus and recirculated dome space } \\
\text { air. }\end{array}$ \\
\hline $\begin{array}{l}\text { AY-102 MIT } \\
\text { thermocouples over } \\
\text { time, and vertical } \\
\text { profile on last } \\
\text { day of reporting } \\
\text { period }\end{array}$ & $\begin{array}{l}\text { Look for evidence of gas build-up in non-convective } \\
\text { layer (evidence would include distorted temperature } \\
\text { profile); correlate with densitometer measurements and } \\
\text { expected behavior due to waste transfer activities; } \\
\text { check for consistency with Riser } 13 \text { and } 16 \text { profiles; } \\
\text { compare with validation probe, if/when it is run. }\end{array}$ \\
\hline $\begin{array}{l}\text { C-106 } \\
\text { thermocouples in } \\
\text { Riser } 14\end{array}$ & $\begin{array}{l}\text { Correlate with tank transfer activities; if TCs are } \\
\text { above waste level, use to check head space } \\
\text { temperatures; below waste level, check for } \\
\text { consistency, look for evidence of hot spots. }\end{array}$ \\
\hline
\end{tabular}


LOCKHEED MARTIN HANFORD CORPORATION

OBJECTIVE AND PURPOSE:

APPLICABILITY: FOR COMPLIANCE
Manual

Section

Page

Effective Date
HNF-SD-HM-PROC-021

24.0, REV 2

15 of 16

November 15,1998

Table 4. Data Interpretation Guidelines. (2 sheets)

\begin{tabular}{|l|l|}
\hline $\begin{array}{l}\text { C-106 } \\
\text { thermocouples in } \\
\text { Riser 8 }\end{array}$ & $\begin{array}{l}\text { Correlate with tank transfer activities; if TCs are } \\
\text { above waste level, use to check head space } \\
\text { temperatures; below waste leve?, check for } \\
\text { consistency, look for evidence of hot spots. }\end{array}$ \\
\hline $\begin{array}{l}\text { AY-102 headspace } \\
\text { hydrogen } \\
\text { concentration }\end{array}$ & $\begin{array}{l}\text { Correlate with exhaust flow, expect lower flowrate to } \\
\text { produce higher cancentration, possible increases } \\
\text { during slujcing, may slowly increase during waiting } \\
\text { periods; sudden rapid increases at any time would be } \\
\text { alarming. }\end{array}$ \\
\hline $\begin{array}{l}\text { AY-102 headspace } \\
\text { hydrogen } \\
\text { concentration }\end{array}$ & $\begin{array}{l}\text { Correlate with exhaust flow, expect lower flowrate to } \\
\text { produce higher concentration, possible decreases } \\
\text { during sluicing, expect, higher concentrations during } \\
\text { sluicing, followed by decrease during waiting periods. }\end{array}$ \\
\hline AY-102 waste leve1 & $\begin{array}{l}\text { Should increase as sluicing campaign proceeds; } \\
\text { correlate with mass transfer rates and change in C-106 } \\
\text { level; verify that increase observed can be explained } \\
\text { by waste transfer activities; gradual increase in } \\
\text { level following a campaign may indicate gas retention. }\end{array}$ \\
\hline C-106 waste level & $\begin{array}{l}\text { Should decrease as sluicing campaign proceeds; } \\
\text { correlate with mass transfer rates and change in } \\
\text { AY-102 level; verify that change observed can be } \\
\text { explained by waste transfer activities (including any } \\
\text { addition of cooling water); gradual increase in level } \\
\text { following a campaign may indicate gas retention. }\end{array}$ \\
\hline
\end{tabular}


LOCKHEED MARTIN HANFORD CORPORATION

OBJECTIVE AND PURPOSE:

APPLICABILITY: FOR COMPLIANCE
Manual

Section

Page

Effective Date
HNF-SD-WM-PROC-021

24.0 , REV 2

16 of 16

This page intentionally left blank. 
LOCKHEED MARTIN HANFORD CORPORATION

TWRS PROCESS ENGINEERING INSTRUCTION HANUAL
Manual

Section

Page

Effective Date

Organization
HNF-SD-WM-PROC-021

25.0 , REV 2

1 of 4

November 15, 1998

TWRS Process

Engineering

TITLE:

SAMPLE ARCHIVE MANAGEMENT

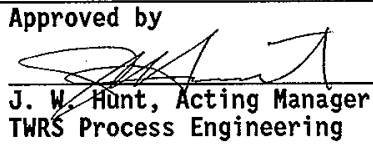

\subsection{OBJECTIVE}

This procedure has two (2) objectives: 1) to outline the roles and responsibilities of the Sample Archive Disposal Team (SADT) and 2) to provide criteria and requirements. for retention and disposal of archived characterization samples.

\subsection{SAMPLE ARCHIVE DISPOSAL TEAM}

The Sample Archive Disposal Team (SADT) has been formed to 1) represent the interests of programs, organizations and projects with potential or actual need for archived samples, 2) provide a forum for the laboratory to surface archive issues and obtain resolution, 3) provide an "official" team to advise management on archive issues and to obtain senior management decisions on policy issues, and 4) provide an efficient mechanism for making routine decisions on sample disposal where senior management involvement is not required (eg., no regulatory or policy issues are involved). The SADT shall be composed of representatives of major programs and projects having potential archive sample needs including but not limited to: characterization, retrieva1, disposa1, safety, operations, laboratory, regulatory compliance and privatization programs, projects and/or organizations. The team is chaired by a manager from the Lockheed Martin Hanford Corporation Process Engineering organization.

The functions and responsibilities of the SADT include but are not necessarily 1 imited to:

- meet periodically (monthiy or quarterly as needed) to discuss sample archive status and issues. (Process Engineering shall keep and distribute formal meeting minutes.)

- evaluate and respond to archive sample needs from programs, projects and organizations

- evaluate, present, and resolve policy and regulatory issues with senior management

- review and approve routine sample archive management actions that do not require senior management attention (eg. do not involve policy or regulatory issues) 
- support the 1aboratory to obtain necessary fiscal support for necessary sample archive management tasks.

\subsection{CRITERIA AND REQUIREMENTS FOR SAMPLE ARCHIVE RETENTION AND DISPOSAL}

\subsection{Archive Inventories}

The laboratory (222-S) shall maintain an auditable inventory of archive samples to include information on number of jars, waste matrix, weight of sample material, tank number, core number, laboratory sample number, jar/vial number, date, segment number and vial size. At present, the inventory sorted by tank:core:matrix can be found in HNF-1641, Rev. 0 . The lab shall make the most recent inventory available by electronic means on a network share area be updated once per month. The SADT chair may also request a hard copy sort of the archive database different from the sort found in HNF-1641.

\subsection{Sample Disposal}

The laboratory is currently authorized to dispose of the following samples 90 days after issuance of the laboratory analytical report:

- small samples less than five (5) grams

- altered samples (digestates)

- non-static tank samples (a tank which has had material added or removed since the sampling event)

- field blanks and liner liquid samples.

\subsection{Archive Sample Repackaging and Consolidation}

The laboratory may repackage archived samples into upgraded jars as necessary to maintain sample integrity and lab safety. However, samples may not be combined (consolidated) without the written authorization of the chair of the SADT.

\subsection{Regulatory Justification for Sample Retention}

The Washington Administrative Code 173-303 provisions for handling, storage and treatment of waste applies to samples unless the samples meet the criteria of WAC 173-303 (3)(1)(i)(C) which provides an exemption. The exemption states, "The sample is being stored temporarily in the laboratory after testing for a specific purpose." 


\begin{tabular}{llr} 
LOCKHEED MARTIN HANFORD CORPORATION & Manual & HNF-SD-WM-PROC-021 \\
& Section & 25.0, REV 2 \\
OBJECTIVE AND PURPOSE: & Page & 3 of 4 \\
APPLICABILITY: FOR COMPLIANCE & Effective Date & November 15, 1998 \\
\hline
\end{tabular}

The samples other than those described in section 3.2 above are being held temporarily in the laboratory for the following specific purposes:

- to provide material for reanalysis should an unexpected problem arise during or after laboratory analysis of the sample

- to provide material for reanalysis should sampling conducted in accordance with Data Quality Objectives and/or Sampling and Analysis Plans prove inadequate to address an issue associated with safe storage, handling or disposal of tank waste

- to provide material that can be used to address as yet undetermined design, operational or regulatory issues associated with tank waste retrieval, pretreatment or disposal.

Because samples are obtained at great expense and because significant personnel exposure is associated with gathering of tank samples and because disposal program needs are not yet completely defined, the current policy is to retain parent samples except as outlined above in Section 3.2 .

\subsection{REFERENCES}

1. WAC, 173-303, 1993, "Dangerous Waste Regulations," Washington Administrative Code, as amended.

2. LMHC, 1998, "Development of an Inventory/Archive Program for the Retention, Management and Disposition of Tank Characterization Samples at the 222-S Laboratory", HNF-1641, Rev. 0, Lockheed Martin Hanford Corp. for Fluor Daniel Hanford, Inc., Richland, Washington.

3. LMHC, 1997, "Technical Basis for Disposition of Tank Waste Samples in Archive", HNF-SD-WM-TRD-006, Rev. 0, Lockheed Mart in Hanford Corp. for Fiuor Danie] Hanford, Inc., Richland, Washington. 
This page intentionally left blank. 


\section{DISTRIBUTION SHEET}

\begin{tabular}{|c|c|c|c|c|c|}
\hline \multirow[b]{2}{*}{ Distribution } & \multirow{2}{*}{\multicolumn{3}{|c|}{$\begin{array}{l}\text { From } \\
\text { Technical Basis and Planning }\end{array}$}} & \multicolumn{2}{|l|}{ Page 1 of 2} \\
\hline & & & & \multicolumn{2}{|c|}{$11 / 02 / 98$} \\
\hline \multicolumn{4}{|l|}{ Project Title/Work Order } & \multicolumn{2}{|l|}{ EDT No. N/A } \\
\hline \multicolumn{4}{|c|}{$\begin{array}{l}\text { HNF-SD-WM-PROC-021, Rev. 2, "Tank Waste Remediation System } \\
\text { Process Engineering Instruction Manua]" }\end{array}$} & \multicolumn{2}{|c|}{ ECN No. ECN-643849 } \\
\hline \multicolumn{2}{|l|}{ Name } & $\begin{array}{c}\text { Text } \\
\text { With } \\
\text { AT7 } \\
\text { Attach }\end{array}$ & Text 0n7y & $\begin{array}{l}\text { Attach./ } \\
\text { Appendix } \\
\text { Only }\end{array}$ & $\begin{array}{l}\text { EDT/ECN } \\
\text { Only }\end{array}$ \\
\hline
\end{tabular}

U.S. Department of Energy - RL DOE/RL Reading Room

H2-53 X

Lockheed Martin Hanford, Corp.

M. R. Adams

D. L. Banning

S. A. Barker

D. A. Barnes

W. B. Barton

R. A. Bechtold

$\checkmark$. L. Benson

J. D. Bingham

V. C. Boyles

M. E. Buxbaum

J. W. Cammann

K. G. Carothers

J. M. Conner

S. D. Estey

J. G. Field

K. D. Fowler

L. D. Frank 7 in

J. A. Glasscock

M. J. Groff

K. M. Hall

R. W. Harmsen

D. C. Hedengren

R. A. Heller

K. L. Hennesay

K. M. Hodgson

M. J. Holm

T. A. Hu

J. W. Hunt

N. L. Hulse

E. I. Husa

L. Jensen

J. Jo

3. A. Johnston

N. W. Kirch

G. M. Koreski

M. J. Kupfer

J. A. Lechelt

M. D. Le Clair

C. J. Lindquist

R2-12

$\mathrm{R} 2-12$

R2-11

R2-11

$\mathrm{R} 2-12$

K7-22

R1-01

R2-11

R2-11

R1-01

R2-11

R2-11

R2-11

R2-11

R2-12

R2-11

$\mathrm{R} 2-12$

R1-01

R2-11

R2-12

R3-75

R2-11

G3-30

R2-12

R2-11

R2-11

R2-12

R2-12

R2-12

R2-11

R2-12

R2-12

R2-12

R2-11

R2-11

R3-75

R2-11

R3-75

R2-12

$x$
$x$
$x$
$x$
$x$
$x$
$x$
$x$
$x$
$x$
$x$
$x$
$x$
$x$
$x$
$x$
$x$
$x$
$x$
$x$
$x$
$x$
$x$
$x$
$x$
$x$
$x$
$x$
$x$
$x$
$x$
$x$
$x$
$x$
$x$
$x$
$x$
$x$
$x$
$x$
$x$
$x$
$x$
$x$




\section{DISTRIBUTION SHEET}

\begin{tabular}{|c|c|c|c|c|c|c|}
\hline \multirow{2}{*}{ To $\quad$ Distribution } & \multirow{2}{*}{\multicolumn{3}{|c|}{$\begin{array}{l}\text { From } \\
\text { Technical Basis and Planning }\end{array}$}} & \multicolumn{3}{|c|}{ Page 2 of 2} \\
\hline & & & & \multicolumn{3}{|c|}{$11 / 02 / 98$} \\
\hline \multicolumn{4}{|l|}{ Project Title/Work Order } & \multicolumn{3}{|c|}{ EDT No. $\quad \mathrm{N} / \mathrm{A}$} \\
\hline \multicolumn{4}{|c|}{$\begin{array}{l}\text { HNF-SD-WM-PROC-021, Rev. 2, "Tank Waste Remediation System } \\
\text { Process Engineering Instruction Manual" }\end{array}$} & \multicolumn{3}{|c|}{ ECN No. ECN-643849 } \\
\hline \multicolumn{2}{|l|}{ Name } & $\begin{array}{l}\text { Text } \\
\text { With } \\
\text { All } \\
\text { Attach. }\end{array}$ & Text 0 & & $\begin{array}{l}\text { Attach. } \\
\text { Appendix } \\
\text { Only }\end{array}$ & $\begin{array}{l}\text { EDT/ECN } \\
\text { Only }\end{array}$ \\
\hline
\end{tabular}

Lockheed Martin Hanford, Corp. - continued

D. J. McCain

S. G. Mckinney

D. M. Nytka

W. E. Prielipp

J. H. Rasmussen

D. A. Reynolds

o. Riojas

L. M. Sasaki

B. C. Simpson

C. K. Spiel

L. A. Stauffer

J. N. Strode

R. R. Thompson

R. R. Wandling

R. A. Watrous

L. R. Webb

S. R. Wi Tmarth

A. E. Young

T.C.S.R.C.

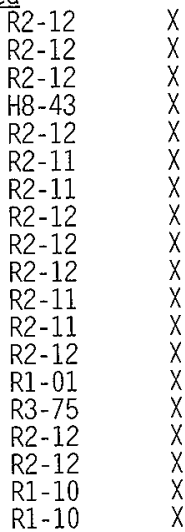

B1-07 $\quad X$

Lockheed Martin Services, Inc.

Central Files 